Developing parasitic weed control strategies for rainfed rice production environments

Dennis Erro Tippe 


\section{Thesis committee}

\section{Promotors}

Prof. Dr N.P.R. Anten

Professor of Crop and Weed Ecology

Wageningen University \& Research

\section{Co-promotors}

Dr L. Bastiaans

Associate professor, Centre for Crop System Analysis

Wageningen University \& Research

Dr J. Rodenburg

Senior lecturer, Natural Resources Institute

University of Greenwich, UK

\section{Other members}

Prof. Dr R.P.O. Schulte, Wageningen University \& Research

Dr C. Riches, Agherba Consultants, Shipham, UK

Dr M.A. Slingerland, Wageningen University \& Research

Dr M.M. Riemens, Wageningen University \& Research

This research was conducted under the auspices of the C.T. de Wit Graduate School for Production Ecology and Resource Conservation 


\title{
Developing parasitic weed control strategies for rainfed rice production environments
}

\author{
Dennis Erro Tippe
}

\author{
Thesis \\ submitted in fulfilment of the requirements for the degree of doctor \\ at Wageningen University \\ by the authority of the Rector Magnificus \\ Prof. Dr A.P.J. Mol, \\ in the presence of the \\ Thesis Committee appointed by the Academic Board \\ to be defended in public \\ on 30 October 2019 \\ at 1.30 p.m. in the Aula.
}




\section{Dennis Erro Tippe}

Developing parasitic weed control strategies for rainfed rice production environments. 146 pages.

$\mathrm{PhD}$ thesis, Wageningen University, Wageningen, NL (2019)

With references, with summary in English

ISBN: 978-94-6343-488-1

DOI: $10.18174 / 465888$ 


\begin{abstract}
Dennis E. Tippe (2019). Developing parasitic weed control strategies for rainfed rice production environments. $\mathrm{PhD}$ thesis, Wageningen University and Research, Wageningen, the Netherlands, with summary in English, 146 pp.
\end{abstract}

Rice is a staple food crop in many countries in sub-Saharan Africa, but its production is often hampered by parasitic weed infestations, like Rhamphicarpa fistulosa in rainfed lowlands and Striga asiatica in rainfed uplands. This study used a two-pronged approach, with a first track focussed on farmer perception of the parasitic weed problem and a second track on field evaluation of control measures. Surveys and workshops with farmers and other stakeholders in three rice growing areas in Tanzania revealed that farmers are aware of the locally occurring parasitic weed species. They mainly practise hand weeding to control them, but are aware of a wide range of control options. Local access, affordability, ease of implementation and control efficacy were considered important criteria for adoption, whereas trade-offs were mentioned as an important break on adoption. Based on informal discussions with farmers, altered sowing time, short-duration rice varieties and organic/inorganic fertilisers were hypothesized as potentially affordable control options. All three measures were tested during three to four seasons in both S. asiatica and R. fistulosa infested fields, in Kyela district southwest of Tanzania. The trials undertook farmer-participatory evaluation of the suitability of the management options. Striga asiatica number and biomass decreased with a delay in sowing time. This strategy proved most suitable when combined with an improved early-maturing variety. Contrastingly, R. fistulosa biomass was increased, and concomitant rice yields decreased, with delayed sowing times. Planting rice at the onset of the rainy season resulted in reduced $R$. fistulosa infection and higher rice grain yields. Clearly, manipulating rice sowing time showed to be an effective strategy to reduce parasitic weed infection and associated yield losses, but the manner in which this strategy should be employed strongly depends on parasitic weed species and ecosystem. Fertilisation with either organic or inorganic soil amendments had a positive effect on rice grain yield, though these effects were less obvious in the presence of parasitic and ordinary weeds. Fertilisation frequently stimulated $R$. fistulosa infection, and had a modest but inconsistent decreasing effect on S. asiatica. In the last chapter, the implications for smallholders' parasitic weed management strategies are discussed and it is argued that it takes a wider effort, including innovations at institutional level, to sustainably solve the parasitic weed problem in rainfed rice. 

Chapter 1 General Introduction 1

Chapter 2 Farmers' knowledge, use and preferences of parasitic weed management 13 strategies in rain-fed rice production systems

Chapter 3 Delayed or early sowing: Timing as parasitic weed control strategy in 45 rice is species and ecosystem dependent

Chapter 4 Infestation by parasitic and ordinary weeds undermines rice yield 71 increasing effects of soil amendments

$\begin{array}{lll}\text { Chapter } 5 \quad \text { General Discussion } & 97\end{array}$

References 111

$\begin{array}{ll}\text { Summary } & 123\end{array}$

$\begin{array}{ll}\text { Acknowledgements } & 129\end{array}$

List of publications $\quad 135$

$\begin{array}{ll}\text { Curriculum vitae } & 137\end{array}$

PE\&RC Training and Education Certificate 141

$\begin{array}{ll}\text { Funding } & 145\end{array}$ 

Chapter 1

General Introduction 


\section{Chapter 1}

\section{Background}

The global population is projected to reach 9 billion people by 2050 (Wise, 2013) and most of this population increase will occur in developing countries. Urban expansion will accelerate; in 2050 an estimated $70 \%$ of the world's population will be living in urban areas (Huang et al., 2007). The world Food and Agricultural Organization (FAO) estimated that farmers will have to produce $60-70 \%$ more food to meet the needs of the world's growing population (William and Nicholas, 2015). In sub-Saharan Africa (SSA), food security is at greatest risk because by 2050 the regional population will increase about 3 -fold and the demand for cereals will also triple (Van Ittersum et al., 2016). Currently, already more than half of the population of SSA depends on cereals as staple food, and this need is only met by supplementing the domestic production by considerable imports.

More than $20 \%$ of the population of SSA depends on rice for their daily calories intake (Seck et al., 2012). Over the last three decades, consumption of this commodity has increased by $300 \%$, while production increased by only $170 \%$ (Seck et al., 2010; Balasubramanian et al., 2007), leading to lower per capita rice production. This trend needs to be reversed. Given the limitation on available land, this increase should come from increases in productivity per unit land area (van Oort et al., 2015) and this, in turn, will only be possible if the main production limiting and reducing factors are addressed. In SSA, the most limiting factors in rice production systems are drought and poor soil fertility, while the factors that reduce yields are diseases, pests and weeds (Seck et al., 2012; Balasubramanian et al., 2007). Weeds in rice in SSA are believed to cause an annual loss of more than 2.2 million tonnes equivalent to US\$ 1.5 billion (Rodenburg and Johnson, 2009). Parasitic weeds, a sub-category of weeds, are causing economic losses of around \$200 M per year; these losses in rice production are conservatively estimated and expected to increase by about $\$ 30 \mathrm{M}$ annually (Rodenburg et al., 2016b). Parasitic weeds are found in rainfed rice production systems (Rodenburg et al., 2010).

\subsection{Parasitic weeds: biology, ecology and distribution}

Parasitic plants are plant species that parasitize on other plants (i.e., their hosts). Through a well-established connection known as haustorium, the root parasites link to their host plants' roots (Parker, 2014). By this connection, the parasite extracts mineral nutrients, water and metabolic products from the host, thereby negatively affecting host plant productivity. When such plants infest crops, they become weedy. The main parasitic weed species occurring in rainfed rice systems in SSA are the well-known Striga asiatica (L.) Kuntze and Striga 
hermonthica Del. Benth., also known as Witchweeds, and the relatively unknown and newly emerging Rhamphicarpa fistulosa (Hochst.) Benth., or Rice Vampireweed (Rodenburg et al., 2010). Striga species, are obligate root hemi-parasitic plants. This means that Striga spp. cannot complete their life cycle without parasitizing a host plant. Striga spp. have two main life-cycle stages, below- and aboveground. Striga spp. seeds germinate in the presence of host roots exudates, and seedlings then attach to the host roots if these are in close proximity, by means of a haustorium. After this connection is made, it takes about 3-8 weeks before a Striga plant emerges aboveground (Spallek et al., 2013). After emergence, the parasite continues to benefit from the host roots while it also conducts photosynthesis itself. The Striga plant then completes its life cycle within 10 to 16 weeks after emergence, and a single Striga plant can produce as many as 25,000 - 200,000 tiny dust-like seeds per plant (Ejeta and Gressel, 2007). Striga asiatica and $S$. hermonthica are mainly found in rainfed upland agro-ecosystems characterised by prolonged drought periods and poor soil fertility (Kamara et al., 2014). In SSA, Striga spp. occur in at least 31 countries with rainfed upland rice production systems (Rodenburg et al., 2016b).

While Striga spp. have been a problem in cereal production for a long time, Rhamphicarpa fistulosa has emerged more recently as a problem (Gbehounou, 2003; Ouédraogo et al., 1999). Rhamphicarpa fistulosa is a facultative root parasitic weed, which entails that it can also complete its life cycle without a host plant. Attachment to a host plant however provides $R$. fistulosa with a benefit, as attached parasites produce considerably more seeds than independently growing plants (Kabiri et al., 2016). Rhamphicarpa fistulosa is found in areas characterized by temporary and uncontrolled floods (Houngbedji et al., 2014; Rodenburg et al., 2011b; Hansen, 1975). In SSA, about 28 countries with rainfed lowland rice production systems are threatened by $R$. fistulosa infestation (Rodenburg et al., 2016b).

\subsection{Problem Statement}

An important reason why the parasitic weed problem is so persistent in rainfed production systems in SSA is that potentially effective solutions are not affordable or not even accessible to the poorly resourced smallholder farmers that grow their crops in these environments. In previous work, research on parasitic weeds focused primarily on maize and sorghum (Parkinson et al., 1987; Kamara et al., 2008). Several strategies have been proposed to control Striga spp. ranging from the application of fertilizers, undertaking crop rotations, using resistant varieties or adjusting sowing methods (Hearne, 2009). 


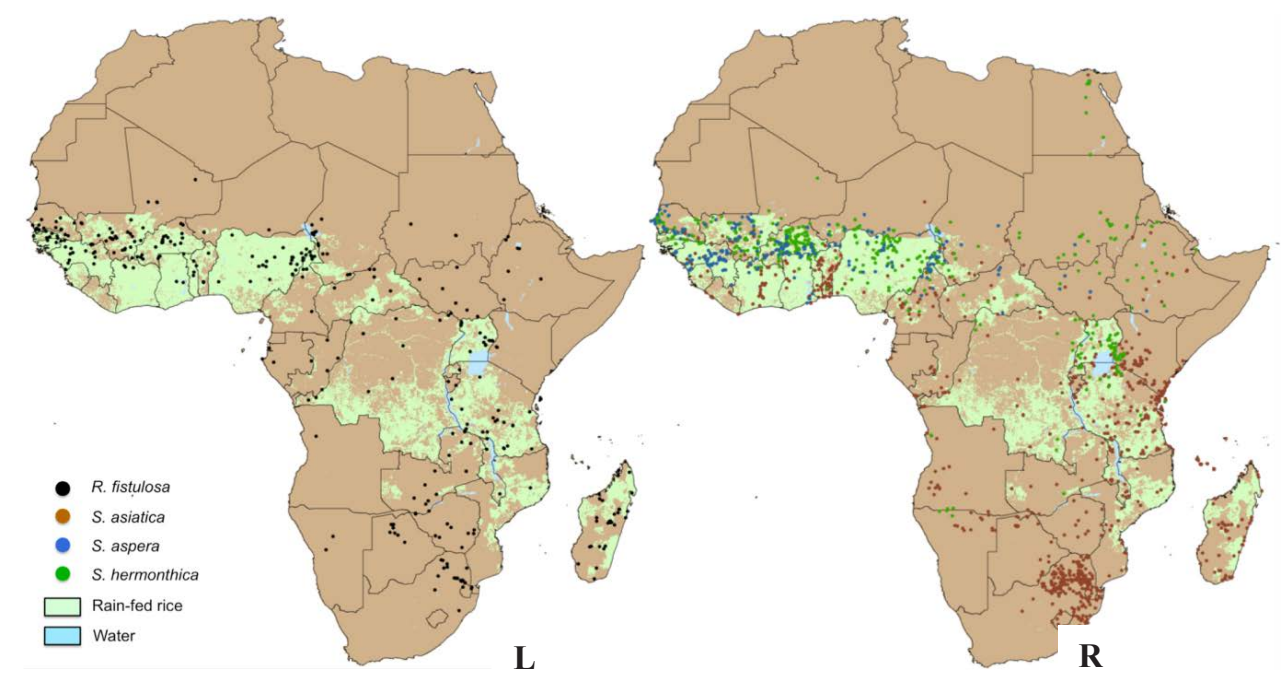

Fig. 1 Parasitic weed incidence and related economic losses in rice in Africa. About 900, 000 ha of rainfed rice field is infested with Striga spp (R), while about 550, 000 ha in rainfed rice is infested with Rhamphicarpa fistulosa (L). Invasion of both parasitic weed species in rice is estimated to cause an annual economic loss of about \$200 M (Adapted from: Rodenburg et al., 2016b).

Despite all these efforts, parasitic weed management strategies that were developed for maize and sorghum have been poorly adopted by farmers (Emeghebe et al., 2004). Often, technology development and transfer were poorly linked to the needs of farmers. A top-down approach was often used, whereby researchers developed a technology without consideration of the farmers' needs and available or accessible resources, and this technology was then promoted to farmers by extension officers (Muzari et al., 2012; Norton et al., 1999). In this way, the extant resources, knowledge, experience and preferences of local farmers may not have been considered. The current situation is that most farmers use hand weeding to control parasitic weeds (N'Cho et al., 2014), which is also their standard control measure for ordinary weeds (Ogwuike et al., 2014). However, hand weeding is not effective for Striga spp., as these parasites cause damage to rice even before they emerge aboveground. Hand weeding also consumes valuable time and resources. Other control options are however often not locally accessible or affordable to poorly resourced smallholder farmers (Emeghebe et al., 2004) Herbicides are also not widely used because they are expensive, and their use requires application equipment and technical know-how that farmers often do not have (Rodenburg and Johnson, 2009).

Since previous technologies developed for parasitic weed management have so far been 
poorly adopted by farmers, it seems important to involve farmers in research priority setting and technology testing. This conclusion was also drawn by researchers from a Crop Protection Programme on Striga in rice in Kyela, southern Tanzania, funded by the UK at the end of the last century. Trials by a group of researchers and agricultural extension agents, working with farmer groups, demonstrated that up to $60 \%$ reduction in Striga numbers and $45 \%$ increase in rice yield could be achieved by applying urea fertilizer (Mbwaga, 2001). Despite the promising results, the farmer groups indicated an unwillingness to adopt the use of urea as a widespread practice, largely due to a lack of financial means for fertiliser purchase (Mbwaga, 2005). Another approach to managing Striga was therefore needed. Some preliminary tests with the green manure species Crotalaria ochroleuca were installed. After farmers picked out the green manure plots and requested further support to test the use of Crotolaria more widely, a new Crop Protection Programme for on-farm verification and promotion of green manure for enhancing upland rice productivity on Striga infested fields was started. This time, after the initiation by the research team, the evaluation of the green manure had become farmer driven. Evidently, such collaboration is more likely to result in the development of control measures that better match with the resources these farmers have at their disposal.

These experiences are the main reason that the current project consists of two parallel tracks. The first track focusses on field-testing of cultural control measures that seem affordable and are inspired by ecological characteristics of parasitic weed species. Such measures are regularly proposed following more detailed ecological research on parasitic weeds but are hardly ever tested for their effectiveness under field conditions, in particular in rice cropping systems. The second track is developed around the interaction with farmers. First, to learn about farmers' knowledge and perceptions of the parasitic weed problem and the possibilities and difficulties they foresee for alternative weed management measures. Second to discuss the proposed options for parasitic weed control, based on visits to the researcher managed on-farm trials and, in the final year, based on their participation in farmer-managed on-farm try-outs.

\subsection{Proposed Solutions}

In the case of Striga hermonthica infestations in sorghum, it has been reported that the time of parasite attachment to the host plant determines the damage level of the host; the earlier the attachment is established the higher the damage caused (Van Ast and Bastiaans, 2006). It was 


\section{Chapter 1}

further shown that crop sowing time to some extent determines the time of parasite attachment (Gbèhounou et al., 2004). Presumably, this would also be true for Rhamphicarpa fistulosa. Another essential reason to embark on this, in view of the farmer participatory approach we wish to pursue, is that farmers themselves, during informal interviews at the start of the project, mentioned that changes in sowing time would be a suitable strategy to reduce parasitic weed infections and concomitant crop losses. The same farmers, however, also indicated that because of their dependency on rain, they mainly aim to synchronize rice sowing with the onset of the rainy season. Later sown crops tend to be prone to water shortages during the essential grain filling stages at the end of the rainy season when rainfall is less reliable. The above indicates that for the development of effective strategies against parasitic weeds numerous dependencies need to be better understood and taken into account.

Another line of defence in terms if parasitic weed control is better management of soil fertility. It is often observed and suggested that Striga spp. incidence is associated with poor soil fertility. It has further been shown that deficiencies in nitrogen and phosphorus in soils stimulate the production of host plant root exudates, which, in turn, trigger Striga spp. seed germination (Jamil et al., 2012). Application of fertilizers was previously observed to have an mitigating effect on $R$. fistulosa infection as well (Rodenburg et al., 2011a). Most of these effects were evidenced under semi-controlled conditions and therefore, the effectiveness of such solutions in farmers' fields remains to be tested. Moreover, the use of recommended (high) doses of mineral fertilizers is often not a feasible option for resource-poor farmers as the costs are high and the reliability of supply is low (Emeghebe et al., 2004). This requires evaluation of locally affordable and accessible soil amendment sources. Cattle manure and rice husks are among the soil amendment materials that can be locally obtained and can lower the costs of fertilizers by replacing mineral fertilizers in part or as a whole. However, their effectivity as a soil amendment to influence the parasitic weed infestation level, has not been tested previously.

\subsection{Thesis Objectives}

The overall objective of this study was to develop locally adaptable and socio-economically acceptable integrated parasitic weed management strategies in rainfed rice production systems. 


\section{Specific objectives were:}

1. To assess the current state in terms of farmer's awareness of parasitic weeds in different rainfed rice environments, their current control practices, their knowledge of alternative control strategies and their reasons for adoption or non-adoption.

2. Investigate the effectiveness of sowing time and improved rice varieties on parasitic weed growth and rice yield as a locally accessible and affordable control measure for parasitic weeds in rainfed rice systems.

3. Investigate effectiveness of different soil amendment sources on parasitic weed growth and rice yield, as control measures for parasitic weeds in rainfed rice systems.

4. Evaluate effectiveness of the selected control measures (i.e. sowing time, rice varieties and soil amendments) in farmer-managed on-farm trials and to assess how farmers appreciate these measures.

The current study used a stepwise farmer participatory and collaborative approach. Farmers participated through surveys, workshops and field experimentation in developing acceptable control measures for the parasitic weeds $S$. asiatica and $R$. fistulosa in rice production systems in Tanzania. The study was carried out in the Mbeya, Ruvuma and Morogoro regions. These three regions are among the top six rice-producing regions in Tanzania, and parasitic weeds are reported in all three. The study specifically focussed on three districts: (1) Kyela in Mbeya, (2) Songea in Ruvuma and (3) Morogoro-rural in Morogoro. In Morogoro-rural district only S. asiatica is present, whereas in Songea district only the presence of $R$. fistulosa is reported. In Kyela district, both parasitic weed species exist (Fig. 2).

In all three study districts, prior to this study, informal discussions with farmers were held, based on which adjusting sowing time and use of organic soil amendments were hypothesised as potentially affordable control options. Structured surveys were conducted to explore farmer's knowledge and experience on the importance of parasitic weeds in rainfed rice production systems. Purposive sampling was used, where individual farmers growing rice in parasitic weed infested fields were contacted.

As a follow-up on the surveys, five farmer participatory workshops were organised in the same three regions. From each participating village, farmers growing rice in parasitic weed infested fields were asked to list and describe the technologies they knew about for controlling a specific parasitic weed and advantages and disadvantages of each technology were discussed within the group. 


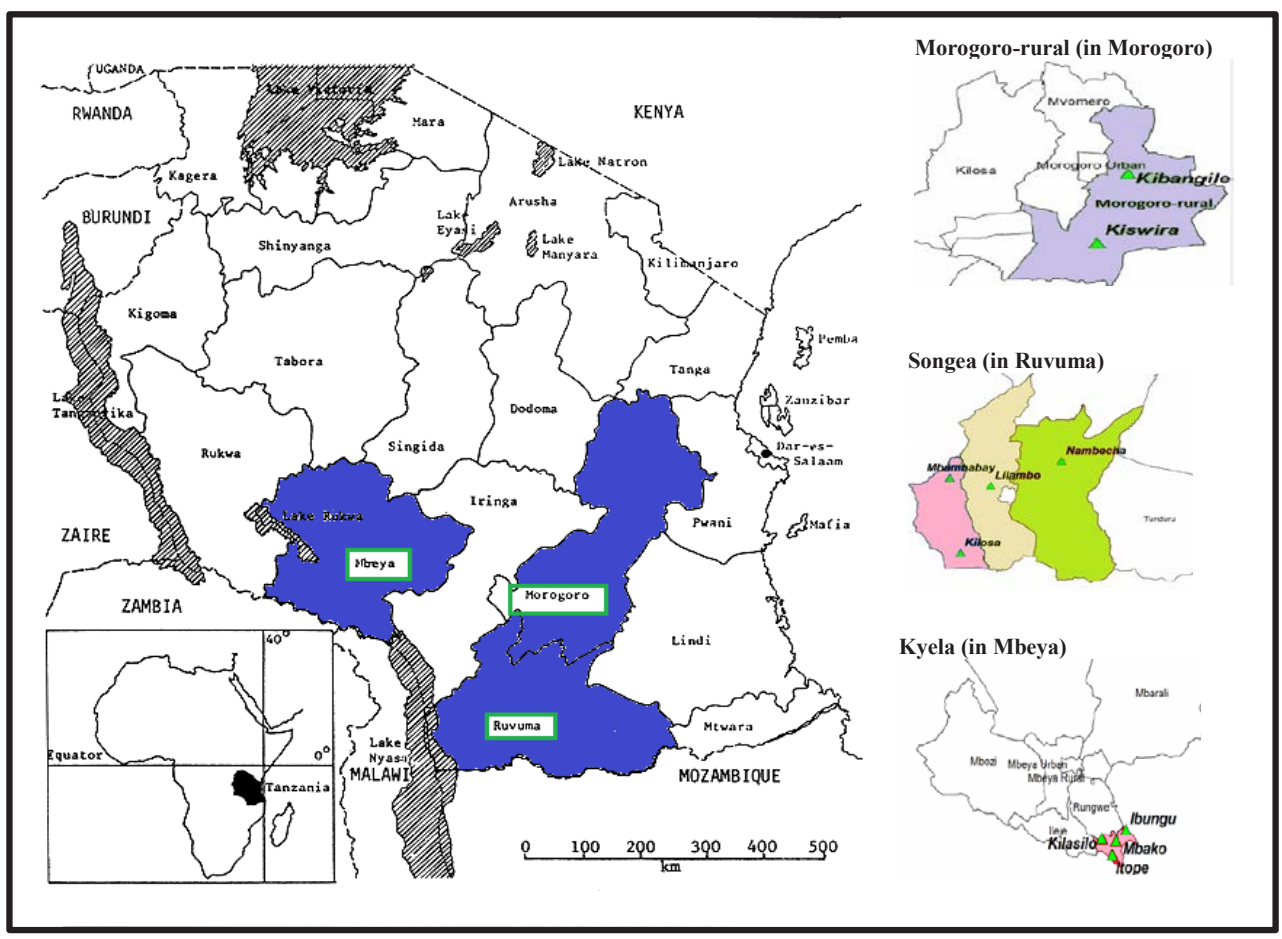

Fig. 2 Map of Tanzania, the study regions and districts. In all three regions and districts parasitic weeds exist. In Mororogoro-rural only Striga asiatica was present and in Songea only Rhamphicarpa fistulosa was found, while in Kyela both weed species exist.

Thereafter, each farmer was asked to select the best three technologies that are effective in control of parasitic weed management, and to motivate this choice.

Kyela district, a hot spot for both S. asiatica and R. fistulosa, was selected for on-farm field trials. The trials were conducted for four consecutive years (2012-2015) and established in an upland field infested by S. asiatica and in a lowland field infested by R. fistulosa. Researcher-managed on-farm trials were aimed at undertaking farmers' participatory evaluation of the two previously selected management options for both parasitic weeds. These management options were: A. Timing of crop establishment and growth, i.e. a combination of rice sowing time and rice varieties varying in growth-cycle duration, and B. Plant nutrition, i.e. an array of soil fertility amendments ranging from purely mineral to purely organic and combinations of these. In the first experiment, three rice cultivars with different growth durations were sown at five different dates with intervals of 14 days, both in upland $(S$. asiatica) and rainfed lowland (R. fistulosa). Rice varieties were Mwangulu, Supa India and NERICA-14 in the upland trial and Supa India, IR64 and NERICA-L-20 in the lowland trial. 
To study the influence of soil amendment on parasitic weeds, local rice variety Supa India was grown with seven different soil fertility treatments. These treatments consisted of mineral fertilizers i.e. DAP + Urea and N-P-K, two types of organic fertilizer i.e. cattle manure and rice husks and combinations of organic and (half the rate of) mineral fertilisers. A control treatment without fertilization was included. All treatments were tested under weedy and weed-free conditions, to enable evaluation of effects on ordinary weeds as well. While parasitic weeds were allowed to grow in all treatments, ordinary weeds were regularly removed in the weed-free treatments and no weed control was conducted in the weedy plots. The plots were maintained in the same field for four years, because effects of soil amendments, in particular of those based on organic material, often take time to come to expression.

Farmers from the nearby villages visited the experiments to rank the strategies (sowing time, variety and soil amendment) and to motivate their preferences. In the last season (20142015), farmers formed groups of five farmers themselves to run farmer managed on-farm try outs of these strategies. This enabled the participating farmers to conduct a more complete assessment of the requirements, challenges and final outcomes of individual technologies as well as that of a strategy that combined them into one integrated approach. Eight groups were formed, with four fields in the lowland and four fields in the upland. During the season, farmer visits were organised to assess their preferences and comments on the employed control technologies, either as stand-alone or integrated. Semi-structured interviews were conducted with all farmers individually, to capture more qualitative data. Additionally, a farmer field day was conducted around harvest time to reach a larger group of rice farmers and stakeholders.

\subsection{Research Questions of this Thesis}

In view of the above problem statement and objectives, in this thesis answers to the following research questions were sought:

1. To what extent are farmers aware of the parasitic weed problem in rice?

2. What do farmers do to combat parasitic weeds in rice; do farmers have an alternative options to manage parasitic weeds apart from the option they use for ordinary weeds?

3. To what extent can early or delayed sowing of rice be used to minimize parasitic weed infection in rice; does sowing time influence parasitic weed infection in rice to a similar magnitude for both Striga asiatica and Rhamphicarpa fistulosa; are early- 


\section{Chapter 1}

maturing varieties a suitable enabling technology for delayed sowing?

4. What is the influence of soil fertility amendments on parasitic weed growth and development, and how do they affect rice grain yield; in the absence or unavailability of mineral fertilizers, is there any soil amendment source that is locally accessible and affordable and thus ready to be used as an alternative; what are implications of enhanced soil fertility for a facultative parasite like $R$. fistulosa and for ordinary weeds; do solutions that showed to be effective under controlled conditions deliver satisfactory results in the field as well and how long does it take before effects are expressed?

\subsection{Outline of the thesis}

The thesis consists of five chapters including the General Introduction and Discussion. Chapters 2-4 address specific objectives as outlined in section 1.4. Figure 3 provides an overview of how the thesis is structured along with its information flow. Following the General Introduction (Chapter 1), Chapter 2 describes farmers' awareness of parasitic weeds, their knowledge and experience, insight on available management options and their current main management strategies. It also describes criteria for adoption of alternative weed control strategies. In Chapter 3, effects of sowing time, varieties with different growing cycles and their combination on parasitic weeds and rice grain yields were evaluated under field conditions. An assessment was done of the efficacy of these locally accessible and affordable control strategies for the two parasitic weeds in rainfed rice system. The sowing time experiments in the field were supplemented by pot experiments in 2016 (conducted in Wageningen, The Netherlands) to further investigate the effect of sowing time on parasitic weed growth and rice plant performance under controlled conditions and with inclusion of parasite-free controls. In Chapter 4, the role of soil fertility enhancement as an alternative option to combat parasitic weeds was assessed using seven soil amendment sources and one locally preferred rice variety in Kyela, Tanzania. Chapter 5 comprises of the General Discussion for this thesis on parasitic weed management in rainfed rice systems and proposes the way forward. 


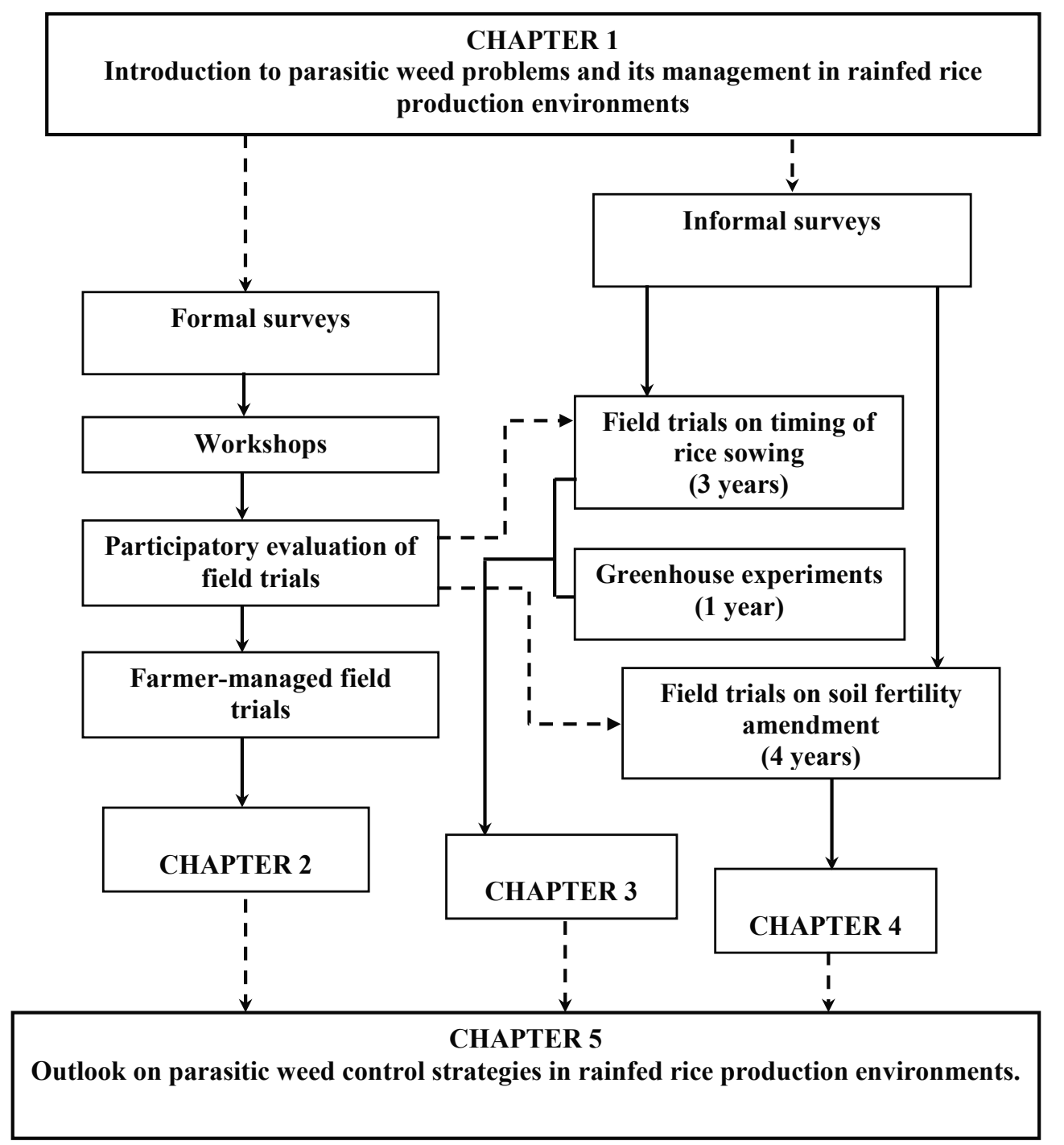

Fig. 3 Schematic overview of the thesis, covering the various approaches that were used throughout the study and their interrelatedness. 



\section{Chapter 2}

Farmers' knowledge, use and preferences of parasitic weed management strategies in rainfed rice production systems

Dennis E. Tippe a, Jonne Rodenburg ${ }^{\text {b }}$, Marc Schut ${ }^{\text {c, d, }}$, Aad van Ast ${ }^{\text {a }}$, Juma Kayeke ${ }^{\text {e, }}$ Lammert Bastiaans ${ }^{\text {a }}$

Published as: D.E. Tippe et al., 2017. Crop Protection 99, 93-107

${ }^{\mathrm{a}}$ Centre for Crop Systems Analysis, Wageningen UR, P.O. Box 430, 6700 AK, Wageningen, The Netherlands

${ }^{\mathrm{b}}$ Africa Rice Center (AfricaRice), 01 BP 4029, Abidjan 01, Côte d'Ivoire

${ }^{\mathrm{c}}$ International Institute of Tropical Agriculture (IITA), P.O. Box 1269, Kigali, Rwanda

${ }^{\mathrm{d}}$ Knowledge, Technology and Innovation, Wageningen UR, P.O. Box 8130, 6700 EW, Wageningen, The Netherlands

${ }^{\mathrm{e}}$ Mikocheni Agricultural Research Institute (MARI), P.O. Box 6226, Dar es Salaam, Tanzania 


\title{
Chapter 2
}

\begin{abstract}
Rain-fed rice production in sub-Saharan Africa is often hampered by parasitic weeds. This study assessed farmers' awareness, use, preference and adoption criteria of parasitic weed management practices in rain-fed rice production environments in Tanzania. Surveys and workshops were organized in three affected rice growing areas in Morogoro-rural, Songea and Kyela district, supplemented with on-farm experiments in Kyela. In all districts, farmers were aware of the locally occurring parasitic weed species, Rhamphicarpa fistulosa (lowland) and Striga asiatica (upland), and they considered these weeds more problematic than non-parasitic weeds. Though they mostly practise hand weeding, farmers were aware of a wide range of control options. Local access, affordability, ease of implementation and control efficacy were considered important criteria for adoption, whereas tradeoffs, like lack of preferred grain quality traits in resistant varieties, were mentioned as an important break on adoption.

Based on informal discussions with farmers, altered sowing times, resistant rice varieties and soil amendments were marked as feasible control options and tested in a farmer-participatory manner in four years of experimentation in upland and lowland fields. In both types of fields, the contribution of soil amendment to parasitic weed suppression was not evident, but rice husk was marked as a suitable and cheap alternative to inorganic fertilisers. Control of $R$. fistulosa in lowlands was perceived to be best realized by early crop establishment, escaping major parasite damage due to the relatively slow early development of this weed species. The local variety Supa India, appreciated for its grain qualities and marketability, remained the preferred variety. For the control of S. asiatica, late planting was preferred, requiring a short-duration variety to minimize risk of drought stress during grain filling. The short-duration NERICA-10 was most preferred, as it combined a favourable short cycle length with resistance to $S$. asiatica and good grain appearance. Farmer participation in technology testing showed to be crucial in defining locally adapted and acceptable parasitic weed control strategies. Yet, it is argued that without lifting important constraints related to credit and input supply, it will be impossible to sustainably solve the parasitic weed problem in rain-fed rice.
\end{abstract}

Keywords: Oryza sativa, Witchweed, Striga asiatica, Rice vampire weed, Rhamphicarpa fistulosa, Participatory research 


\section{Introduction}

Rice is an increasingly important cereal commodity in many countries of sub-Saharan Africa (SSA) (Seck et al., 2012) due to growing populations and changes in consumer preferences (Balasubramanian et al., 2007). Domestic rice production lags behind consumption rates (Seck et al., 2012). This is in part due to suboptimal production, caused by a myriad of production constraints that are insufficiently addressed. Under rain-fed conditions, rice production is often hampered by poor soil fertility, drought, uncontrolled floods and weeds (Diagne et al., 2013). Parasitic weeds, a sub-category of weeds, are becoming a more prominent threat to rain-fed rice production (N'Cho et al., 2014; Rodenburg et al., 2010). An important reason is that farmers, in order to increase production, expand rice production into areas where parasitic weeds naturally or historically occur (Rodenburg et al., 2011a). Rice cultivation provides favourable conditions for these weeds to reproduce and spread, and consequently they develop into serious problems in these rain-fed rice production systems (Ejeta, 2012).

Parasitic weeds are estimated to negatively affect 1.3 million ha of rainfed rice fields in SSA, leading to production losses of nearly half a million tons of milled rice (worth US \$200 million) per year (Rodenburg et al., 2016b). Among those weeds, Striga asiatica (L.) Kuntze and Rhamphicarpa fistulosa (Hochst.) Benth. are considered the most important species (Rodenburg et al., 2010). Striga asiatica is adapted to rain-fed upland rice systems. It is an obligate parasitic weed, meaning that it cannot complete its life cycle without a host plant (Parker, 2013). Rhamphicarpa fistulosa is an emerging problem in rain-fed lowland rice production systems (Ouédraogo et al., 1999; Rodenburg et al., 2011b). It is a facultative parasite, capable of completing its life cycle also in the absence of a host plant (Parker, 2013).

Throughout rain-fed rice fields in SSA, parasitic weed invasions not only result in severe crop losses, but frequently drive farmers to abandon their fields (Houngbedji et al., 2014; N'Cho et al., 2014). Most of the rice producers in SSA are resource-poor farmers with little access to external inputs. This limits their options for parasitic weed management, which in turn poses a threat to their food security and income generation (N'Cho et al., 2014).

With some exceptions (e.g. Riches et al., 2005), relatively few research efforts focussed on parasitic weeds in rain-fed rice in SSA (Schut et al., 2015a,b). Most research on parasitic weeds focused on two dominant staple crops, i.e. maize and sorghum. For these crops, a number of control options have been suggested, such as the use of fertilisers, cereal-legume intercropping, use of resistant and tolerant varieties and modifications in sowing methods 


\section{Chapter 2}

(Hearne, 2009). Technologies developed for one crop or one parasitic weed species are, however, not necessarily effective or suitable for another crop or weed species. Moreover, despite all research and development efforts regarding parasitic weed problems in maize and sorghum, relatively few parasitic weed management strategies have been adopted by farmers (Mrema et al., 2017; Schut et al., 2015a; Rodenburg et al., 2015d). In this context, Norton et al. (1999) pointed out that early involvement and participation of farmers in research priority setting and development is key to the adoption of the new strategies that ultimately derive from such efforts. Where technology transfer is characterized by a top-down approach, critical factors for acceptance of a new technology might easily be overlooked. Farmers who have experience with parasitic weeds in their fields are likely to be a valuable source of information, particularly if the aim is to develop and disseminate acceptable and affordable control strategies. Attempts to explore and utilize such farmers' knowledge in the context of parasitic weeds have, however, hardly been undertaken in the past (Rodenburg et al., 2015d).

The objectives of this study were therefore to assess farmers' awareness on parasitic weeds in different rain-fed rice environments, to take stock of their current control practices, their knowledge on alternative control strategies and to identify their reasons for adoption or non-adoption of strategies or technologies. A further aim was to define management strategies against parasitic weeds in rice that are applicable for resource-poor farmers.

\section{Materials and methods}

\subsection{Study sites}

Surveys and workshops were conducted in Mbeya, Ruvuma and Morogoro. These regions were selected because of their importance to Tanzania in terms of rice-production and because parasitic weeds are reported to cause problems in rice (e.g. Kayeke et al., 2010). Mbeya and Ruvuma are located in the Southern highlands, while Morogoro region is located in the Eastern highlands. The study specifically concentrated on the districts of Kyela $\left(09^{\circ} 25^{\prime} \mathrm{S} 35^{\circ}\right.$ $\left.41^{\prime} \mathrm{E}\right)$ in Mbeya, Songea ( $\left.10^{\circ} 41^{\prime} \mathrm{S} 35^{\circ} 39^{\prime} \mathrm{E}\right)$ in Ruvuma and Morogoro-rural $\left(06^{\circ} 54^{\prime} \mathrm{S} 37^{\circ}\right.$ $\left.54^{\prime} \mathrm{E}\right)$ in Morogoro. The two districts in the Southern Highlands are characterized by a unimodal annual rainfall regime, with a rainy season between November and May. Annual rainfall ranges from 2000 to $2300 \mathrm{~mm}$ in Kyela, and from 900 to $1300 \mathrm{~mm}$ in Songea. Morogoro-rural district is characterized by a bimodal annual rainfall regime, with the main rainy season between March and June, and annual rainfall ranging from 1000 to $2000 \mathrm{~mm}$.

The rice farmers surveyed for this study in Morogoro rural district encountered $S$. 
asiatica, whereas the farmers surveyed in Songea district dealt with $R$. fistulosa infestations. In farmers' fields in Kyela district, both parasitic weed species are found and this location was therefore chosen for the field trials where various locally accessible control strategies were tested.

\subsection{Surveys}

In all three districts, surveys were conducted from January to April, 2012 to explore farmers' awareness, knowledge and experience with parasitic weeds in rain-fed rice production systems. Following a Participatory Rural Appraisal (PRA) approach (Cavestro, 2003), questionnaires were administered by researchers, following group discussions that involved experienced individual rice farmers. In addition, visual observations by walking around the fields were done to appreciate incidences of both parasitic weed species. In Kyela district, farmers from Mbako, Kilasilo, Itope and Ibungu villages participated (95 farmers), in Morogoro-rural, farmers from Kibangile and Kiswila villages were involved (40 farmers), while in Songea district Chabuluma, Namanditi,Wambati, Lilambo and Ruhuwiko villages were represented (18 farmers). These villages were selected purposefully based on the presence of parasitic weed species. Instead of entire households, individual farmers were targeted, because, according to local traditions, members of the same household own individual plots at different sites under their own management and responsibility. Farmers were selected randomly from selected villages. This facilitated farmers with different experiences and knowledge to express their perceptions. Interviews were held in Kiswahili, a language well understood by both the enumerators and the farmers in all locations. Empirical data were captured through questionnaires and group discussions. During the interviews, information was collected on: (i) Farmers' profile e.g. age and occupation (ii) Crop production e.g. priority crops, rice farm size, production methods, inputs and constraints and (iii) Farmers' knowledge of parasitic weeds, current parasitic weed management strategies and factors determining the choice of a strategy.

\subsection{Workshops}

As a follow up on the surveys, five farmer participatory workshops were organised in the same three districts involving largely the same farmers. Before each meeting, the purpose of the meeting was explained to the participants by the facilitators of the project. Each meeting was facilitated by researchers with the help of the extension staff from the district. In Kyela 


\section{Chapter 2}

district, three workshops were conducted between April and June, 2012. From the village Kilambo, with $S$. asiatica infested rice fields, 28 farmers participated. From the villages Mbako and Kilasilo, with $S$. asiatica and $R$. fistulosa infested rice fields, 33 farmers participated, while from Ibungu, with $R$. fistulosa infested rice fields, 28 farmers participated. In both Morogoro-rural ( $S$. asiatica) and Songea ( $R$. fistulosa) district one workshop was conducted in October 2012 with 25 and 19 participating farmers, respectively. During the workshops, farmers listed and described all possible control technologies against the parasitic weed(s) that prevailed in their fields. In Kyela, the workshop facilitators complemented these lists with other technologies, to be as exhaustive as possible. Each technology was described on a separate flip-over chart, including the pro's and con's mentioned by the participants. Farmers were then asked to select the three best technologies for controlling the parasite. Thereafter, farmers were guided to discuss issues like accessibility, affordability and effectiveness of the selected technologies.

\subsection{Researcher-managed on-farm trials}

Researcher-managed trials were conducted for three consecutive years (2012-2014) in Kyela district. Kyela district was selected because of the presence of two parasitic weed species within the same rice growing area. Conducting experiments on both weed species in the same location offered the opportunity to compare differences in effectiveness of management strategies between the two species. The experiments were laid out in an upland field infested by $S$. asiatica in Mbako village and in a lowland field infested by $R$. fistulosa in the neighbouring village Kilasilo. The trials enabled a farmer-participatory evaluation of the effectiveness of three locally accessible management options, selected after informal discussions with farmers in Kyela district. Farmers indicated that sowing late in upland fields helped to avoid parasitic weed problems. However, because of the progressive later onset of rains, presumably part of a climate change trend, farmers indicated they were reluctant to implement this strategy. Modern, improved short duration varieties, including those possessing parasitic weed resistance traits, were known by farmers but they prefer growing the local aromatic rice variety Supa India because of the guaranteed market price. Thirdly, farmers mentioned that improved soil fertility could alleviate parasitic weed problems but they considered it too risky (i.e. cattle manure application may import ordinary weed seeds) or too expensive (i.e. inorganic fertilisers).

Consequently, an experiment was conducted with three rice varieties with different 
growth cycle durations sown at five different sowing dates with intervals of 14 days between December 20 and February 17 during the cropping seasons of 2012, 2013 and 2014. For the $S$. asiatica infested upland field, the selection comprised the local varieties Mwangulu (late maturing) and Supa India (medium maturity) and the improved variety NERICA-14 (early maturity). For the $R$. fistulosa infested lowland field, the local variety Supa India (late maturing), NERICA-L-20 (medium maturing) and the international check IR64 (early maturing) were selected. In the uplands, Supa India is of intermediate growth duration, but when compared with the lowland varieties it is a relatively long duration variety. In addition, a soil fertility experiment was conducted with seven treatments. These treatments consisted of two types of inorganic fertilisers: (1) Di-Ammonium Phosphate (DAP and Urea) in locally recommended rates (125 $\mathrm{kg} \mathrm{ha}^{-1}$ each), and (2) the less frequently used N-P-K (200 kg ha $\left.{ }^{-1}\right)$. Two locally available sources of organic soil amendments were included: (3) cattle manure and (4) rice husks, each at $10 \mathrm{tha}^{-1}$. In addition, both organic amendments were combined with half the recommended rates of inorganic fertiliser (DAP $\mathrm{p}$ Urea), representing treatments (5) and (6). Lastly, a control treatment without fertilization (7) was included. The plots were maintained in the same field for three years to be able to identify longer-term effects of the treatments. Variety Supa India was used in all three seasons.

In each season, before harvest, rice farmers from the villages of Kilasilo and Mbako (both parasitic weeds) and nearby Ibungu ( $R$. fistulosa) were invited for a participatory technology evaluation. The number of participating farmers was 56 (2012), 40 (2013) and 72 (2014). Farmers were asked to individually rank the options (sowing time, rice variety and soil amendment application) and to motivate their preferences.

\subsection{Farmer managed on-farm trials}

Farmer-managed on-farm trials were conducted in 2015 (December 2014 and July 2015) with interested farmers from Kilasilo and Mbako villages in Kyela district. They formed groups of five farmers themselves to avoid social friction. Eight groups were formed: four groups with fields in the $R$. fistulosa infested lowland and four with fields in the $S$. asiatica infested upland. The trials aimed at generating further insights in the acceptability and suitability of the proposed technologies for controlling S. asiatica and R. fistulosa. Each group established its own standard conventional practice and independently decided on alternatives regarding sowing time, rice variety and soil amendment. Apart from the farmers' practice and the three alternatives, a fifth treatment was installed in which all three selected technologies were 


\section{Chapter 2}

combined. Each group of farmers established their trials in an area of about one acre (4000 $\mathrm{m}^{2}$ ). Each trial field was subdivided into five plots of around $800 \mathrm{~m}^{2}$ to which the five treatments were assigned. In each plot, three quadrats of $1 \mathrm{~m}^{2}$ size were installed, that were used to assess parasitic weed number and parasite biomass. Rice grain yield was based on a 9 $\mathrm{m}^{2}$ area.

In upland fields, evaluated rice varieties were the local Supa India and three S. asiaticaresistant upland NERICA varieties, and sowing time varied from 5 January till 15 February. In lowland fields, local variety Supa India and three $R$. fistulosa-resistant lowland NERICA varieties were evaluated and the plots following farmers practice were sown soon after the first rains, while the plots with the alternative sowing time treatment were sown two weeks later. For both environments (upland and lowland) soil amendments included DAP, Urea and rice husks. In April 2015, all farmer groups visited all other fields to enable all farmers to appreciate effectiveness of different strategies across locations and conditions. After the visit, semi-structured interviews were conducted with all farmers individually, to obtain information regarding their perceptions.

\section{Results}

\subsection{Surveys e farm characterizations}

Two third of the interviewed farmers were male, and the age of the farmers ranged from 18 to 80 years (Table 1). The interviewed farmers regarded agriculture as their first and most rewarding occupation. More than half of the farmers had a second occupation, particularly in Morogoro-rural (65\%), including livestock keeping, hand crafting, small-scale enterprising, tailoring, mining, tree nursery raising. Rice was the priority crop for nearly all interviewed farmers in Kyela (96\%). In the other two districts, this was the case for 70\% (Morogoro-rural) and $78 \%$ (Songea) of the farmers. In all districts, maize was the most important second crop. In Morogoro-rural (28\%) and in Kyela (49\%) other crops were mentioned as second crop, including cassava, cocoa, groundnut, sweet potatoes, bambara groundnut, oil palm, banana and citrus. In Songea and Kyela, farmers exclusively used seed of local rice cultivars, mainly sourced from their own or neighbouring farms. In Morogoro-rural, $23 \%$ of the farmers used improved varieties and just over 50\% used own farm seed. Other seed sources were nearby villages, NGO's, farmer organizations, seed companies and the local market. 
Table 1. Rice farmers' profile from the main three rice growing districts of Tanzania: Morogoro-rural (S. asiatica), Songea (R. fistulosa) and Kyela (S. asiatica and R. fistulosa). Results were obtained from surveys conducted in 2012.

\begin{tabular}{|c|c|c|c|c|}
\hline & & \multicolumn{3}{|c|}{ Districts } \\
\hline & & $\begin{array}{l}\text { Morogoro-rural } \\
(n=40)\end{array}$ & $\begin{array}{l}\text { Songea } \\
(n=18)\end{array}$ & $\begin{array}{l}\text { Kyela } \\
(n=95)\end{array}$ \\
\hline Gender (\%) & Male & 67.5 & 66.7 & 69.5 \\
\hline \multirow[t]{2}{*}{ Age (years) } & Range & $18.0-80.0$ & $32.0-79.0$ & $19.0-80.0$ \\
\hline & Average & 53.7 & 43.4 & 45.7 \\
\hline \multicolumn{5}{|l|}{ Farmer's occupation (\%) } \\
\hline First & Agriculture & 100.0 & 100.0 & 98.9 \\
\hline Second & Others & 65.0 & 38.9 & 55.8 \\
\hline \multicolumn{5}{|l|}{ Farmer's field size } \\
\hline Farm owned (acres) & Average & 2.80 & 3.40 & 4.20 \\
\hline Total farm size (acres) & Average & 3.10 & 3.90 & 4.60 \\
\hline \multicolumn{5}{|l|}{ Priority crops (\%) } \\
\hline \multirow[t]{3}{*}{ Crops $1 \& 2$} & Rice first crop (second) & $70.0(25.0)$ & $77.8(22.2)$ & $95.8(3.2)$ \\
\hline & Maize first crop (second) & $25.0(47.5)$ & $22.2(77.8)$ & $3.20(48.4)$ \\
\hline & Others first crop (second) & $5.0(27.5)$ & $0.00(0.00)$ & $1.10(48.5)$ \\
\hline \multicolumn{5}{|l|}{$\begin{array}{l}\text { Rice cultivar access to } \\
\text { farmers }(\%)\end{array}$} \\
\hline \multirow[t]{2}{*}{ Cultivars type } & Local variety & 77.5 & 100.0 & 100.0 \\
\hline & Improved variety & 22.5 & 0.00 & 0.00 \\
\hline \multirow[t]{4}{*}{ Cultivar seed source } & Own farms & 52.5 & 77.8 & 95.8 \\
\hline & Other farms & 25.0 & 22.2 & 4.3 \\
\hline & Farm organization \& NGO’s & 12.5 & 0.00 & 0.00 \\
\hline & Seed company/ local market & 10.0 & 0.00 & 0.00 \\
\hline \multicolumn{5}{|l|}{$\begin{array}{l}\text { Rice production techniques } \\
(\%)\end{array}$} \\
\hline \multirow[t]{4}{*}{ Land preparation type } & Ploughed and harrowed & 25.0 & 38.9 & 90.5 \\
\hline & Ploughed only & 25.0 & 16.7 & 4.20 \\
\hline & Slash and burn & 17.5 & 0.00 & 0.00 \\
\hline & Combination of the three above & 32.5 & 44.4 & 5.30 \\
\hline \multirow[t]{2}{*}{ Land preparation techniques } & Manual & 92.5 & 94.4 & 2.10 \\
\hline & Animal traction/ mechanization & 7.50 & 5.60 & 97.9 \\
\hline \multirow[t]{4}{*}{ Sowing methods } & Broadcasting & 20.0 & 0.00 & 89.5 \\
\hline & Direct seeding (dibbing) & 65.0 & 27.8 & 3.20 \\
\hline & Transplanting & 10.0 & 72.2 & 0.00 \\
\hline & Various methods & 5.00 & 0.00 & 7.30 \\
\hline \multirow{4}{*}{$\begin{array}{l}\text { Fertiliser use (\%) } \\
\text { Do you apply any fertiliser? } \\
\text { What fertiliser type do you } \\
\text { apply? }\end{array}$} & & & & \\
\hline & Yes & 10.0 & 77.8 & 44.2 \\
\hline & Inorganic fertiliser & 0.00 & 72.2 & 38.9 \\
\hline & Organic fertiliser & 10.0 & 5.60 & 5.30 \\
\hline \multirow[t]{2}{*}{$\begin{array}{l}\text { Rice production purpose } \\
(\%)\end{array}$} & Subsistence & 85.0 & 83.3 & 34.7 \\
\hline & Subsistence \& commercial & 15.0 & 16.7 & 65.3 \\
\hline
\end{tabular}




\section{Chapter 2}

In Morogoro-rural and Songea farmers grew rice for subsistence only (84\%), while in Kyela rice was more frequently grown for both subsistence and commercial purposes $(65 \%)$. Most of the respondents in the surveyed locations had difficulties in acquiring agricultural credits, rice production inputs, particularly fertilisers and herbicides, good quality seed material and extra labour (Table 2). In addition, they had difficulties in managing weeds, and consequently most respondents indicated that their rice crop was suffering from weed competition. The majority of the respondents (56 and 78\% across districts) mentioned that parasitic weeds were the most important group of weeds causing problems in their rice fields (Table 3 ). Around $15 \%$ considered ordinary weeds to be the main problem, and the other farmers were not sure.

\subsection{Surveys; farmers' knowledge on parasitic weeds}

In Morogoro-rural district, $90 \%$ of the respondents indicated to know Striga asiatica, where $84 \%$ had experienced the weed in their field. The majority of these farmers, growing rice in the uplands, perceived an increase in importance of the weed in recent years, but had no idea of the underlying reason. In Songea, with rice fields located in the lowlands, S. asiatica was not well known (6\%). In Kyela district, $70 \%$ of the respondents indicated to know S. asiatica and $58 \%$ had experienced it in their fields. About 39\% of the respondents perceived an increase in importance of the weed over the years, whereas a slightly larger group (52\%) had no clear idea about changes over time. Farmers in Kyela reported climate change, loss of soil fertility and crop intensification as possible causes of the change in S. asiatica intensity.

In Morogoro-rural, none of the upland rice farmers knew about $R$. fistulosa. By contrast in Songea and Kyela, the majority of respondents indicated that they knew the parasitic weed (83 and 76\%, respectively) and experienced the weed in their fields (72 and 62\%, respectively). In Kyela, $56 \%$ of the farmers perceived an increase in importance of the weed in recent years. In Songea, 39\% shared this perception. Climate change and loss in soil fertility were mentioned as the main causes for this. None of the farmers in Songea, and only $10 \%$ of the farmers in Kyela, perceived a decrease in importance of $R$. fistulosa in recent years.

Most of the interviewed farmers started controlling parasitic weeds only after their field was invaded (Table 3). Some did nothing and a small number abandoned their field because of parasitic weed infestation. For the majority of farmers, the management strategy applied to parasitic weeds was not different from what was done against ordinary weeds. 
Farmers' knowledge, use and preferences of parasitic weed management strategies in rice

Weed control through hand weeding was the most common intervention in Morogororural $(84 \%)$, Songea (87\%) and Kyela (97\%). Farmers in Morogoro-rural indicated that a parasitic weed control technology should preferably be locally accessible (30\%) of low-cost (25\%) and easy to implement (15\%) (Table 3). For farmers in Songea, dealing with $R$. fistulosa, control options should be low-cost (33\%) and easy to access (22\%). For farmers in Kyela, a strategy should be easy to implement (37\%), effective (20\%) and locally accessible (17\%). Only $8 \%$ of the farmers in Kyela mentioned the costs of a technology as important.

Table 2. Opinion of farmers on constraints that hinder rice production in three rice growing districts in Tanzania: Morogoro-rural (S. asiatica), Songea ( $R$. fistulosa ) and Kyela ( $S$. asiatica and R. fistulosa). Results are from surveys conducted in 2012.

\begin{tabular}{|c|c|c|c|c|}
\hline & & \multicolumn{3}{|c|}{ Districts } \\
\hline & & Morogoro-rural & Songea & Kyela \\
\hline $\begin{array}{l}\text { Important rice production } \\
\text { constraints }(\%)\end{array}$ & Comments & $(n=40)$ & $(n=18)$ & $(n=95)$ \\
\hline \multirow[t]{2}{*}{ Difficult to get credits } & Agree & 60.0 & 72.2 & 90.5 \\
\hline & Not agree (not sure) & $22.5(17.5)$ & $5.60(22.2)$ & $8.40(1.10)$ \\
\hline \multirow[t]{2}{*}{ Difficult to get production inputs } & Agree & 67.5 & 88.9 & 91.6 \\
\hline & Not agree (not sure) & $10.0(22.5)$ & $5.60(5.60)$ & $7.4(1.10)$ \\
\hline \multirow[t]{2}{*}{ Difficult to get good quality seeds } & Agree & 67.5 & 66.7 & 77.9 \\
\hline & Not agree (not sure) & $17.5(15.0)$ & $27.8(5.60)$ & $17.9(4.20)$ \\
\hline \multirow[t]{2}{*}{ Difficulty to get extra labour } & Agree & 70.0 & 61.1 & 62.1 \\
\hline & Not agree (not sure) & $15.0(15.0)$ & $27.8(11.1)$ & $36.9(1.10)$ \\
\hline \multirow[t]{2}{*}{ Difficulties in weed management } & Agree & 75.0 & 77.7 & 95.8 \\
\hline & Not agree (not sure) & $12.5(12.5)$ & $16.7(5.60)$ & $4.2(0.00)$ \\
\hline \multirow[t]{2}{*}{ Damages caused by weeds } & Agree & 70.0 & 88.9 & 97.9 \\
\hline & Not agree (not sure) & $12.5(17.5)$ & $11.1(0.00)$ & $1.10(1.10)$ \\
\hline
\end{tabular}




\section{Chapter 2}

Table 3. Farmers' experience on parasitic weeds from three rice growing districts in Tanzania: Morogoro-rural (S. asiatica), Songea ( $R$. fistulosa) and Kyela ( $S$. asiatica and $R$. fistulosa). Results are from surveys conducted in 2012.

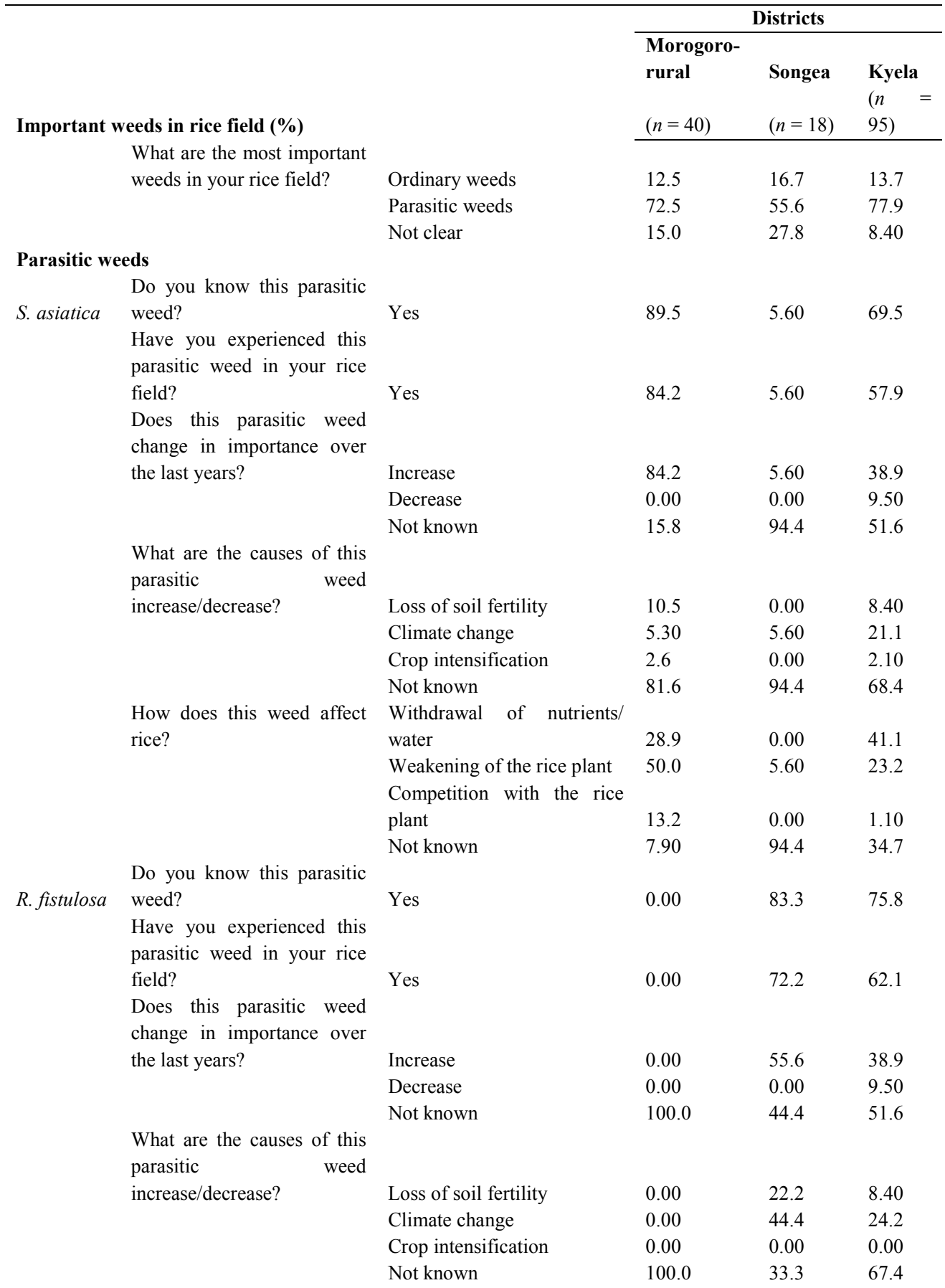


Table 3 (Continued). Farmers' experience on parasitic weeds from three rice growing districts in Tanzania: Morogoro-rural ( $S$. asiatica), Songea ( $R$. fistulosa) and Kyela $(S$. asiatica and R. fistulosa). Results are from surveys conducted in 2012.

\begin{tabular}{|c|c|c|c|c|}
\hline $\begin{array}{l}\text { How does this weed affect } \\
\text { rice? }\end{array}$ & $\begin{array}{l}\text { Withdrawal of nutrients/ } \\
\text { water } \\
\text { Weakening of the rice plant } \\
\text { Competition with the rice } \\
\text { plant } \\
\text { Not known }\end{array}$ & $\begin{array}{l}0.00 \\
100.0\end{array}$ & $\begin{array}{l}5.60 \\
33.3\end{array}$ & $\begin{array}{l}3.20 \\
33.7\end{array}$ \\
\hline \multicolumn{5}{|l|}{ Weed management strategies (\%) } \\
\hline \multirow[t]{2}{*}{$\begin{array}{l}\text { What do you do if parasitic weeds invade } \\
\text { your rice farm? }\end{array}$} & Control & 75.0 & 72.2 & 89.5 \\
\hline & Do nothing (Abandon field) & $22.5(2.50)$ & $\begin{array}{l}22.2 \\
(5.60)\end{array}$ & $\begin{array}{l}8.40 \\
(2.10)\end{array}$ \\
\hline \multicolumn{5}{|l|}{$\begin{array}{l}\text { Do you know parasitic weed management } \\
\text { options other than what you do to manage }\end{array}$} \\
\hline What type of weed control do you use? & Hand weeding & $\begin{array}{l}84.2 \\
15.8\end{array}$ & $\begin{array}{l}87.2 \\
128\end{array}$ & $\begin{array}{r}96.6 \\
3.40\end{array}$ \\
\hline $\begin{array}{l}\text { How did you come to know this parasitic } \\
\text { weed management strategy? }\end{array}$ & $\begin{array}{l}\text { Personal try-out } \\
\text { From extension } \\
\text { Others }\end{array}$ & $\begin{array}{l}30.0 \\
35.0 \\
35.0\end{array}$ & $\begin{array}{l}66.7 \\
22.2 \\
11.1\end{array}$ & $\begin{array}{l}28.4 \\
35.8 \\
35.8\end{array}$ \\
\hline \multirow{6}{*}{$\begin{array}{l}\text { Adoptable parasitic weed management } \\
\text { strategies }\end{array}$} & Ease of implementation & 15.0 & 11.1 & 36.8 \\
\hline & Ease of access & 30.0 & 22.2 & 15.8 \\
\hline & Low financial cost & 25.0 & 33.3 & 8.40 \\
\hline & $\begin{array}{l}\text { Appropriateness/Effectivene } \\
\text { ss }\end{array}$ & 10.0 & 5.60 & 20.0 \\
\hline & Low labour demand & 12.5 & 11.1 & 2.10 \\
\hline & Not sure & 7.50 & 16.7 & 16.8 \\
\hline
\end{tabular}

\subsection{Workshops; farmers' knowledge and perceptions on parasitic weed management strategies}

During the workshops, a range of parasitic weed management strategies was recorded and the pro's and con's of all these measures were listed and discussed. Thereafter, each participating farmer made a personal selection of the three best control strategies. The results are summarized in Fig. 1 (S. asiatica) and Fig. 2 (R. fistulosa).

In Morogoro-rural, intercropping, crop rotation and resistant varieties were most frequently mentioned as suitable control strategies against $S$. asiatica. Intercropping with leguminous crops was considered a suitable option (83\%), as it not only reduces $S$. asiatica infestation, but also improves soil fertility. Crop rotation also featured frequently in the topthree most suitable control technologies selected by individual farmers (63\%). It was regarded 


\section{Chapter 2}

a cheap option, that also improves soil health. Feasibility is hampered by the lack of suitable alternative non-host crops and insufficient land to withdraw from rice production. Resistant varieties were also frequently mentioned as a possible option (60\%). Farmers know of the existence of rice varieties that resist or tolerate $S$. asiatica, but indicated that these varieties are often not available. In Morogoro-rural, curative weed control (hoe weeding, herbicides, hand weeding) was also selected, though not very frequently (Fig. 1). Some farmers mentioned that weeding does not target the underground $S$. asiatica, which then continues to cause damage to rice. Hand weeding was also not regarded a very suitable option as it is a labour intensive approach.

Also in Kyela, crop rotation, and to a lesser extent rice intercropping with legumes, were frequently selected as the best strategy to control S. asiatica (Fig. 1). Farmers mentioned that these technologies improve soil fertility and increase food security by spreading the risk of crop failure. Crop rotation and fallow were, however, not frequently used, as their implementation has clear disadvantages according to farmers. The area under rice would be reduced with fallow or rotations, which immediately results in a reduced income. Furthermore, the high cost of land preparation after fallow was mentioned as a drawback. Following intercropping, rice yield is often reduced and insufficiently compensated by the second crop. Additionally, operations on the second crop, such as harvesting, can negatively affect rice. Row planting (selected by $32 \%$ ), was reported to reduce the required amount of rice seed, enhance ease of weeding and increase rice yield. However, its efficacy for $S$. asiatica control was questioned. Additionally, row planting was perceived as time and labour demanding. Early maturing varieties were frequently selected $(29 \%)$ and connected to late planting. According to farmers, late planting is an effective option for escaping S. asiatica, but combined with traditional varieties the risk of drought stress during ripening is simply too high. Farmers (30\%) indicated that early maturing varieties are needed to minimize this risk. Use of fertilisers, particularly manure and rice husks were considered to be another option for reducing $S$. asiatica infestation, whereas it also positively affects soil fertility. Manure was, however, not widely used, because it was believed to contain weeds seeds, which increase the ordinary weed infestation level. Other restrictions that were mentioned in relation to cattle manure, were the relatively high transportation costs and the uncertainty about the required application rate. Hand weeding was hardly mentioned among the first three most preferred options (5\%), as farmers were well aware that hand weeding is time consuming, laborious and costly and does not control $S$. asiatica during the initial underground stages of the weed. 

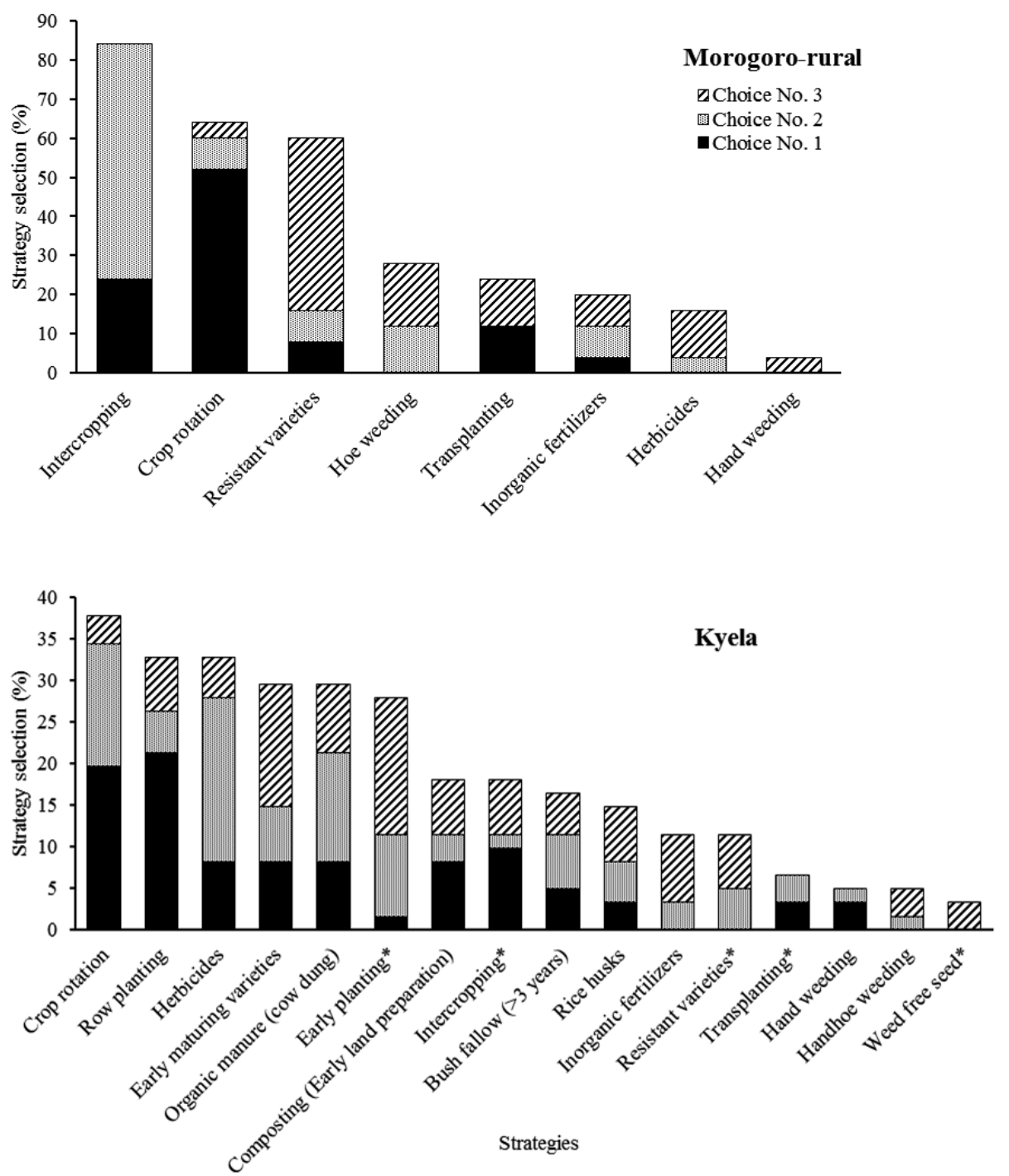

Fig. 1. Striga asiatica control strategies selected by farmers in Morogoro-rural and Kyela districts in Tanzania. Results are obtained from the workshops in 2012. *Additional technologies proposed by facilitators; the remainder of the technologies was suggested by the farmers.

In Songea, farmers most frequently mentioned hand weeding as the number one control strategy for $R$. fistulosa (74\%) (Fig. 2). This practice reduces $R$. fistulosa infestation and gives good crop yield, but it was also marked as a laborious and time consuming activity, which does not fully eradicate the weed. Farmers were aware of the existence of herbicides, which can considerably shorten the weeding time. Still, herbicides were less frequently mentioned 


\section{Chapter 2}

(38\%), because they are considered expensive and their use requires technical know-how. With regard to alternative varieties, both early maturing (48\%) and resistant (21\%) rice varieties were selected.
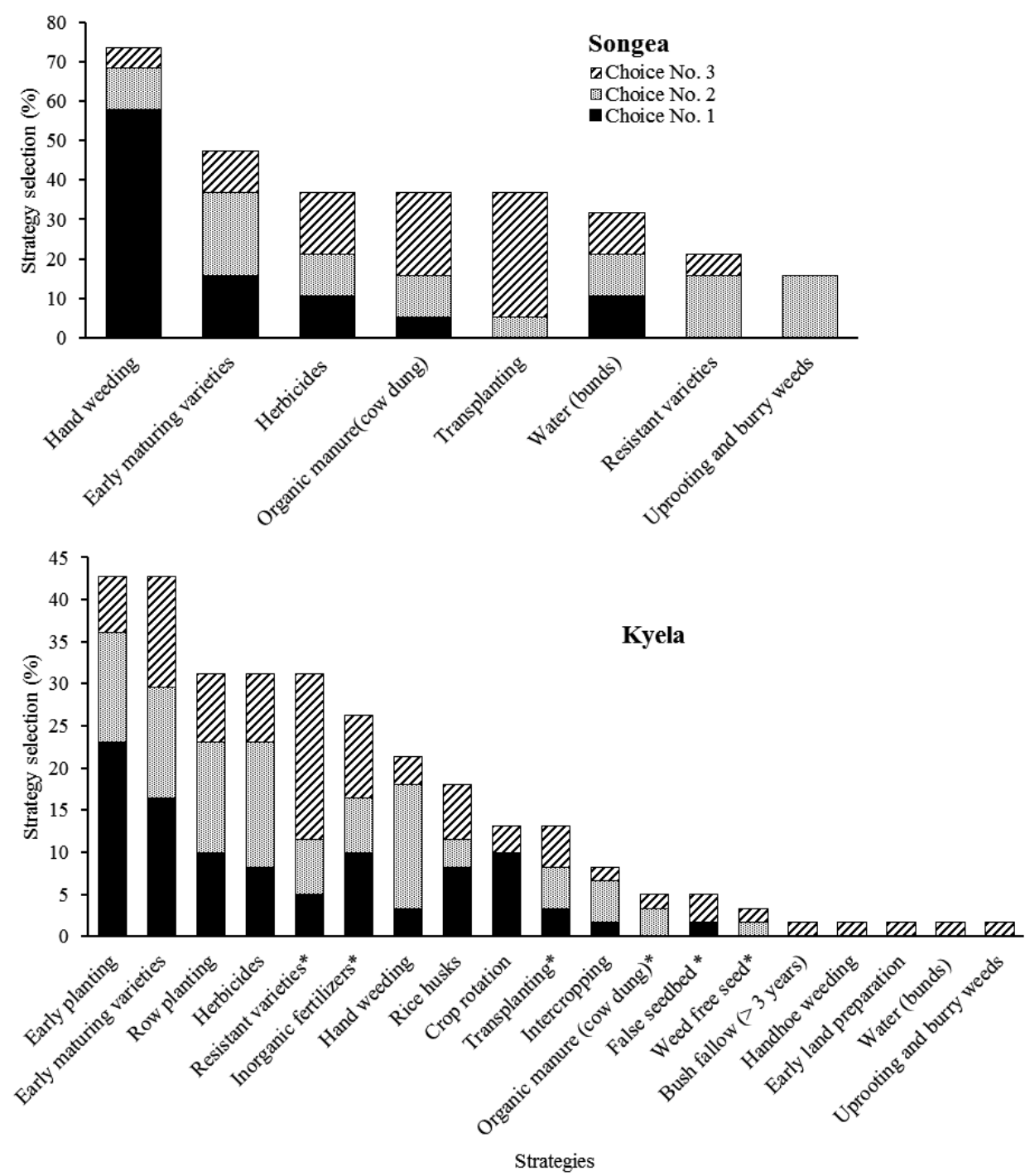

Fig. 2. Rhamphicarpa fistulosa control strategies selected by farmers in Songea and Kyela districts in Tanzania. Results are obtained from the workshops in 2012. *Additional technologies proposed by facilitators; the remainder of the technologies was suggested by the farmers. 
According to farmers, early maturing varieties are capable of escaping $R$. fistulosa infection and because of early harvest, they expect to fetch good prices. However, availability of early maturing and resistant rice varieties is usually limited, whereas their acquisition adds to the overall production costs. Other options farmers selected were the use of transplanting and bunding. Farmers indicated that these options require fewer seeds, reduce weed infestation and thus weeding costs, improve grain weight and assure good crop performance. However, both options are costly and time consuming, and the practice is limited to levelled and irrigated fields. It was also mentioned that under bunded conditions uncontrolled floods sometimes adversely affect the crop, whereas in poorly drained fields there is the risk of iron toxicity.

In Kyela, early sowing (43\%) and use of early maturing rice varieties (42\%) were the most frequently selected means to reduce, or even escape, $R$. fistulosa infestation (Fig. 2). Additional advantages according to farmers were the increased food security and reduced hunger due to earlier food supply, the income generation by fetching a better price on the market and the increased time for land preparation for the subsequent season. Also clear disadvantages of early sowing and harvests were pointed out, like the limited or untimely availability of agro-inputs, increased proneness to bird attacks resulting in high costs of bird control, and a high social pressure to lend rice to neighbours.

Farmers also suggested that usually a high ordinary weed intensity during the season is encountered when sown early, as the first weed emergence flush coincides with crop establishment. According to farmers, options like crop rotation, intercropping and bush fallow (preferred by 13,9 and $2 \%$ of the farmers, respectively) improve soil fertility, save fertiliser costs and increase farm income. Applicability of these options was mentioned to be limited due to the lack of alternative crops adapted to lowland or hydromorphic conditions and shortage of land for fallow.

Farmers were aware of herbicides for controlling $R$. fistulosa, and 32\% of the farmers selected this control option. Indicated disadvantages of herbicides were the high costs of chemicals and equipment. Farmers also indicated that herbicide application is a male task and, consequently, it has a gender limitation effect. The use of rotary/push weeder was mentioned as a method to enhance weeding, but not selected, since in Kyela the rice crop is usually broadcasted, and equipment and experience are lacking. Fertilisers were among the preferred control options by $26 \%$ of the farmers. They were considered to have positive effects beyond the control of R. fistulosa, but were also regarded as expensive. Rice husks (18\%) and manure 


\section{Chapter 2}

(7\%) were selected and mentioned to improve soil fertility, enhance soil water retention and improve soil structure. One general disadvantage mentioned by the farmers concerned the long time lag for the expression of benefits of these organic soil improving inputs. Farmers also indicated their fear that the application of manure increases the ordinary weed infestation level.

\subsection{Researcher-managed on-farm trials and farmer-participatory technology evaluation}

In the rice variety - sowing time experiment under upland conditions, the average rice grain yield for 2012-2014 was 2 ton $\mathrm{ha}^{-1}$. The second season, 2013, stood out as a year with heavy $S$. asiatica infection, with an average rice grain yield of 0.8 ton $\mathrm{ha}^{-1}$ for the traditional long duration varieties (Mwangulu and Supa India) and of 1.9 ton $\mathrm{ha}^{-1}$ for NERICA-14. For all rice varieties, delayed sowing caused a reduction in S. asiatica infection level, whereas rice grain yield showed an optimum at intermediate sowing times. In 2012 and 2014, the two years with mild $S$. asiatica infection, the negative effect of late sowing on rice grain yield was more pronounced. In 2012, rice yields dropped from an average of 4 ton $\mathrm{ha}^{-1}$ at first sowings, to around 2.5 ton $\mathrm{ha}^{-1}$ for the last sowing dates. In 2014, the risk associated to late sowing was further confirmed, as the yield of Mwangulu, a traditional long duration variety, dropped from around 1.5 ton $\mathrm{ha}^{-1}$ with earlier sowings to just 0.5 ton $\mathrm{ha}^{-1}$ at the last sowing time.

In the $S$. asiatica infested upland rice growing environment in Kyela, the best sowing date, according to the farmers evaluating the researcher-managed on-farm trials, was midJanuary, though preferences ranged from late December to mid-February (Fig. 3). In selecting the best sowing date, farmers mentioned that late sowing: (1) might enable the crop to escape Striga infection, (2) enables early weed control before the rice crop is sown, which in turn saves weeding time, (3) minimizes bird damage, since bird pressure is spread over many fields. The perceived risk connected to late sowing is that crops are prone to drought. This risk perception is also reflected in the strong preference of the farmers ( $>90 \%$ of the cases) for the short-duration rice variety NERICA-14 (Fig. 3).

In the rice $\times$ sowing time experiment under lowland conditions, average rice grain yield from 2012 to 2014 was about 3.5 ton ha $^{-1}$. Infestation level of $R$. fistulosa was highest in 2012 and gradually dropped from an intermediate level in 2013, to a low infestation level in 2014. In all seasons, parasite infestation levels increased with a delay in sowing time. This resulted in a gradual decline in rice grain yield with delayed sowing, except for 2014, when parasite infestation did not affect rice grain yield to a great extent. In none of the years, obvious 
infection or yield differences between rice varieties were observed.
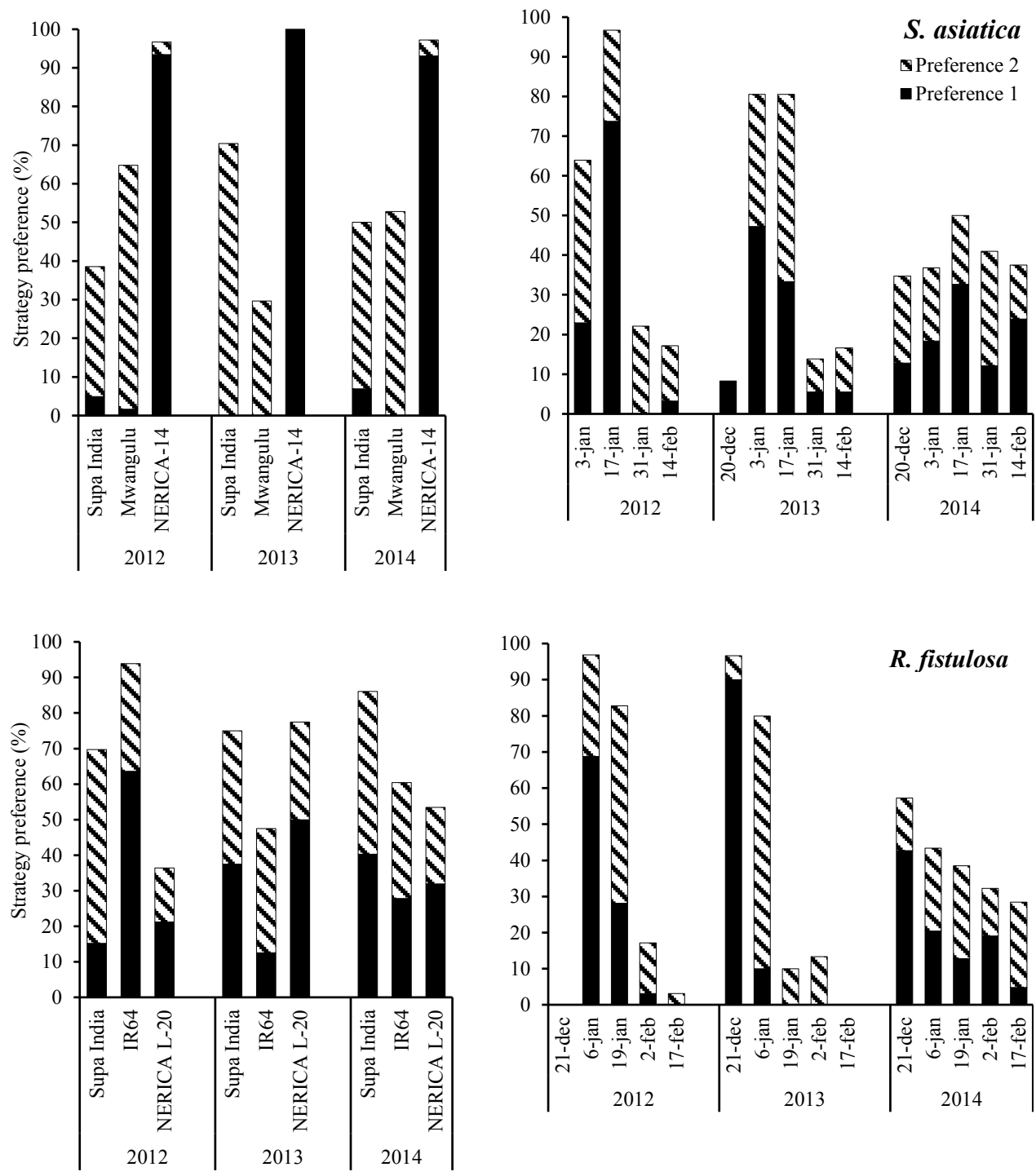

Sowing date

Fig. 3. Rice variety and sowing date preferences of farmers expressed during their visit to the researcher-managed on-farm trials in upland ( $S$. asiatica) and lowland ( $R$. fistulosa) fields that were established in Kyela district, Tanzania. Results are obtained during the farmer visits in 2012-2014. 

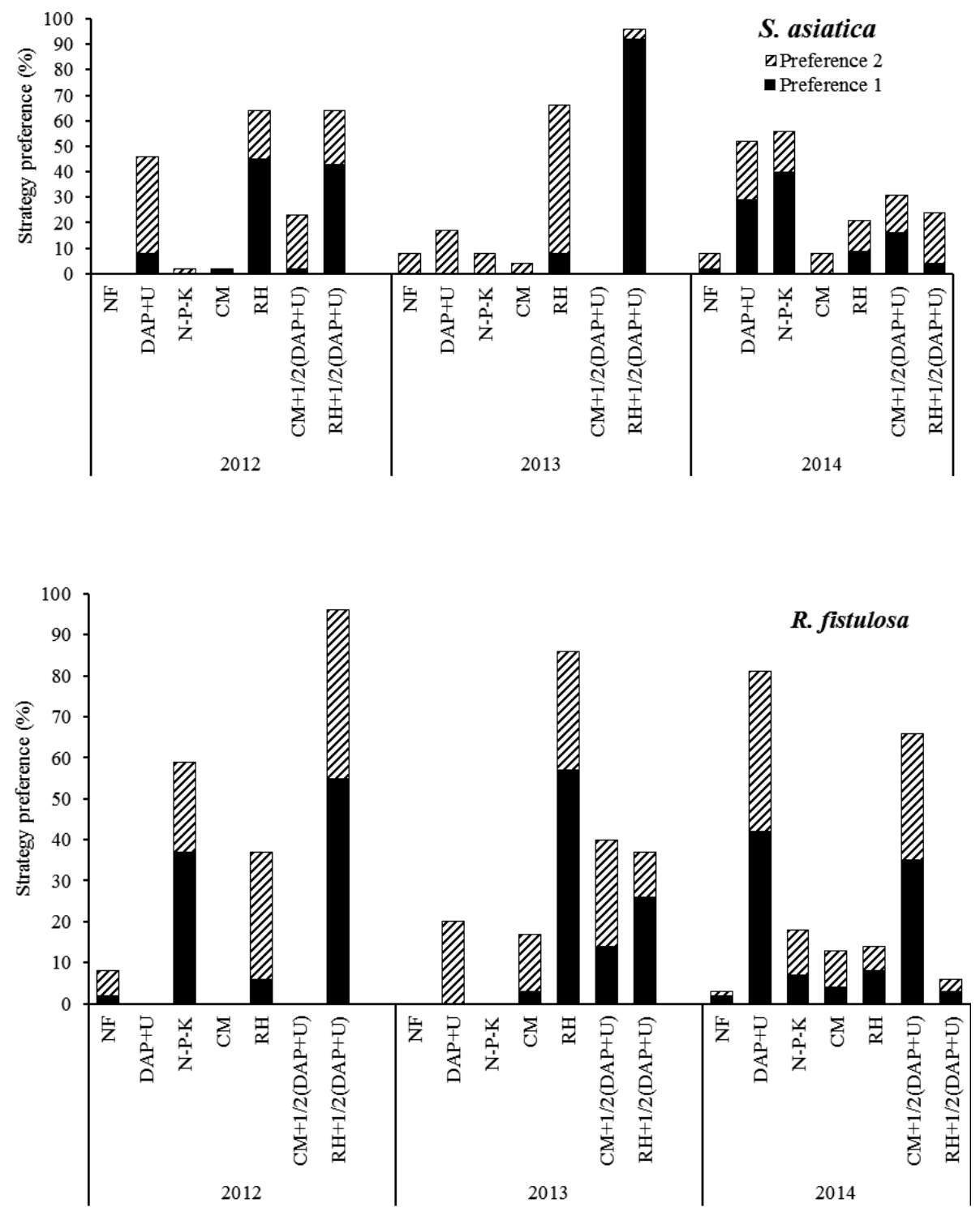

Fig. 4. Soil amendment preferences of farmers expressed during their visit to the researchermanaged on-farm trials in upland (S. asiatica) and lowland ( $R$. fistulosa) fields established in Kyela district, Tanzania. Results are obtained during the farmer visits in 2012-2014.

Where: $N F=N o, D A P=D i$-Ammonium Phosphate, $U=U$ Urea, $N-P-K=$ Nitrogen, Phosphorus and Potassium, $C M=$ Cattle Manure, and $R H=$ Rice husks 
In the $R$. fistulosa infested lowland rice growing environment in Kyela, the best sowing dates according to the participating farmers, was from the third week of December to the first week of January (Fig. 3). Sowing early was considered to (1) be an effective strategy to escape $R$. fistulosa, which mostly emerges in late sown fields, (2) avoid risks caused by unpredictable rainfall and (3) be a good strategy to make sure sowing is completed before fields get flooded. Farmers' preferences for rice varieties were inconsistent across years (Fig. $3)$. The preference for the local rice variety Supa India was relatively stable, whereas the preference for IR64 and NERICA-L-20 varied from year to year. The local rice variety Supa India is best known to the farmers, and appreciated for its aroma, cooking quality and marketability.

In the soil amendment experiment, average rice grain yield from 2012 to 2014 was about 2 ton $\mathrm{ha}^{-1}$ under upland and about 3 ton $\mathrm{ha}^{-1}$ under lowland conditions. Without soil amendment, rice grain yield in both situations was 0.7-0.8 ton ha ${ }^{-1}$ less. Highest yields were obtained if rice husks were combined with half the recommended rate of inorganic fertiliser, resulting in average rice grain yields of 2.5 ton $\mathrm{ha}^{-1}$ under upland and 4 ton ha $\mathrm{ha}^{-1}$ under lowland conditions. Striga asiatica infection level was highest in 2013, resulting in an average rice grain yield just below 1 ton $\mathrm{ha}^{-1}$. In this, nor in the other years, an effect of soil amendment on $S$. asiatica infection level was observed. In the lowland site, $R$. fistulosa infestation was most severe in 2012, resulting in an average rice grain yield of just 1 ton $\mathrm{ha}^{-1}$. In all years, the addition of soil amendments resulted in a higher R. fistulosa infestation level. Apparently, the facultative parasite profited directly or indirectly from the improved soil fertility status. For parasite infestation level, no clear differences between the types of soil amendments were observed.

Regarding the preference of soil amendments under both upland and lowland conditions, there was a clear preference for the treatments that contained rice husks, particularly during the first two years of experimentation (Fig. 4). An important consideration mentioned by farmers was the affordability of this soil amendment option. In the last season, the result of the evaluation differed markedly from that of the first two seasons. Farmers preferences during the last season shifted from organic to inorganic s, and also the combination of cattle manure with inorganic fertiliser was more frequently ranked among the preferred options. This shift in preference was likely affected by the timing of the evaluation, where this exercise was carried out relatively late in the season, combined with a heavy rain the day before the evaluation. Rice in plots treated with organic fertiliser and combinations of organic 


\section{Chapter 2}

and inorganic fertiliser were lodged under the impact of the rain due to heavy panicles. In plots that received inorganic fertiliser, the plants had lighter panicles and did not lodge. To farmers, lodged crops add extra strain during harvesting, representing additional costs.

\subsection{Farmer-managed on-farm trials; perceptions and preferences based on experimentation}

For the upland rice farmers, the standard sowing time was mostly set to mid-January, with one group sowing three weeks later (Table 4). Supa India was set as the conventional variety. Application of Di Ammonium Phosphate (DAP) combined with Urea or just DAP was established as the conventional soil fertility management practice. For the improved $S$. asiatica management strategy in the uplands, NERICA-1, -4 and -10 were selected. During Participatory Variety Selection (PVS) conducted in the same location in the previous years, these short-duration varieties had shown to be more $S$. asiatica resistant than the shortduration NERICA variety tested in the sowing-date trials (NERICA-14). One group decided to postpone sowing with four weeks, whereas another group postponed sowing with 10 days as a means to minimize the risk of $S$. asiatica infection. The third group did not dare to postpone sowing any later than the conventional practice, while the fourth group advanced sowing with one week, compared to the conventional sowing date. In all four sites, rice husks combined with DAP and Urea was used as an alternative soil amendment.

In the lowland fields, sowing dates following farmer practice were set from the last week of December to mid-January (Table 4). Farmers mentioned that early sowing usually results in lower R. fistulosa infection. The combination of the local rice variety Supa India with inorganic fertilisers was selected as the conventional farmer practice. For improved $R$. fistulosa management strategy, lowland NERICA-L-12, -L-31 and -L-39 were selected as alternative varieties as they had a similar growth duration as NERICA-L-20 but were more resistant against $R$. fistulosa. This selection was also the result of a PVS conducted alongside the researcher-managed on farm trials in the same period (2012-2014). Alternative sowing times initially selected by the farmers were not much different from the conventional times and differed from 10 days earlier for the group planning to sow early January, to a five days delay for the group that planned to sow mid-December. Due to a delayed onset of the rains, the actual implemented sowing dates in the trials were however adjusted. Plots with farmers practice were sown soon after the first rains (early January) and plots with the alternative sowing date treatment were sown two weeks later. 
Table 4. Proposed parasitic weed management strategies for the farmer-managed on-farm trials in upland (groups A, B, C and D) and lowland fields (groups E, F, G and H) in Kyela district, Tanzania. Results were obtained during individual group discussions in November 2014, shortly before instalment of the trials.

\begin{tabular}{|c|c|c|c|c|}
\hline \multicolumn{4}{|l|}{ Upland (Striga asiatica) } & \\
\hline Standard practice & A & B & C & D \\
\hline Proposed sowing time & 15 January & 10 February & 10 January & 15 January \\
\hline Variety & Supa India & Supa India & Supa India & Supa India \\
\hline Soil amendment & $\mathrm{DAP}+\mathrm{U}$ & $\mathrm{DAP}+\mathrm{U}$ & $\mathrm{DAP}+\mathrm{U}$ & DAP \\
\hline \multicolumn{5}{|l|}{ Alternative practice } \\
\hline Sowing time & -10 days & 0 day & +7 days & +29 days \\
\hline Variety & NERICA-1,4, 10 & NERICA-1,-4, -10 & NERICA-1,-4, -10 & NERICA-1,-4, -10 \\
\hline Soil amendment & $\mathrm{RH}+1 / 2(\mathrm{DAP}+\mathrm{U})$ & $\mathrm{RH}+1 / 2(\mathrm{DAP}+\mathrm{U})$ & $\mathrm{RH}+1 / 2(\mathrm{DAP}+\mathrm{U})$ & $\mathrm{RH}+1 / 2(\mathrm{DAP}+\mathrm{U})$ \\
\hline \multicolumn{5}{|c|}{ Lowland (Rhamphicarpa fistulosa) } \\
\hline Standard practice & $\mathbf{E}$ & $\mathbf{F}$ & G & $\mathbf{H}$ \\
\hline Proposed sowing time & 5 January & 1-15 January & 23 December & 15 December \\
\hline Variety & Supa India & Supa India & Supa India & Supa India \\
\hline Soil amendment & $\mathrm{DAP}+\mathrm{U}$ & $\mathrm{DAP}+\mathrm{U}$ & $\mathrm{DAP}+\mathrm{U}$ & DAP \\
\hline \multicolumn{5}{|l|}{ Alternative practice } \\
\hline Sowing time & 0 day & -10 days & -3 days & +5days \\
\hline Variety & NERICA-L-31 & NERICA-L-39 & NERICA-L-39 & NERICA-L-12 \\
\hline Soil amendment & $\mathrm{DAP}+\mathrm{U}$ & $\mathrm{RH}+1 / 2(\mathrm{DAP}+\mathrm{U})$ & $\mathrm{RH}+1 / 2(\mathrm{DAP}+\mathrm{U})$ & $\mathrm{DAP}+\mathrm{U}$ \\
\hline
\end{tabular}

$R H=$ Rice husks, DAP $=$ Di-Ammonium Phosphate, NPK $=$ Nitrogen, Phosphorus, and Potassium, $U=$ Urea , Supa India = local rice cultivar also known as Kilombero

Table 5. Farmers' outlook on the three components of a parasitic weed management strategy that were evaluated in famer-managed on-farm trials in upland and lowland fields in Kyela district - Tanzania, 2015. Results were obtained during individual farmer interviews $(n=40)$, shortly after the farmer group visits to the trials just before crop maturity. Answers per category are expressed in $\%$.

\begin{tabular}{llcc}
\hline Technology evaluation & & $\begin{array}{c}\text { Upland } \\
\text { S. asiatica })\end{array}$ & $\begin{array}{c}\underline{\text { Lowland }} \\
(\text { R.fistulosa })\end{array}$ \\
\hline (1) Sowing time & & 0.0 & 80.0 \\
Are you going to modify sowing time? & Yes, to an earlier time & 5.0 & 17.5 \\
& No & 95.0 & 2.5 \\
(2) Variety & Yes, to a later time & 17.5 & 87.0 \\
Which variety do you prefer? & Supa India & 82.5 & - \\
& NERICA-10 & - & 13.0 \\
(3) Soil amendment & NERICA-L-31 & & \\
Which soil amendment do you prefer? & DAP, Urea & 0.0 & 35.0 \\
& Rice husks + 1/2 (DAP + U) & 90.3 & 65.0 \\
& None & 9.7 & 0.0 \\
\hline
\end{tabular}




\section{Chapter 2}

Including rice husks as soil amendment was decided on by two groups, while other groups preferred to use DAP + Urea.

The year 2015 was characterized with heavy S. asiatica-infections. Average rice grain yield was 1.4 ton $\mathrm{ha}^{-1}$. Late sown plots clearly showed lower infection levels than the earlier sown plots, and the plots with NERICA-varieties were less infected than the plots sown with Supa India. At the end of the season, the vast majority of farmers in the uplands selected late sowing (95\%), preferably combined with NERICA-10 (83\%), as the best way to combat $S$. asiatica (Table 5). Farmers characterized NERICA-10 as an early maturing variety with good grain appearance and S. asiatica resistance. The majority of the farmers (90\%) selected rice husks $+1 / 2($ DAP + Urea $)$ rates as the preferred soil amendment option. This selection was motivated by the realisation that application of the relatively cheap rice husks allowed farmers to reduce the rates of the relatively expensive inorganic fertilisers by $50 \%$, without compromising productivity.

Only mild infestations of $R$. fistulosa were encountered in 2015 and average rice grain yield was just below 4 ton $\mathrm{ha}^{-1}$. A negative effect of a delayed sowing time on $R$. fistulosa infection level was noted, while differences between varieties were not observed. At the end of the season a majority of the farmers $(80 \%)$ indicated a commitment not to delay sowing times in future (Table 5). Some farmers, however, expressed their concern that with early sowing, their local rice variety would be more affected by Rice Yellow Mottle Virus (RYMV). In the absence of differences in R. fistulosa infection level between varieties, most farmers $(87 \%)$ preferred to stick to their local rice variety Supa India. Use of rice husks in combination with $1 / 2$ (DAP and Urea) $(65 \%)$ or DAP and urea only (35\%) were the preferred soil fertility amendments among farmers in the lowlands. The substitution of part of the inorganic fertiliser by rice husks was motivated by financial reasons.

\section{Discussion}

\subsection{Farmer awareness regarding parasitic weeds}

Our survey in three rice growing districts of Tanzania revealed that most farmers are well aware of the existence of parasitic weeds, and they mostly consider these weeds ( $R$. fistulosa and $S$. asiatica) a more important problem for rice production than ordinary weeds. This corroborates Parker (2012) and Rodenburg et al. (2010), who assumed that, if present, parasitic weeds may be the dominant weed problem for farmers as apart from the usual competitive effects, these weeds exert additional damage through parasitism. About half of 
the surveyed farmers perceived that the parasitic weed problem is increasing, whereas the other half indicated to have no clue whether the magnitude of the problem is changing. Hardly any farmer indicated a decrease of these weeds, however. Evidence from the literature in support of the perceived increase of parasitic weeds in rice in the course of time is limited, but R. fistulosa has been reported to increase in Benin (Rodenburg et al., 2011a) and Uganda (Rodenburg et al., 2015a), while the rice area infested by S. hermonthica is reportedly increasing in Côte d'Ivoire (Kouakou et al., 2015). Parker (2012) suggested that an increase of this type of weeds is indeed likely to result from ongoing, unsustainable crop production intensification and concomitant losses in soil fertility.

In all surveyed districts, farmers largely rely on hand weeding for parasitic weed control. This observation corresponds to Houngbedji et al. (2014) and $\mathrm{N}^{\prime} \mathrm{Cho}$ et al. (2014), who reported that hand weeding is the main control strategy used by the farmers in most of the rain-fed rice systems. Despite its wide application, it was only in Songea that hand weeding was selected as the preferred strategy. In this district, $R$. fistulosa is thriving and removing the weed at early stages of growth, before it connects to its host plant, is indeed assumed to be effective in reducing the damage (Kabiri et al., 2016). In Kyela, the other district with $R$. fistulosa infestation, hand weeding was only ranked seventh. Despite its efficacy, farmers consider hand weeding laborious, and therefore time-consuming and costly. This observation confers with Oswald (2005), who also reported that farmers are reluctant to conduct hand weeding. Farmers dealing with $S$. asiatica were even more critical, and rated hand weeding ineffective. Farmers are well aware that this parasite usually continues to emerge after the first weeding and that already a lot of damage has been done during the underground growth stages of the parasite.

\subsection{Obstacles for implementation of alternative control options}

During the workshops, a wide range of alternative control options, including crop diversification, variety selection, sowing time, soil fertility management and alternative planting methods, were discussed and ranked. Despite the wide knowledge on potential control strategies among farmers, most of the suggested measures were not used by them due to high costs, lack of local availability or trade- offs. Alternative curative control practices, like hoe weeding and herbicides, for instance, were both considered too expensive. Farmers indicated that hoe weeding also requires row planting, which brings an additional cost due to the high additional labour requirement for crop establishment. Application of herbicides was 


\section{Chapter 2}

mentioned by farmers to require knowledge on suitable products, application rates and timing to be effective and to avoid phytotoxic effects on the crop. During the course of this study for instance, stunted and yellowish rice crops as a result of the use of atrazine were observed in Kyela. Misuse of herbicides by rice farmers due to lack of knowledge and information is more frequently observed in SSA (Rodenburg and Johnson, 2009).

Affordability of technologies was not just related to costs of products. Crop diversification, consisting of intercropping with legumes and crop rotation, was selected as the preferred option against $S$. asiatica. Alternating host crops with non-host crops is expected to reduce the Striga infestation level and accordingly the damage that results from infection (e.g. Kamara et al., 2008; Kayeke et al., 2007; Riches et al., 2005). Despite the high ranking of diversification by upland farmers, they expressed their concerns regarding implementation of this strategy. They mentioned the lack of suitable alternative non-host crops and the fact that they simply possess insufficient land to withdraw a part of that from rice production, their main subsistence crop. Crop diversification strategies as a way to address $R$. fistulosa was hardly mentioned by farmers confronted by this weed. The obvious reason for this is that very few crops can sustain the hydromorphic conditions typical for the lowlands (Kirchhof et al., 2000) where this species is found. Kabiri et al. (2016) further suggested that crop diversification would not be effective because of the facultative parasitic nature of this species, rendering it relatively independent from a suitable host.

Poor accessibility to seeds of improved varieties was frequently mentioned as an obstacle for the use of resistant rice varieties. Recently systematic screenings of popular rice varieties were undertaken to find good sources of resistance and tolerance against both $S$. asiatica and R. fistulosa (Cissoko et al., 2011; Jamil et al., 2011b; Rodenburg et al., 2015a, 2016a). But prior to these exercises, very few adapted and high-yielding rice varieties with effective resistance or tolerance were known. In the current study, farmers demonstrated awareness of the existence and potential of resistant varieties. At the same time, apart from the poor accessibility of seeds, the strong consumer preferences for local varieties have made farmers reluctant to adopt improved varieties. Rice grain quality, good taste and aroma are among the preferred varietal attributes that secure a good price at the local market (Singh et al., 2013; Diako et al., 2010). In sorghum, Mrema et al. (2017) also noted that the adoption rate of Striga-resistant varieties was low due to a lack of locally preferred traits.

The use of organic and inorganic fertilisers was hampered by a variety of reasons. Fertile soils are usually assumed to harbour less parasitic weeds (e.g. Kamara et al., 2008). Striga 
incidence for instance, is often associated with poor soil fertility (Kabiri et al., 2015; Mohamed et al., 2006). Application of both inorganic fertilisers and cattle manure could reverse this (Kamara et al., 2014), and this seems to be known and understood by the farmers that participated in this study who mentioned fertilization as a component of a parasitic weed control strategy. Regarding cattle manure, farmers mentioned the high transportation costs, related to its bulkiness, and the possible introduction of non-parasitic weed seeds as drawbacks. The increase in other weeds could come from weed seeds ingested by browsing cattle if after passing through the digestive system of the animals seed viability is not lost (Blackshaw et al., 2005). Obstacles to implementation of the use of inorganic fertilisers, on the other hand, were the high costs and the unreliable timing of their availability on the market. Particularly in Kyela, farmers frequently complained about the relatively late availability of inorganic fertilisers on the market at the start of cropping seasons. In this regard, the introduction of rice husks as one of the treatments in the researcher-managed onfarm trials is of interest. In the informal discussions with farmers preceding these experiments, rice husks were proposed as a locally-available and relatively cheap alternative soil amendment option. In both upland and lowland, the treatments containing rice husks were frequently ranked high, even though parasitic weed pressure was not markedly reduced. Farmers mentioned that this ranking was related to the fact that rice husks form a relatively cheap alternative and crop performance in plots amended with rice husks was at least identical to that of the performance following inorganic fertiliser treatments. In the farmer managed onfarm trial, the majority of farmers preferred the use of rice husks in combination with half the recommended rates of inorganic fertilisers (DAP and Urea). Also in this case, the farmers indicated that this choice was made from a cost-saving perspective. Evidently, farmers valued the measures from a whole-farm perspective, rather than just from a crop-protection perspective.

The above examples clearly illustrate that knowledge and understanding regarding the control methods of parasitic weeds do not guarantee their actual implementation by farmers. This notion was already reflected in a study on technologies for improving maize productivity in Striga-infested areas (Debrah, 1994). The author concluded that adoption of innovative technologies for the control of Striga was hampered because of a disparity between technologies and the farmers' socio-economic conditions. Also in the current study, the vast majority of farmers mentioned to face difficulties with acquiring credits and the availability of production inputs such as good quality seeds, fertilisers, herbicides and extra labour. When 


\section{Chapter 2}

farmers were asked which factors in their view favour acceptability and adoption of potential strategies against parasitic weeds, they specifically mentioned local accessibility, ease of implementation, effectiveness and low costs. This corresponds with Emechebe et al. (2004), who concluded that acceptable strategies should not require further resources for their implementation.

\subsection{Species-specific control strategies}

This study clearly showed that parasitic weed control strategies in rain-fed rice systems differ considerably between species. Adjusting the sowing time was one of the major elements of both the researcher and the farmer-managed on-farm experiments. It was selected based on informal discussion with farmers in Kyela, who frequently mentioned it as a strategy that meets the criteria of affordability, local accessibility and ease of implementation. The researcher managed on-farm experiments allowed to extensively test effectiveness of this practice and to obtain a clear view on the farmers' perception regarding this strategy. The scores based on the sowing time by variety trial showed a number of consistent differences between S. asiatica (upland) and R. fistulosa (lowland). Farmer-preferred sowing date for the Striga-infested upland field was mid-January, combined with a strong preference for the short duration NERICA-14.

A delayed sowing may indeed be a good strategy to avoid parasitism as already preconditioned Striga seeds may have returned to a state of secondary dormancy by the time the roots system of the late-sown rice starts to develop (Mohamed et al., 1998). To enable farmers to pursue late sowing as a control strategy, early maturing varieties are needed. With the late maturing local varieties, the risk of encountering drought stress during grain filling is simply too high, making late sowing less attractive (Pantuwan et al., 2002). The farmer managed on-farm experiment in 2015 confirmed the effectiveness of this method. Since in this season $S$. asiatica was prevailing, there was a good basis for comparing the suggested strategies against this parasitic weed.

Late sowing combined with early maturing NERICA-10 was selected as the preferred strategy by majority of the farmers. Apart from its short growth-duration, NERICA-10, in contrast to Supa India, is also resistant against the parasite (Rodenburg et al., 2015a; Cissoko et al., 2011; Jamil et al., 2011b). The difference between these two varieties was clearly expressed due to the relatively high Striga incidence in 2015. In addition to short-duration and resistance, grain quality remained an important trait and it was for this reason that farmers 
preferred NERICA-10 over NERICA-1 and 4, which are also short-duration and Striga resistant varieties. The observation that short duration, Striga resistance and grain quality can be found in one variety convinced farmers to change their preference for the local variety Supa India to an alternative variety.

In the researcher managed on-farm trials in the lowland field the preferred sowing date was shortly after the onset of the first rain (mid-December to early-January). Here no clear variety preference was observed, although the preference for the local variety Supa India was most consistent across the experimental years. Early sowing was regarded as a suitable strategy against the relatively late-emerging $R$. fistulosa, as it helps to partly escape the detrimental effect of the parasite. The strategy does not rely on an early maturing variety, simply because early sowing combined with the hydromorphic to flooded conditions of the lowlands allows the rice crop to mature without being exposed to conditions of severe drought stress. In the farmer managed on-farm trial, Supa India was compared with NERICA-varieties that had demonstrated resistance against $R$. fistulosa in previous seasons (Rodenburg et al., 2016a).

Despite the absence of good resistance, Supa India, with its superior taste, aroma and good grain quality, remained the farmers' preferred choice. It should be noted that 2015 was characterized by relatively low $R$. fistulosa infestation levels, rendering the virtues of resistance less evident. Moreover, compared to the resistant NERICA varieties, Supa India showed to be superiorly tolerant to R. fistulosa parasitism (Rodenburg et al., 2016a). Also the preference for early sowing was confirmed in these farmer managed trials. In Kyela, early sowing is already widely practiced, since broadcast sowing (the locally preferred crop establishment method) is less appropriate once the fields are flooded. Discussions with farmers also revealed a number of drawbacks associated with early sowing. With early sowing, farmers usually encounter high ordinary weed infestation levels, as the emergence of the first weed flush coincides with crop emergence. This first weed flush is relatively easy to remove if crop sowing is postponed and the weed seedlings can be removed in the absence of the crop.

Additionally, early sowing of the local variety Supa India was mentioned by farmers to promote the incidence of Rice Yellow Mottle Virus (RYMV), a common production constraint in rice in Tanzania and the rest of SSA (Banwo et al., 2002; Balasubramanian et al., 2007). Still, according to the participating farmers, the advantages of early sowing outweighed these disadvantages. Evidently, it shows that defining an effective and suitable 


\section{Chapter 2}

control strategy for smallholder farmers to deal with a biotic production constraint, is a delicate process in which the involvement of farmers is essential for its success.

\section{Conclusion}

This study showed clear complementarity in research methods. The surveys provided an overview of perceptions of rice farmers on weed problems, the measures they use to address these problems and criteria they consider important for acceptability of control measures. The workshops yielded the necessary insights in potential control options and farmers views on important advantages and disadvantages as well as acceptance of specific control measures. On-farm trials provided insights in the actual efficacy of locally-accessible measures. The researcher-managed trials allowed to reach a large group of farmers, whereas the farmer managed experiments created opportunities for in depth discussions with and among farmers and showed which measures actually work under genuine conditions and management. To disseminate findings to a wider audience than just the farmers that participated or visited the on-farm trials other rice stakeholders (e.g. agro-dealers, extension officers and local village leaders) were invited to visit the field trials during the farmers field day and representatives of local radio and television stations were invited during the farmer field day in 2015 to air the event. Scientific publications and policy briefs are used as a means to disseminate our findings to a wider group of stakeholders in the rice value chain.

The surveys and workshops conducted in three rice growing areas in Tanzania, indicated that farmers are well aware of the parasitic weed species that are of local relevance, i.e., $S$. asiatica in uplands and $R$. fistulosa in lowland conditions. Farmers do recognize parasitic weeds as a severe constraint in rain-fed rice production systems. Despite the rather extensive knowledge among farmers about alternative management strategies, hand weeding is currently the most widely used control measure to deal with parasitic weeds. The most important breaks on implementation and adoption of alternative parasitic weed management strategies are land scarcity, preventing the introduction of crop diversification, and lack of availability and/or affordability of production inputs, like seeds of resistant varieties, herbicides and fertilisers.

Farmers engagement in on-farm experimentation resulted in the definition of speciesspecific, low-cost control options. For the lowlands, early sowing was identified as a feasible strategy against $R$. fistulosa, whereas $S$. asiatica in uplands was best controlled by late sowing. Early sowing in lowlands allows farmers to keep using their locally preferred variety 
Farmers' knowledge, use and preferences of parasitic weed management strategies in rice

Supa India. Late sowing in uplands requires a short-duration variety. NERICA-10 was the most appreciated short-duration variety by farmers, because of its Striga resistance and good grain quality. However, only the availability of seed of this variety, at an acceptable price, will secure actual implementation of this technology.

This study confirms that, particularly in smallholder production systems, crop protection options are evaluated against more than just their technical efficacy. Lack of resources, limited access to credit and poor input supply are constraints that emphasize the wider dimension of crop protection issues. Only when such aspects are included and simultaneously addressed, it will be possible to sustainably solve the parasitic weed problem in rain-fed rice. 



\section{Chapter 3}

Delayed or early sowing: Timing as parasitic weed control strategy in rice is species and ecosystem dependent

Dennis E. Tippe ${ }^{\mathrm{a}}$, Jonne Rodenburg ${ }^{\mathrm{b}}$, Aad van Ast ${ }^{\mathrm{a}}$, Niels P.R. Anten ${ }^{\mathrm{a}}$, Ibnou Dieng ${ }^{\mathrm{b}}$, Juma Kayeke ${ }^{\mathrm{c}}$, Mamadou Cissoko ${ }^{\mathrm{d}}$, Lammert Bastiaans ${ }^{\text {a }}$

Published as: D.E. Tippe et al., 2017. Field Crops Research 214, 14-24

${ }^{\mathrm{a}}$ Centre for Crop Systems Analysis, Wageningen UR, P.O. Box 430, 6700 AK, Wageningen, The Netherlands

${ }^{\mathrm{b}}$ Africa Rice Center (AfricaRice), 01 BP 4029, Abidjan 01, Côte d'Ivoire

${ }^{\mathrm{c}}$ Mikocheni Agricultural Research Institute (MARI), P.O. Box 6226, Dar es Salaam, Tanzania

${ }^{\mathrm{d}}$ Department of Animal and Plant Sciences, University of Sheffield, Sheffield S10 2TN, UK 


\title{
Chapter 3
}

\begin{abstract}
Parasitic weeds are a severe problem in rain-fed rice production ecosystems in sub-Saharan Africa. In this study, effects of sowing time of rice on parasitic weed infection and crop yields were investigated. Field experiments were conducted in Striga asiatica-infested upland and Rhamphicarpa fistulosainfested lowland systems from 2012 to 2014 in Kyela district, Tanzania. In each system, three rice varieties were planted at five sowing times, the first coinciding with the start of the rainy season and the four other ones followed each at two weeks' intervals. The chosen rice varieties were the late maturing local varieties Supa India (upland and lowland) and Mwangulu (upland) and earlier-maturing NERICA-14 (upland), NERICA-L-20 (lowland) and IR64 (lowland) as alternatives.
\end{abstract}

A greenhouse pot-experiment was conducted in Wageningen, the Netherlands, combining staggered planting of rice at two weeks' intervals with introduction of either S. asiatica or R. fistulosa at one moment in time. In both field and pot experiments, sowing time influenced parasite growth and rice grain yield, but the direction of these effects differed considerably between weed species and associated agro-ecosystems. In upland, S. asiatica number and biomass decreased with a delay in sowing time. It was postulated that with these delays an increasing share of the $S$. asiatica seed population would return to a state of dormancy from where they are unable to germinate. Under conditions of heavy infection (2013) rice yields were highest at later sowing dates. Under moderate $S$. asiatica infection levels (2012 and 2014) the positive effects of late sowing on rice yield were annihilated, due to increased chances of drought stress during kernel filling. This risk was mitigated by the use of an improved early maturing variety (NERICA-14). In lowland, there was a significant increase in $R$. fistulosa biomass with delayed sowing times. Planting rice before optimum soil moisture conditions (i.e. saturation) for $R$. fistulosa seed germination are met, would result in partial escape from infection by this facultative parasite, and consequently higher rice grain yields. Manipulating rice-sowing time is a feasible control strategy to minimize parasitic weed infection, but the proper application and associated risk of this practice are strongly species and ecosystem dependent.

Keywords: Oryza sativa, Striga asiatica, Rhamphicarpa fistulosa, Rice varieties, NERICA 


\section{Introduction}

Parasitic weeds are a severe problem in rain-fed rice production systems in sub-Saharan Africa (SSA) (Parker, 2013; Rodenburg et al., 2010). Infestations by parasitic weeds lead to considerable rice yield losses and even make farmers decide to abandon their fields (Houngbedji et al., 2014; N'Cho et al., 2014). In a recent study, the economic losses caused by parasitic weeds in rain-fed rice production systems in Africa were conservatively estimated at US \$ 200 million per year (Rodenburg et al., 2016b). In rain-fed upland rice systems, the most important parasitic weed species are the Witchweeds, particularly Striga asiatica (L.) Kuntze, and S. hermonthica (Del.) Benth (Rodenburg and Johnson, 2009). Striga infestation in rice fields is accelerated by continuous cultivation of cereal crops without proper soil fertility replenishment (Spallek et al., 2013; Ayongwa et al., 2006). In addition, the use of crop seeds contaminated with Striga seeds (Berner et al., 1994) and rainfall variability are important causes contributing to high infestation levels (Mohamed et al., 1998). In rain-fed lowlands, Rice Vampire weed, Rhamphicarpa fistulosa (Hochst.) Benth, is an important parasitic weed species (Rodenburg et al., 2015b; Ouédraogo et al., 1999). Rhamphicarpa fistulosa was not regarded a major problem in lowland rice some two decades ago, but has increased in recent years (Houngbedji et al., 2014; Rodenburg et al., 2011b) The main reason for this increase is probably that rice farmers are increasingly exploiting marginal wetlands, which can be natural habitats of this species (Kabiri et al., 2015). Rhamphicarpa fistulosa is most prominent in rice production systems characterized by poor soil fertility and poor water management ( $\mathrm{N}^{\prime} \mathrm{Cho}$ et al., 2014). The weed is able to cause considerable yield reductions; average losses ranging from 24 to $73 \%$ have been reported depending on rice variety (Rodenburg et al., 2016b).

Parasitic weeds constitute a severe problem, mainly because potentially effective solutions are not affordable or not accessible for resource-poor subsistence farmers. Crop rotation, a commonly used option to deal with Striga (Kayeke et al., 2007) and soil-borne diseases (Conway, 1996), is often not an option due to scarcity of land and water while smallholder farmers need their land for growing their main subsistence crops (Rigg, 2006). In rain-fed lowlands, the lack of alternative crops that grow well under seasonally flooded conditions (Andriesse and Fresco, 1991) is another factor complicating the feasibility of crop rotation. Soil fertility management also bears potential as a control strategy. Particularly, Striga incidence is often associated with poor soil fertility (Kamara et al., 2014; Jamil et al., 2012). However, the lack of financial resources and limited access to credit supply often 


\section{Chapter 3}

prevents farmers from using fertilisers (Tippe et al., 2017a). The use of resistant or tolerant varieties is another promising track. Recently, several improved rice varieties with resistance and tolerance against $S$. asiatica, $S$. hermonthica and $R$. fistulosa have been identified (Rodenburg et al., 2017; Rodenburg et al., 2016a). Complex national variety release procedures and the absence of functional seed systems, however, still hamper the use of this technology in many parts of Africa. Herbicides, a commonly used curative weed control measure in many parts of the world, are difficult to source and knowledge intensive (N'Cho et al., 2014; Rodenburg and Johnson, 2009). Herbicides are also poorly effective against Striga spp., as these species first attach to the roots of their host and already severely affect the crop before they emerge aboveground where they can be targeted (Hearne, 2009). Technologies like seed coating of herbicide-tolerant varieties, to address this technical shortcoming of herbicides, are not yet available for rice. As a consequence, the currently most used control strategy is hand weeding (Tippe et al., 2017a; N'Cho et al., 2014). However, hand weeding is considered laborious, time consuming (Ogwuike et al., 2014) and therefore expensive, as extra labour needs to be deployed (Oswald, 2005). Additionally, similar to herbicides, this measure is not effective in controlling Striga spp., since most of the damage to the crop has already been done before emergence of the parasite (Spallek et al., 2013).

In discussions with farmers, sowing time of rice was often mentioned as a factor influencing parasitic weed infection levels (Tippe et al., 2017a). Farmers indicated that delayed sowing reduced Striga infection levels in uplands. Hence, sowing time may constitute a potential component of an integrated parasitic weed management strategy in rice. Whether the response to sowing time is consistent and whether it is identical for $S$. asiatica and $R$. fistulosa is, however, not yet known. Changing the sowing time may also imply risks. Delayed sowing is more likely to result in drought stress during grain filling, particularly for the traditional late-maturing rice varieties under upland conditions (Pantuwan et al., 2002). To mitigate such risks, potentially the strategy could benefit from the introduction of an earlymaturing rice variety.

The objectives of the current study were therefore to investigate (i) the effects of sowing time on parasitic weed infection and rice yield levels, (ii) whether this effect differed between parasitic weed species and (iii) the extent to which these sowing time effects on rice yields can be modified by using varieties with different growth durations. Field experiments were supplemented by a greenhouse experiment, in which the effects of rice sowing time on dry matter production of rice were compared under parasite-free and parasite-infested conditions. 


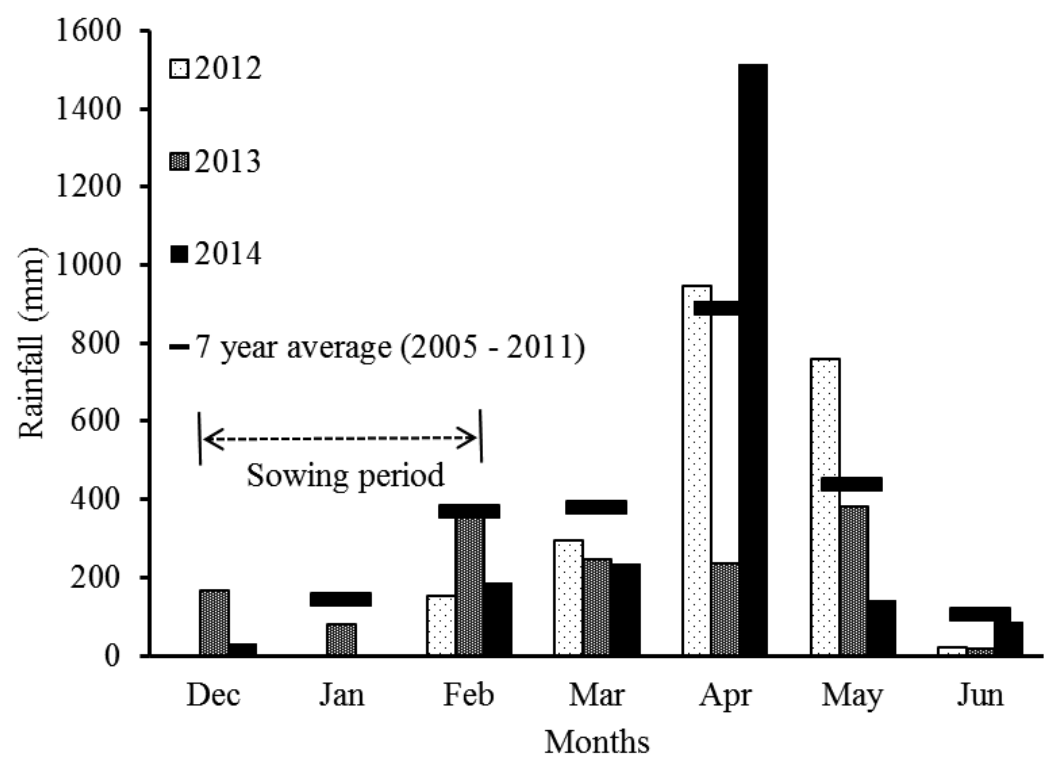

Fig. 1. Cumulative monthly rainfall $(\mathrm{mm})$ as recorded in the experimental fields in Kyela district, Tanzania from December to June, during the three years of experimentation. Additional data for the past 7 years prior to this experimentation was received from Kyela District Agriculture and Livestock Office.

\section{Material and methods}

\subsection{Field experiments}

\subsubsection{Site characterization}

Field experiments were conducted in three consecutive years (2012-2014) at Kilasilo and Mbako village in Kyela district, South West Tanzania $\left(09^{\circ} 35^{\prime} 08^{\prime \prime} \mathrm{S}-33^{\circ} 48^{\prime} 43^{\prime \prime} \mathrm{E}\right.$ and $9^{\circ}$ $37^{\prime} 30^{\prime \prime} \mathrm{S}-33^{\circ} 52^{\prime} 30^{\prime \prime} \mathrm{E}$, respectively). The fields are situated in an endemic S. asiatica and $R$. fistulosa infested rice-growing area. Two fields were selected: (1) a Striga asiatica-infested upland field and (2) a Rhamphicarpa fistulosa infested lowland field. Fields were not inoculated by supplemental parasitic weed seed and an experimental design with blocks was used to control for the inherent heterogeneity of the original infestation. The two fields were $900 \mathrm{~m}$ apart from each other and are located at around 529 and $520 \mathrm{~m}$ above sea level (upland and lowland, respectively), with monthly average temperatures ranging from 19 to $23{ }^{\circ} \mathrm{C}$ in the months of May to October and from 29 to $31{ }^{\circ} \mathrm{C}$ in November to April. The sites have a unimodal rainfall regime with an average seasonal rainfall of around $2300 \mathrm{~mm}$ (Fig. 1). In $2011 / 2012$, the rainy season commenced relatively late, whereas in $2012 / 2013$, the amount was considerably lower than in the other two seasons and the reference period. 


\section{Chapter 3}

Prior to the sowing, soil samples from both sites were collected at 0-20 cm depth. The soil in both upland and lowland sites was characterized as a strongly acidic $(\mathrm{pH}=4.8)$ sandy clay loam, with estimated sand:silt:clay ratios of 63.1:11.6:25.2 in the upland field and 50.2:17.6:32.1 in the lowland field. Extraction according to Mehlich (1984) showed that the available phosphorous $(\mathrm{P})$ ranged from high to medium in upland and lowland sites (5.24 ppm and $3.6 \mathrm{ppm}$, respectively), while exchangeable potassium (K) was $230 \mathrm{ppm}$ in upland and 127 ppm in lowland. Soil organic matter content (Colometric; Walkley and Black, 1934) was $2.09 \%$ (upland) and 1.27\% (lowland) and total nitrogen (Kjeldahl; Bremner and Mulvaney, 1982) was $0.11 \%$ (upland) and $0.06 \%$ (lowland). Soil cation exchange capacity (CEC) and electric conductivity (EC) were relatively low $\left(7.9 \mathrm{cmol}(+) \mathrm{kg}^{-1}\right.$ and $95.7 \mathrm{uScm}^{-1}$, respectively).

\subsubsection{Experimental set-up}

In both fields, a split-plot experimental design with five replications was used, with rice variety at the main plot and sowing time at the subplot level. The experimental treatments included three rice varieties, each with different growth duration. For the upland field experiment, the local rice varieties Mwangulu (late maturing; 152 days), Supa India (medium maturing; 144 days) and upland NERICA-14 (early maturing; 131 days) were selected. The rice cultivars are all susceptible to $S$. asiatica infection, although Supa India is more susceptible than the other two (Rodenburg et al, 2015a). In lowland, the selected rice varieties were Supa India (late maturing; 144 days), NERICA-L-20 (medium maturing; 142 days) and IR64 (early maturing; 134 days). Varieties Supa India and NERICA-L-20 were more susceptible to $R$. fistulosa than IR64 (Rodenburg et al., 2016a). The varieties were sown at five different times, with intervals of 14 days. The selected sowing dates were: 20-22 December (S1), 3-5 January (S2), 17-19 January (S3), 31 January - 2 February (S4) and 1417 February (S5). In the first season, the onset of the rainy season was relatively late and for that reason S1 was skipped in the lowland experiment.

In the upland experiment, the size of a sub-plot was $3.0 \times 3.0 \mathrm{~m}$. With a plant hill distance of $20 \times 20 \mathrm{~cm}$, this resulted in $15 \times 15$ hills per sub-plot. The outer two rows were used as border rows and not considered for sampling or observation purposes, leaving a harvest area of $11 \times 11$ hills $\left(4.84 \mathrm{~m}^{2}\right)$. For more detailed observations, the central 9 hills were used. In the lowland experiment, the sub-plot size was $2.0 \times 3.0 \mathrm{~m}$, with the same plant distance as in the upland experiment resulting in $10 \times 15$ hills, with a harvest area of $6 \times 11$ 
hills $\left(2.64 \mathrm{~m}^{2}\right)$. In this case the central 6-hill area $(2 \times 3$ hills $)$ was used for more detailed observations.

\subsubsection{Field preparation, sowing and crop management}

In the first cropping season, starting in December 2011, the field was disc-ploughed by tractor and harrowed using an ox-plough. A day after harrowing, the field was prepared to a fine tilth whereby crop and weed residues were removed and the land was levelled manually using hand hoes. One day after levelling, the experiment was marked out with pegs. In the second and third season, plots were only manually cultivated to a fine tilth using hand hoes and rakes. At sowing, the soil in each planting hole was mixed with about $0.5 \mathrm{~g}$ of an insecticide (Furadan ${ }^{\circledR}$ ) to control termites and other seed predators. About 5-6 rice seeds per hill were directly sown by hand at a depth of about $2 \mathrm{~cm}$. Seeds of NERICA-14, NERICA-L-20 and IR64 were obtained from Africa Rice Center in Dar es Salaam, Tanzania. Seeds of the local rice varieties were obtained from farmers in Kyela district, Tanzania. The crop stand was adjusted where necessary, by thinning or gap filling, at 21 days after sowing (DAS) to arrive at 3 plants per hill. Fertiliser N-P-K (20-10-10) was applied once, at a rate of $174 \mathrm{~kg} \mathrm{ha}-1$ at 30 days after sowing (DAS). Manual hand weeding was done every 2-3 weeks by removing all non-parasitic weeds. Additionally, an insecticide Dursban ${ }^{\circledR}$, with Chlorpyrifos as the active ingredient, was sprayed twice within 2 weeks after rice tiller initiation and then 4 weeks later to control insect vectors of diseases like Rice Yellow Mottle Virus, which is endemic in Kyela.

\subsubsection{Data collection}

Every 2-3 weeks, the parasitic plants in the indicated area in the centre of the plot were counted until crop harvest. At rice maturity, the parasitic plants from this area were sampled and oven dried at $70{ }^{\circ} \mathrm{C}$ for two days and then weighed. Rice panicles were harvested from the $11 \times 11$-hill harvest area in the upland experiment and from the $11 \times 6$-hill harvest area in the lowland experiment. Panicles were air dried for at least two weeks, threshed and winnowed to separate filled rice grains from chaff and rachis. Weight of the filled grains was determined, followed by an assessment of the grain moisture content using a digital grain moisture meter of SATAKE (Model SS-7). This enabled conversion of grain weights to a standard $14 \%$ moisture content. Based on the regular counting of parasitic weed plants, the maximum number recorded at any given time ( $S$ max for $S$. asiatica and RNmax for $R$. 


\section{Chapter 3}

fistulosa) was determined and used for analysis.

\subsection{Pot experiment}

Two parallel pot experiments were carried out in a greenhouse of Wageningen University, the Netherlands (51 59'4" N and 5'39'57” E), between April and October 2016. Screens were used to create $12 \mathrm{~h}$ day length (08:00-20:00). Air temperature was regulated and set to $27^{\circ} \mathrm{C}$ during the day and $23{ }^{\circ} \mathrm{C}$ during the night. Humidity varied in the range of $60-80 \%$. When at daytime light intensity outside the greenhouse dropped below $910 \mu \mathrm{E} \mathrm{m}^{-2} \mathrm{~s}^{-1}$, lamps (SON-T Agro, 400W, Philips) switched on automatically.

\subsubsection{Experimental set-up}

Experiments with either $S$. asiatica or $R$. fistulosa were conducted following a two factorial randomized complete block design in five replications. Rice plants were grown in pots in either the absence or presence of the parasitic weed. This was combined with six different rice-sowing times (S1-S6), with intervals of 14 days.

A total of 60 (S. asiatica experiment) and 90 (R. fistulosa) 61 -pots were filled with a (1:1) mixture of sand and arable soil from the experimental farm Droevendaal. Each pot was filled to a total weight of $7.5 \mathrm{~kg}$ of soil (semi-wet, including the pot weight of $120 \mathrm{~g}$ ). On 18 April (2016), $1.8 \mathrm{mg}$ of $S$. asiatica seeds (germination rate: 66\%) were mixed through the upper 10 $\mathrm{cm}$ of the soil, simultaneous with first rice sowing. Around 100 seeds of $R$. fistulosa (germination rate: 46\%) were shallow-sown six weeks after the start of rice sowing to establish a representative comparison between early and late sowing time in relation to parasite emergence time. Four weeks after sowing, $R$. fistulosa plants were thinned to 10 plants per pot. In the $R$. fistulosa experiment an additional treatment factor was included: $R$. fistulosa without a host plant. For the $S$. asiatica experiment, upland rice variety IAC165 was used, whereas the lowland rice variety IR64 was used in the R. fistulosa experiment. Both are international check varieties that have been included in previous parasitic weed research work. Before sowing, rice seeds were pre-germinated in an incubator at $33^{\circ} \mathrm{C}$ for about $48 \mathrm{~h}$. Due to the poor germination rate of the IAC165 seeds at S1, the first sowing time was cancelled. Parasitic weed seeds were collected from infested rice fields in Kyela, Tanzania. Rice seeds were sourced from Africa Rice Center in Dar es Salaam, Tanzania.

In the first two weeks after weed seed sowing, watering was done every day by misting soil with a fine spray of water, to avoid disturbance of the seedbed. Once seedlings were robust 
enough, a coarser sprayer was used for watering. In the $S$. asiatica experiment, the soil in each pot was kept around Field Capacity to mimic upland soil moisture conditions. For R. fistulosa, the soil in the pots was kept saturated during the entire growth period, to mimic rain-fed lowland soil moisture conditions. Regular weeding was done to remove ordinary weeds. Additionally, in the $R$. fistulosa experiment, when rice plants showed the first symptoms of nutrient deficiency (around 70 DAS) a standard nutrient solution, containing $0.57 \mathrm{~g} \mathrm{~N} \mathrm{~L}^{-1}$, was applied at a rate of $100 \mathrm{~mL}^{-1}$ pot $^{-1}$. For each of the sowing times this nutrition was applied once, at around 70 DAS.

\subsubsection{Data collection}

For the S. asiatica sowing time experiment, weed counting was done every week. In both experiments, rice plants and parasitic weeds were harvested at maturity of the rice. Rice harvesting was done at an average of 110 DAS for IAC165 and 120 DAS for IR64. Shoots and roots of both rice and parasitic weeds were harvested. Rice panicles were threshed to determine kernel dry weight. Total plant dry weight, of rice and the parasitic weeds, was determined after drying in an oven for $48 \mathrm{~h}$ at $70{ }^{\circ} \mathrm{C}$. For $R$. fistulosa, mature seed capsules were collected throughout the growing period, this was done purposely because matured capsules easily shed seeds. Collected capsules and seed were later combined with other plant parts (shoots and roots) for total plant dry weight determination.

\subsection{Data analysis}

Before analyses, field and pot data were checked for homoscedasticity (Sokal and Rohlf, 1995). Thereafter, data were analysed using a linear mixed model except for SNmax, RNmax, $S$. asiatica-free period and $R$. fistulosa-free period (field data) and $S$. asiatica numbers and $S$. asiatica-free period assessed in the pot experiment. In these cases, a generalized linear mixed model (McCullagh and Nelder, 1989) was used under the assumption of a Poisson distribution. We first performed a log likelihood ratio test for the homogeneity of variance and, when the variance was not constant, we took into account the heterogeneity of the variances.

For field data, we tested whether there was a significant Year $\times$ Variety $\times$ Sowing Time interaction effect, and, where this was the case, we fitted a model for each year $(2012,2013$ and 2014) separately, where Variety, Sowing Time and Variety $\times$ Sowing Time were considered as fixed factors and Replicate within Variety as random factor. For pot data, we 


\section{Chapter 3}

considered (parasitic weed) Presence, Sowing Time and Presence $\times$ Sowing Time as fixed factors and Replicate as random factor. For each parameter, least-square means (LS-Means) of Variety $\times$ Sowing Time for field data and LS-Means of Presence $\times$ Sowing Time for pot data were computed. For parameters for which there was a significant effect, ANOVA's were followed by a comparison of means using Tukey's honest significant difference test.

Analyses were performed in R software, Version 3.3.2 (R Core Team, 2016) using the lme4 package (Bates et al., 2015) for the ANOVA models, the lsmeans package (Lenth, 2016) for the LS Means estimation and the multcomp package (Hothorn et al., 2008) for Tukey's multiple comparisons of means.

\section{Results}

\subsection{Striga asiatica}

\subsubsection{Field experiment}

For the upland experiments with $S$. asiatica, significant Year $\times$ Variety $\times$ Sowing Time interaction effects were observed on all traits (Table 1): the S. asiatica-free period (SFP; defined as duration of time without emerged parasites, expressed in days), the maximum parasite number (SNmax; expressed in number of plants $\left.\mathrm{m}^{-2}\right)$, parasite biomass $\left(S D W ; \mathrm{g} \mathrm{m}^{-2}\right)$ and rice grain yield $\left(G D W ; \mathrm{t} \mathrm{ha}^{-1}\right)$. Following these interactions, data were analysed for each year separately. In all three years, and for all traits, significant Variety $\times$ Sowing Time interactions were observed, except for the $S$. asiatica-free period in 2013, for which only a significant sowing time main effect was found. In this year, the $S$. asiatica-free period for the last sowing time (S5) was significantly longer than for the earlier sowing times (Fig. 2). This same pattern was observed with Supa India in 2014, whereas no significant differences between sowing times were observed for the other two varieties. In 2012, no clear sowing time pattern was observed for any of the varieties. Between years, there were considerable differences in average S. asiatica-free periods. In 2013, the first S. asiatica plants emerged after around 40 days, whereas in 2014 it was after 55 days and in 2012 it took about 80 days.

For maximum above-ground $S$. asiatica numbers (SNmax) a consistent pattern was observed for all three years and for all three varieties (Fig. 3). The highest parasite numbers were observed following early sowing times $(\mathrm{S} 1, \mathrm{~S} 2)$, and these numbers gradually decreased with a delay in sowing time. The number of parasites that were observed during early sowing times differed considerably between years. In 2013, the average number (for S1 and S2) ranged from around 60 plants $\mathrm{m}^{-2}$ for Mwangulu and Supa India, to more than 100 plants $\mathrm{m}^{-2}$ 
Table 1. Analysis of variance of $S$. asiatica-free period (SFP; days), $S$. asiatica maximum plant numbers (SNmax; plants $\left.\mathrm{m}^{-2}\right), S$. asiatica above-ground dry weight $\left(S D W ; \mathrm{g} \mathrm{m}^{-2}\right)$, rice grain dry weight $\left(G D W ; \mathrm{t} \mathrm{ha}^{-1}\right)$ as obtained from the experimental field during the three cropping seasons (2012-2014) in Kyela, Tanzania.

\begin{tabular}{|c|c|c|c|c|c|c|c|c|c|c|c|c|c|}
\hline & & & & & & & Para & mete & & & & & \\
\hline Year (s) & Source of & & & & & & & & & & & & \\
\hline & Variation & $S F$ & & & $S N$ & & & $S D$ & & & $G D$ & & \\
\hline & & Df & F. value & $P$ & Df & F. value & $P$ & Df & F. value & $P$ & Df & F. value & $P$ \\
\hline $2012-14$ & Year (Y) & 2 & 40.65 & $* * *$ & 2 & 28.26 & $* * *$ & 2 & 9.12 & $* * *$ & 2 & 28.26 & $* * *$ \\
\hline & Variety (V) & 2 & 0.77 & & 2 & 4.37 & $* * *$ & 2 & 5.29 & $* *$ & 2 & 4.37 & $* * *$ \\
\hline & Sowing & & & & & & & & & & & & \\
\hline & Time (S) & 4 & 16.20 & $* * *$ & 4 & 12.71 & $* * *$ & 4 & 6.39 & $* * *$ & 4 & 12.71 & $* * *$ \\
\hline & $\mathrm{Y} \times \mathrm{V}$ & 4 & 1.05 & & 4 & 9.42 & $* * *$ & 4 & 4.73 & $* * *$ & 4 & 9.42 & $* * *$ \\
\hline & $\mathrm{Y} \times \mathrm{S}$ & 8 & 10.18 & $* * *$ & 8 & 15.33 & $* * *$ & 8 & 3.84 & $* * *$ & 8 & 15.33 & $* * *$ \\
\hline & $\mathrm{V} \times \mathrm{S}$ & 8 & 4.80 & $* * *$ & 8 & 7.36 & $* * *$ & 8 & 3.06 & $* * *$ & 8 & 7.36 & $* * *$ \\
\hline & $\mathrm{Y} \times \mathrm{V} \times \mathrm{S}$ & 16 & 2.63 & $* * *$ & 13 & 2.75 & $* * *$ & 15 & 3.15 & $* * *$ & 13 & 2.75 & $* * *$ \\
\hline 2012 & V & 2 & 0.27 & & 2 & 2.37 & & 2 & 1.90 & $*$ & 2 & 2.37 & \\
\hline & S & 4 & 16.86 & $* * *$ & 4 & 19.33 & $* * *$ & 4 & 3.96 & $* * *$ & 4 & 19.33 & $* * *$ \\
\hline & $\mathrm{V} \times \mathrm{S}$ & 8 & 2.45 & $* *$ & 6 & 2.25 & $*$ & 7 & 2.74 & $* *$ & 6 & 2.25 & $*$ \\
\hline 2013 & V & 2 & 0.29 & & 2 & 18.87 & $* * *$ & 2 & 5.08 & $* *$ & 2 & 18.87 & $* * *$ \\
\hline & $\mathrm{S}$ & 4 & 7.80 & $* * *$ & 4 & 5.06 & $* * *$ & 4 & 4.96 & $* * *$ & 4 & 5.06 & $* * *$ \\
\hline & $\mathrm{V} \times \mathrm{S}$ & 8 & 1.74 & & 7 & 3.11 & $* * *$ & 8 & 3.20 & $* * *$ & 7 & 3.11 & $* * *$ \\
\hline 2014 & V & 2 & 3.11 & & 2 & 9.85 & $* * *$ & 2 & 4.34 & $* *$ & 2 & 9.85 & $* * *$ \\
\hline & $\mathrm{S}$ & 4 & 11.79 & $* * *$ & 4 & 7.85 & $* * *$ & 4 & 6.45 & $* * *$ & 4 & 7.85 & $* * *$ \\
\hline & $\mathrm{V} \times \mathrm{S}$ & 8 & 5.85 & $* * *$ & 8 & 8.98 & $* * *$ & 8 & 3.45 & $* * *$ & 8 & 8.98 & $* * *$ \\
\hline
\end{tabular}

For $S$. asiatica-free period and $S$. asiatica maximum plant numbers, the F-test was based on a Generalized Linear Mixed Model, with a Poisson distribution, rather than classical ANOVA. *significant at $P<0.05 ; * *$ significant at $P<0.01 ; * * *$ significant at $P<0.001$.

for NERICA-14. In both 2012 and 2014 these numbers were substantially lower, with on average about 8 plants $\mathrm{m}^{-2}$ during the first sowing times.

The differences in S. asiatica infection levels between years were also reflected in parasite biomass at harvest (SDW; Fig. 4). In 2013, S. asiatica biomass at first sowing ranged from $5 \mathrm{~g} \mathrm{~m}^{-2}$ for Mwangulu and Supa India to $35 \mathrm{~g} \mathrm{~m}^{-2}$ for NERICA-14. These values were much higher than observed in $2012\left(0.3-3.2 \mathrm{gm}^{-2}\right)$ and $2014\left(0.2-1.8 \mathrm{gm}^{-2}\right)$. 


\section{Chapter 3}
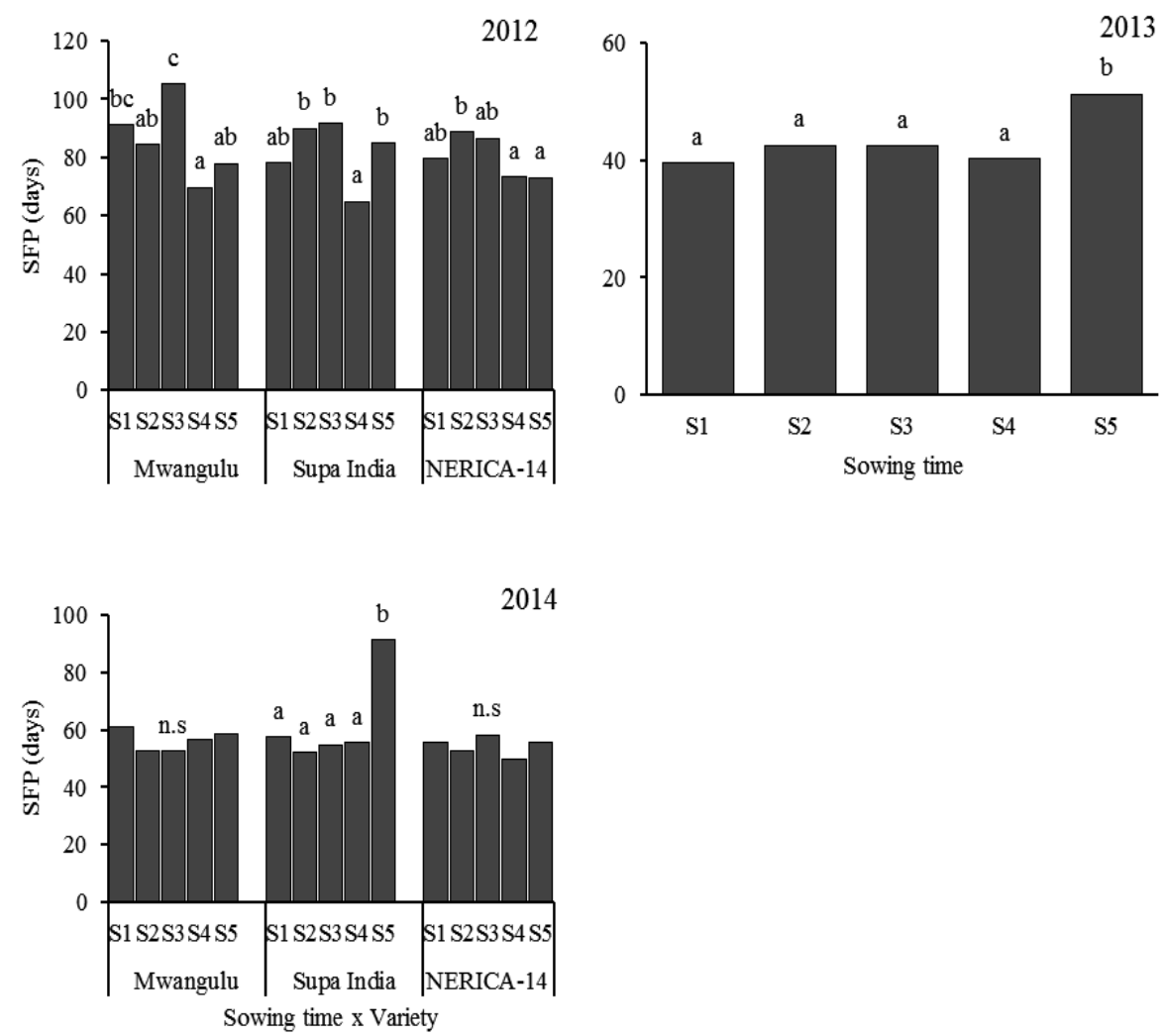

Fig. 2. S. asiatica-free period (SFP, days), as affected by sowing time and rice variety during three cropping seasons (2012-2014) in Kyela, Tanzania. First sowing (S1) was conducted with the onset of the first rains, with consecutive plantings following with a time interval of two weeks. Means within the same rice variety, followed by the same letter are not significantly different according to LSD at $P<0.05$. For 2013, the values represent the averages of the three rice varieties, as only a significant effect of sowing time was observed.

A significant reduction of $S$. asiatica biomass with a delay in sowing time was observed for Supa India in 2012 and for Mwangulu and NERICA-14 in 2013 and 2014. In the other Variety $\times$ Year combinations no significant effect of sowing time on parasite biomass was observed. For rice grain yield, significant Variety $\times$ Sowing Time interaction effects were observed for all three years (Table 1). Overall, there was a trend of declining yields with sowing date in 2012, while this trend was absent or even reversed in the following two years (Table 2). In 2012, across varieties, rice grain yield of sowing time S1, S2 and S3 were mostly significantly higher than that obtained at S4 and S5. Average grain yield for 2012 was around $3 \mathrm{tha}^{-1}$, with the highest grain yields obtained with early sowings of Mwangulu (around $4.5 \mathrm{t}$ $\mathrm{ha}^{-1}$ ). 

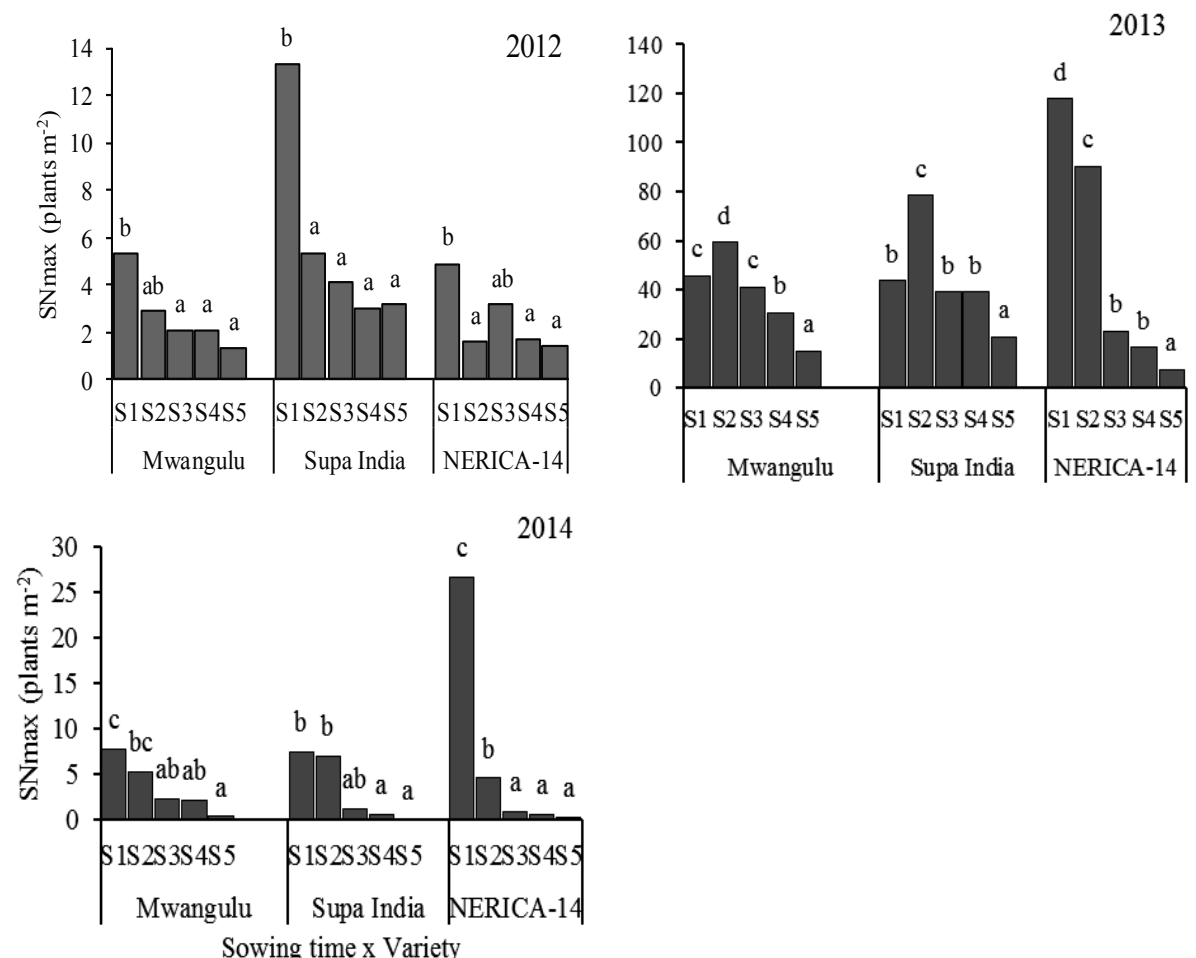

Fig. 3. Maximum above-ground $S$. asiatica numbers ( $S N m a x$, plants $\mathrm{m}^{-2}$ ), as affected by rice variety and sowing time during three cropping seasons (2012-2014) in Kyela, Tanzania. First sowing (S1) was conducted with the onset of the first rains, with consecutive plantings following with a time interval of two weeks. Means within the same rice variety, followed by the same letter are not significantly different according to LSD at $P<0.05$.

In 2013, the year with the highest $S$. asiatica-infection level, grain yield across varieties was substantially lower than that obtained in 2012 and there were more distinct differences between varieties. Average grain yield of NERICA-14 $\left(1.9 \mathrm{t} \mathrm{ha}^{-1}\right)$ was more than double that of the two traditional varieties $\left(0.8 \mathrm{t} \mathrm{ha}^{-1}\right)$. Grain yields of these two varieties (Mwangulu and Supa India) was highest at the intermediate sowing time (S3) while the grain yields of NERICA-14 were relatively high and fairly stable beyond the first sowing dates. 


\section{Chapter 3}
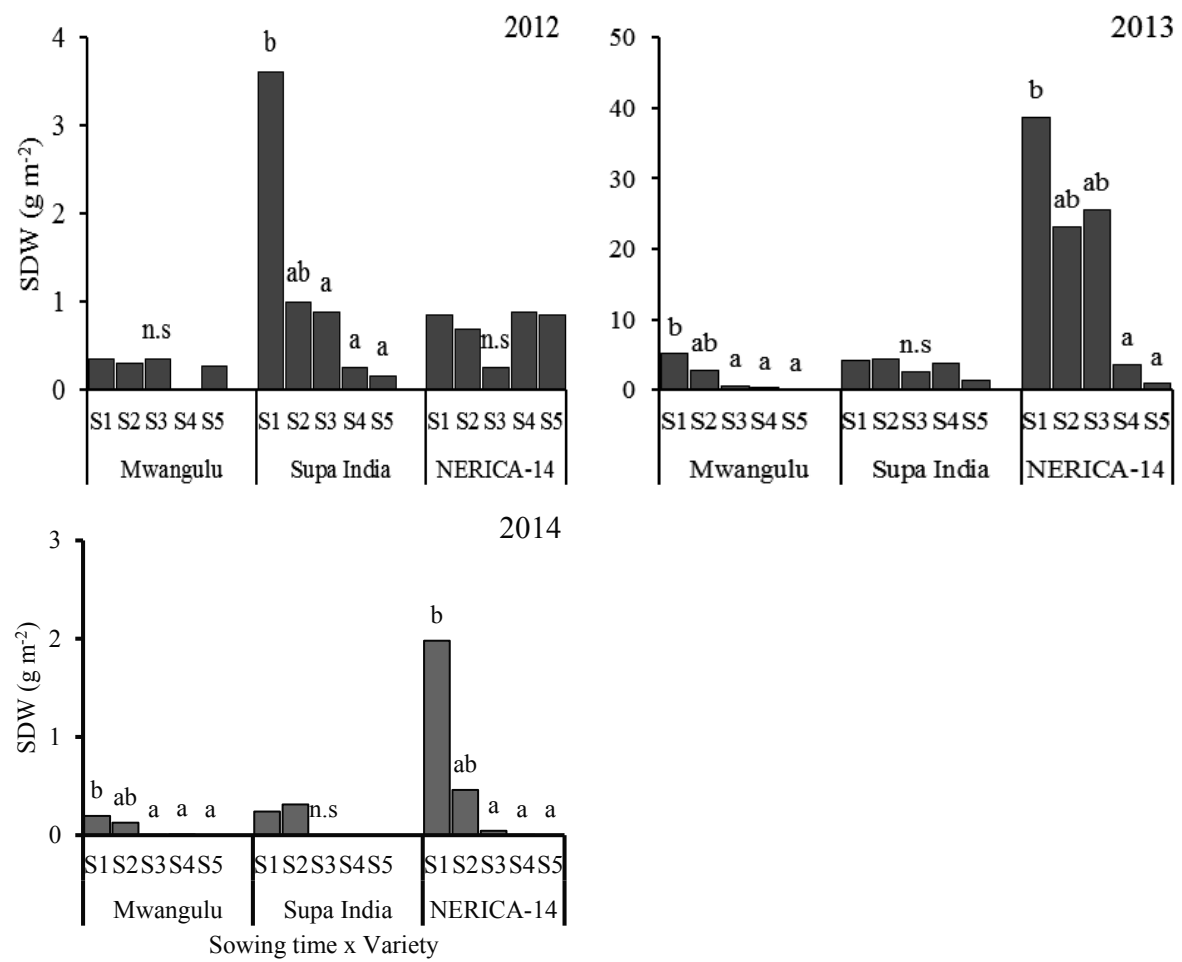

Fig. 4. Total above-ground dry weight of $S$. asiatica $\left(S D W, \mathrm{~g} \mathrm{~m}^{-2}\right)$, as affected by rice variety and sowing time during three cropping seasons (2012-2014) in Kyela, Tanzania. First sowing (S1) was conducted with the onset of the first rains, with consecutive plantings following with a time interval of two weeks. Means within the same rice variety, followed by the same letter are not significantly different according to LSD at $P<0.05$, - in 2012, SDW in S4 for Mwangulu was missing.

In 2014, average grain yield $\left(1.8 \mathrm{t} \mathrm{ha}^{-1}\right)$ was intermediate compared to 2012 and 2013. The response to sowing time differed greatly between varieties in this year. For Mwangulu and Supa India grain yield was not significantly affected by sowing time, except that for Mwangulu grain yield at S5 $\left(0.45 \mathrm{t} \mathrm{ha}^{-1}\right)$ was significantly lower than at S2-S4 (around $1.6 \mathrm{t}$ $\mathrm{ha}^{-1}$ ), whereas for Supa India grain yield at S1 was significantly lower than at S3. With NERICA-14, grain yields gradually increased with sowing time. No significant differences were observed between grain yields at S2-S4, but all of them were significantly higher than the yields obtained at $\mathrm{S} 1$ and lower than yields at S5. 
Table 2. Rice grain yield $\left(\mathrm{t} \mathrm{ha}^{-1}\right)$ per rice variety and sowing time during the three cropping seasons (2012, 2013 and 2014) in the S. asiatica infested upland field in Kyela, Tanzania. First sowing (S1) was conducted with the onset of the first rains, with consecutive plantings following with a time interval of two weeks.

\begin{tabular}{|c|c|c|c|c|c|c|c|}
\hline & \multirow[b]{2}{*}{ Variety } & \multicolumn{5}{|c|}{ Sowing times } & \multirow[b]{2}{*}{ Mean } \\
\hline & & S1 & S2 & S3 & S4 & S5 & \\
\hline \multirow[t]{4}{*}{2012} & Mwangulu & $4.73 \mathrm{~b}$ & $4.37 \mathrm{~b}$ & $4.26 \mathrm{~b}$ & $2.21 \mathrm{a}$ & $1.78 \mathrm{a}$ & 3.47 \\
\hline & Supa India & $3.67 \mathrm{~b}$ & $3.53 \mathrm{~b}$ & $3.47 \mathrm{~b}$ & $2.95 \mathrm{ab}$ & $2.26 \mathrm{a}$ & 3.18 \\
\hline & NERICA-14 & $-{ }^{1}$ & $3.97 \mathrm{~b}$ & - & $2.47 \mathrm{a}$ & $2.39 \mathrm{a}$ & 2.94 \\
\hline & Mean & 4.20 & 3.96 & 3.87 & 2.54 & 2.14 & \\
\hline \multirow[t]{4}{*}{2013} & Mwangulu & $0.49 \mathrm{a}$ & $0.66 \mathrm{a}$ & $1.20 \mathrm{~b}$ & $0.71 \mathrm{a}$ & - & 0.77 \\
\hline & Supa India & $0.72 \mathrm{ab}$ & $0.50 \mathrm{a}$ & $1.04 \mathrm{~b}$ & $0.75 a b$ & $0.76 \mathrm{ab}$ & 0.75 \\
\hline & NERICA-14 & $1.05 \mathrm{a}$ & $2.26 \mathrm{~b}$ & $1.94 \mathrm{ab}$ & $2.18 \mathrm{~b}$ & $1.96 \mathrm{ab}$ & 1.88 \\
\hline & Mean & 0.75 & 1.14 & 1.39 & 1.21 & 1.36 & \\
\hline \multirow[t]{4}{*}{2014} & Mwangulu & $1.39 \mathrm{ab}$ & $1.63 \mathrm{~b}$ & $1.70 \mathrm{~b}$ & $1.57 \mathrm{~b}$ & $0.45 \mathrm{a}$ & 1.35 \\
\hline & Supa India & $1.21 \mathrm{ab}$ & $2.42 b c$ & $2.74 \mathrm{c}$ & $1.72 b c$ & $2.16 b c$ & 2.05 \\
\hline & NERICA-14 & $1.01 \mathrm{a}$ & $1.71 \mathrm{~b}$ & $1.91 \mathrm{~b}$ & $2.16 \mathrm{~b}$ & $3.07 \mathrm{c}$ & 1.97 \\
\hline & Mean & 1.20 & 1.92 & 2.12 & 1.82 & 1.89 & \\
\hline
\end{tabular}

${ }^{1}$ Hyphens ( - ) indicate missing data. For each year, means within the same rice variety, followed by the same letter are not significantly different according to LSD at $P<0.05$.

\subsubsection{Pot experiment}

In the pot experiment, the $S$. asiatica-free period and SNmax were significantly $(\mathrm{P}<0.05)$ affected by sowing time (Table 3 ). There was also a declining trend of $S$. asiatica biomass with delayed sowing time but this trend was not significant $(P=0.434)$. The $S$. asiatica-free period initially decreased from S2 to S3 and S4, but with a further delay in sowing (S5 and S6) the S. asiatica-free period increased. At S6, no S. asiatica plants emerged in any of the pots, whereas the highest number of emerged $S$. asiatica plants were observed at S2 (7.2 plants per pot) and S3 (4.6 plants), corresponding to rice sowing at two and four weeks after introduction of the parasitic seed. There were significant main effects of sowing time and presence of $S$. asiatica on total rice biomass (Table 3). Total rice dry weight gradually dropped with sowing time from $18.4 \mathrm{~g} \mathrm{pot}^{-1}$ at S2 to $11.5 \mathrm{~g} \mathrm{pot}^{-1}$ at S6, reflecting the lower light intensities inside the greenhouse during the last part of the experiment.

Evidently, the additional artificial lighting inside the greenhouse in September and October was not able to compensate for the lower ambient radiation levels in this period. 


\section{Chapter 3}

Presence of $S$. asiatica resulted in a significant reduction in total rice biomass of $2.7 \mathrm{~g} \mathrm{pot}^{-1}$. Although no significant interaction effect between sowing time and presence of $S$. asiatica was observed, relative reductions in rice biomass for S3-S5 (on average 26\%) were considerably higher than those at S2 and S6 (8\%).

Table 3. Influence of rice sowing time on $S$. asiatica-free period (days), S. asiatica maximum plant numbers (SNmax; plants per pot), total dry weight of $S$. asiatica (g per pot) and on total dry weight of rice ( $g$ per pot) in the absence and presence of $S$. asiatica, during the greenhouse experiment in 2016. Sowing interval of rice was 14 days (S1 to S6). Seeds of $S$. asiatica were introduced simultaneous with first rice sowing (S1). Due to poor germination of rice seeds at $\mathrm{S} 1$, this treatment was cancelled.

\begin{tabular}{lcccccccccc}
\hline & \multicolumn{4}{c}{ Sowing time } & & Effect $^{2}$ & Df & F-value & $\mathrm{P}^{3}$ \\
\hline Striga & $\mathrm{S} 2$ & $\mathrm{~S} 3$ & $\mathrm{~S} 4$ & $\mathrm{~S} 5$ & $\mathrm{~S} 6$ & & & & \\
S. asiatica-free period & $77.0 \mathrm{~b}^{1}$ & $53.0 \mathrm{a}$ & $42.0 \mathrm{a}$ & $110.0 \mathrm{c}$ & $110.0 \mathrm{c}$ & & $\mathrm{S}$ & 4 & 59.9 & $* * *$ \\
S. asiatica numbers & $7.15 \mathrm{~b}$ & $4.62 \mathrm{~b}$ & $1.54 \mathrm{a}$ & $0.19 \mathrm{a}$ & $0.00 \mathrm{a}$ & & $\mathrm{S}$ & 4 & 6.27 & $* * *$ \\
S. asiatica biomass & 1.16 & 1.30 & 0.69 & 0.08 & 0.00 & & $\mathrm{~S}$ & 4 & 0.95 & \\
Rice & & & & & & Mean & & & & \\
S. asiatica-free biomass & 19.3 & 14.8 & 14.7 & 12.9 & 11.9 & $14.7 \mathrm{~B}$ & $\mathrm{~S}$ & 4 & 16.2 & $* * *$ \\
S. asiatica-infected biomass & 17.7 & 9.92 & 10.9 & 10.3 & 11.0 & $12.0 \mathrm{~A}$ & $\mathrm{Pp}$ & 1 & 21.6 & $* * *$ \\
Mean & $18.5 \mathrm{~B}$ & $12.4 \mathrm{~A}$ & $12.8 \mathrm{~A}$ & $11.6 \mathrm{~A}$ & $11.5 \mathrm{~A}$ & & $\mathrm{~S} \times \mathrm{Pp}$ & 4 & 1.43 & \\
\end{tabular}

${ }^{\mathrm{I}}$ Means of parasite number, parasite biomass and rice biomass followed by the same letter are not significantly different according to LSD at $P<0.05$. 2S $=$ Sowing Time, $\mathrm{Pp}=$ Presence of parasite. ${ }^{3 * * *}$ significant at $P<0.001$.

\subsection{Rhamphicarpa fistulosa}

\subsubsection{Field experiment}

Significant Year $\times$ Variety $\times$ Sowing Time interaction effects were observed on $R$. fistulosafree period $(R F P)$, maximum parasite number ( $R N \max )$ and rice grain yield ( $G D W$; Table 4$)$. Data were therefore analysed for each year separately. For parasite biomass $(R D W)$, no threeway interaction was observed, but a significant Year $\times$ Sowing Time interaction effect was found.

A main effect of sowing time on $R$. fistulosa-free period was found in 2012, whereas in the 2013 and 2014 cropping seasons a significant Variety $\times$ Sowing Time effect was noted. In 2012, the $R$. fistulosa-free period showed an optimum at S3, beyond which it gradually decreased (Fig. 5). In 2013, a gradual decrease of $R$. fistulosa-free periods was observed for IR64, but with NERICA-L-20 and Supa India the $R$. fistulosa- free periods were variable across sowing times. 
Table 4. Analysis of variance of $R$. fistulosa-free period (RFP; days), R. fistulosa maximum plant numbers (RNmax; plants $\left.\mathrm{m}^{-2}\right), R$. fistulosa above-ground biomass dry weight $(R D W ; \mathrm{g}$ $\left.\mathrm{m}^{-2}\right)$, rice grain dry weight $\left(G D W ; \mathrm{t} \mathrm{ha}^{-1}\right)$ as obtained from the experimental field during the three cropping seasons (2012-2014) in Kyela, Tanzania.

\begin{tabular}{|c|c|c|c|c|c|c|c|c|c|c|}
\hline \multirow{3}{*}{ Year (s) } & \multicolumn{10}{|c|}{ Parameters } \\
\hline & \multirow[t]{2}{*}{ Source of Variation } & \multicolumn{3}{|c|}{$R F P$} & \multicolumn{2}{|l|}{$R N \max$} & \multicolumn{2}{|l|}{$R D W$} & \multicolumn{2}{|l|}{$G D W$} \\
\hline & & Df & F. value & $P$ & F. value & $P$ & F. value & $P$ & F. value & $P$ \\
\hline \multirow[t]{7}{*}{$2012-14$} & Year (Y) & 2 & 3.70 & & 13.37 & $* * *$ & 6.26 & $* *$ & 4.84 & $* *$ \\
\hline & Variety (V) & 2 & 0.43 & & 1.07 & & 1.22 & & 1.51 & \\
\hline & Sowing Time (S) & 4 & 68.18 & $* * *$ & 136.80 & $* * *$ & 18.51 & $* * *$ & 17.34 & $* * *$ \\
\hline & $\mathrm{Y} \times \mathrm{V}$ & 4 & 0.72 & & 0.44 & $*$ & 0.38 & & 4.74 & \\
\hline & $\mathrm{Y} \times \mathrm{S}$ & 7 & 25.38 & $* * *$ & 86.62 & $* * *$ & 3.85 & $* * *$ & 9.91 & $* * *$ \\
\hline & $\mathrm{V} \times \mathrm{S}$ & 8 & 11.98 & $* * *$ & 33.85 & $* * *$ & 0.41 & & 2.17 & $*$ \\
\hline & $\mathrm{Y} \times \mathrm{V} \times \mathrm{S}$ & 14 & 6.81 & $* * *$ & 5.19 & $* * *$ & 0.44 & & 2.19 & $* *$ \\
\hline \multirow[t]{3}{*}{2012} & $\mathrm{~V}$ & 2 & 1.04 & & 0.24 & & 0.31 & & 7.91 & * \\
\hline & $\mathrm{S}$ & 3 & 52.56 & $* * *$ & 80.79 & $* * *$ & 20.02 & $* * *$ & 22.87 & $* * *$ \\
\hline & $\mathrm{V} \times \mathrm{S}$ & 6 & 1.79 & & 18.99 & $* * *$ & 1.06 & & 3.32 & $* * *$ \\
\hline \multirow[t]{3}{*}{2013} & $\mathrm{~V}$ & 2 & 0.34 & & 1.42 & & 0.92 & & 0.79 & \\
\hline & $\mathrm{S}$ & 4 & 8.95 & $* * *$ & 202.65 & $* * *$ & 4.34 & $* * *$ & 6.48 & $* * *$ \\
\hline & $\mathrm{V} \times \mathrm{S}$ & 8 & 14.27 & $* * *$ & 25.08 & $* * *$ & 0.11 & & 1.59 & \\
\hline \multirow[t]{3}{*}{2014} & $\mathrm{~V}$ & 2 & 0.19 & & 0.49 & & 0.18 & & 0.65 & \\
\hline & $\mathrm{S}$ & 4 & 64.10 & $* * *$ & 24.28 & $* * *$ & 5.20 & $* * *$ & 0.85 & \\
\hline & $\mathrm{V} \times \mathrm{S}$ & 8 & 8.25 & $* * *$ & 3.62 & $* * *$ & 0.44 & & 0.89 & \\
\hline
\end{tabular}

For R. fistulosa-free period and R. fistulosa maximum plant numbers, the F-test was based on a Generalized Linear Mixed Model, with a Poisson distribution, rather than classical ANOVA. *significant at $P<0.05$; **significant at $P<0.01$; ***significant at $P<0.001$.

In 2014, a decrease in the R. fistulosa-free period with sowing time was observed as the general trend for all three varieties, although some variability could be observed. Across seasons, the $R$. fistulosa-free period varied between 50 and 100 days, indicating that in all situations rice grew without hinder from this parasitic weed for at least the first seven weeks.

Significant Variety $\times$ Sowing Time interaction effects on maximum $R$. fistulosa plant numbers (RNmax) were observed in all three years. While in all these years, differences between varieties were apparent, the trends for all varieties within a specific year were largely identical (Fig. 6). Clear differences were, however, observed between years. Whereas in 2012 the maximum number of $R$. fistulosa plants gradually increased with sowing time, the opposite trend was observed in 2013. 


\section{Chapter 3}
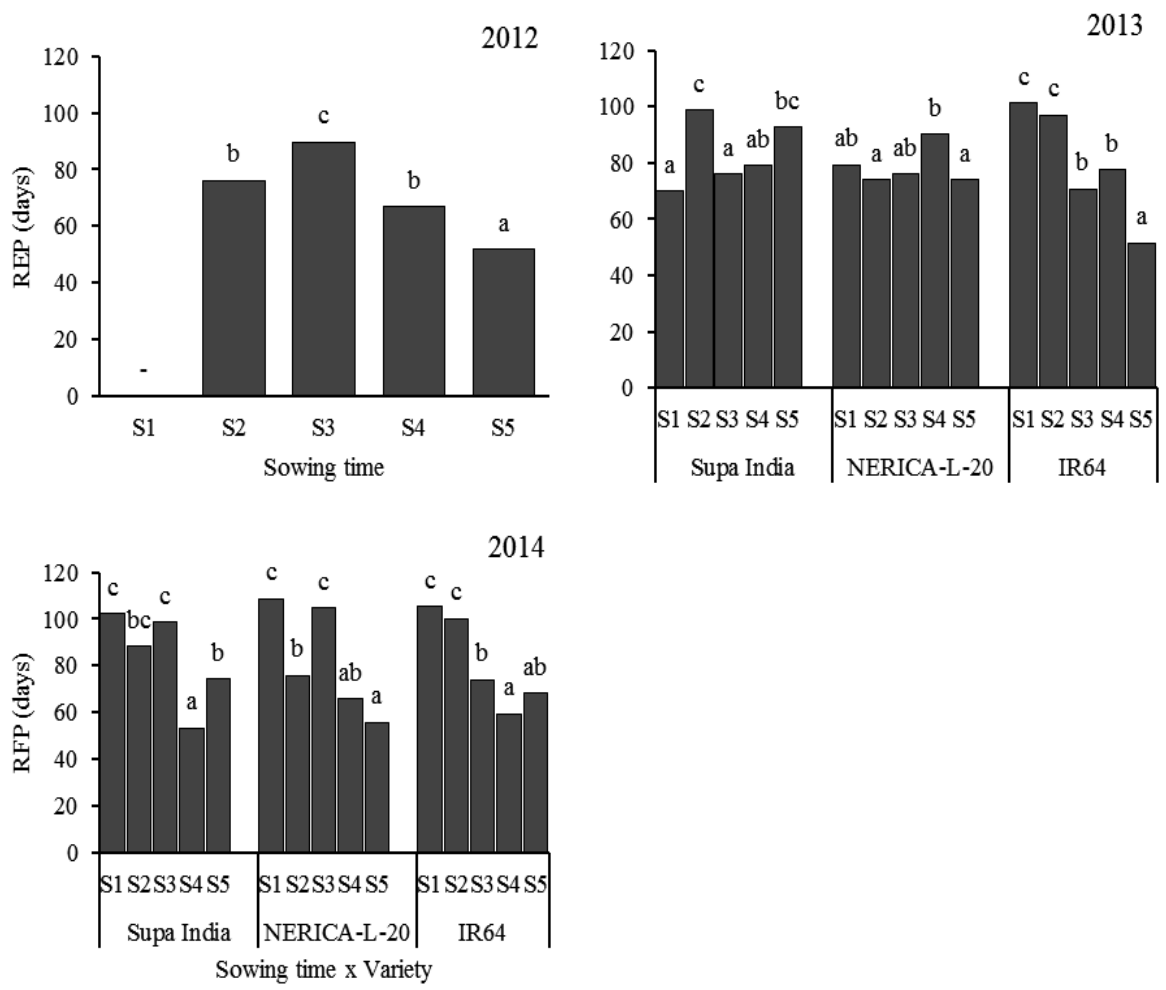

Fig. 5. R. fistulosa-free period (RFP, days), as affected by sowing time and rice variety during three cropping seasons (2012-2014) in Kyela, Tanzania. First sowing (S1) was conducted with the onset of the first rains, with consecutive plantings following with a time interval of two weeks. Means within the same rice variety, followed by the same letter are not significantly different according to LSD at $P<0.05$. For 2012, the values represent the averages of the three rice varieties, as only a significant effect of sowing time was observed.

In 2014, an initial increase was followed by a decrease with an optimum RNmax at intermediate sowing times (S3 or S4). Compared between years, maximum $R$. fistulosa plant numbers were highest in 2012 (up to 60 plants $\mathrm{m}^{-2}$ ), followed by 2013 (maximum of 40 plants $\mathrm{m}^{-2}$ ). In 2014, parasite infection level was considerably lower, with a maximum of just 14 plants $\mathrm{m}^{-2}$.

The above described differences between years were also reflected in R. fistulosa biomass (RDW), with maximum values of 100, 60 and $23 \mathrm{~g} \mathrm{~m}^{-2}$, in 2012, 2013 and 2014, respectively (Fig. 7). No significant Variety main effect or Variety $\times$ Sowing Time interaction effects were observed on $R$. fistulosa biomass. For all three years, a significant Sowing Time main effect was observed, with a gradual increase in parasite biomass with delayed sowing. 

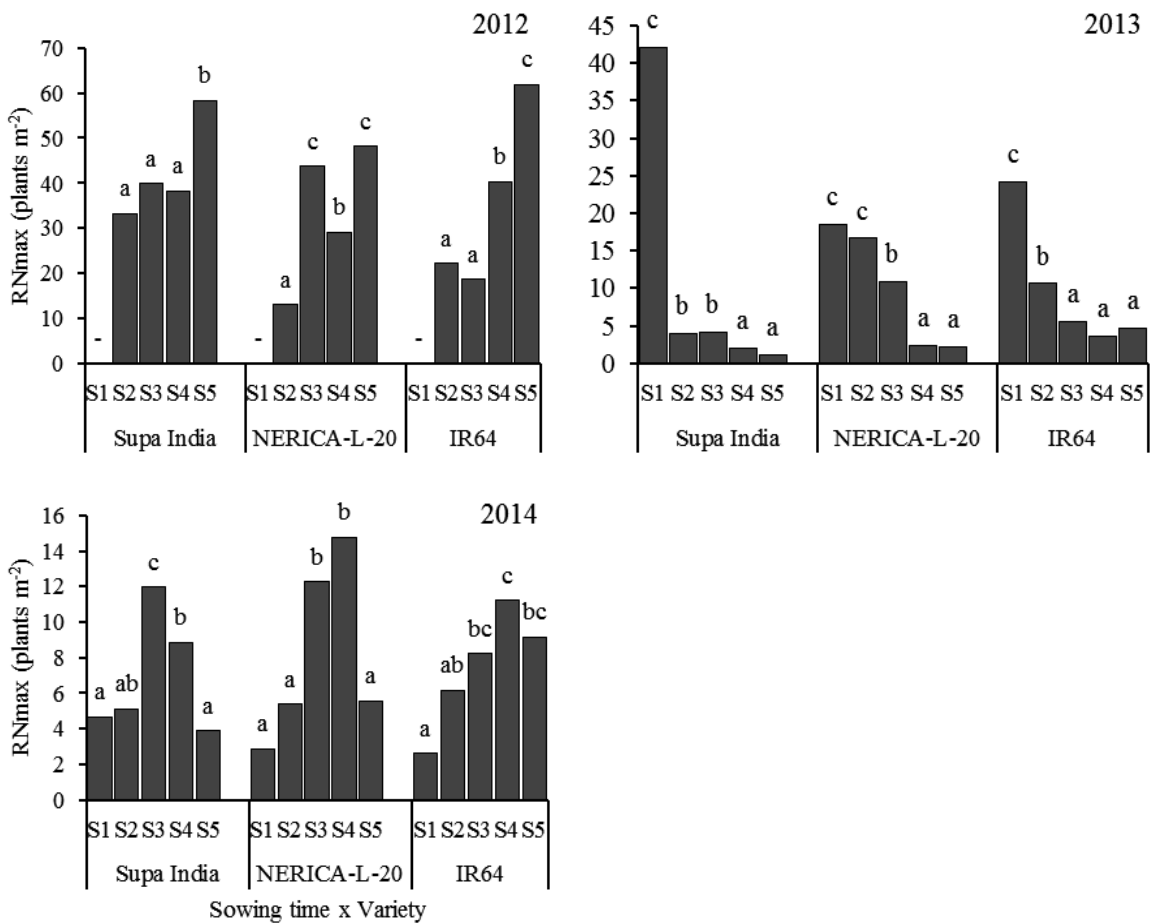

Fig. 6. Maximum $R$. fistulosa plant numbers $\left(R N \max\right.$, plants $\left.\mathrm{m}^{-2}\right)$, as affected by rice variety and sowing time during three cropping seasons (2012-2014) in Kyela, Tanzania. First sowing (S1) was conducted with the onset of the first rains, with consecutive plantings following with a time interval of two weeks. Means within the same rice variety, followed by the same letter are not significantly different according to LSD at $P<0.05$.
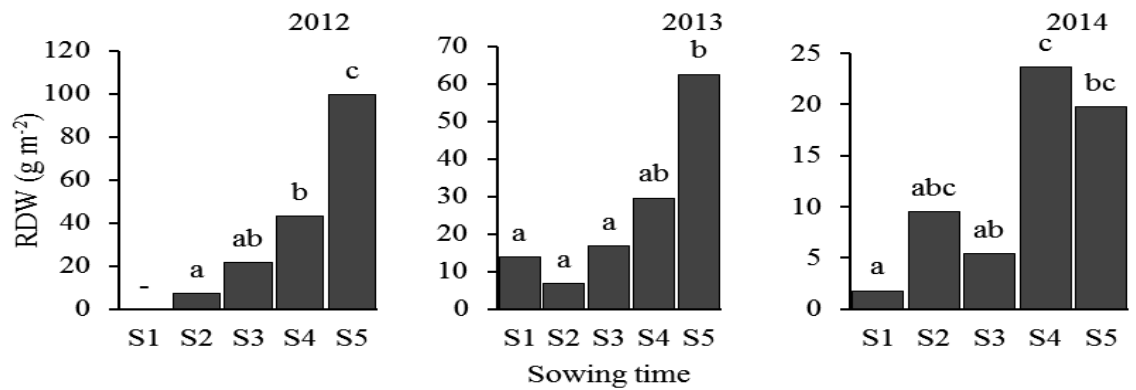

Fig. 7. Total above-ground $R$. fistulosa dry weight $\left(R D W, \mathrm{~g} \mathrm{~m}^{-2}\right)$, as affected by sowing time during three cropping seasons (2012-2014) in Kyela, Tanzania. First sowing (S1) was conducted with the onset of the first rains, with consecutive plantings following with a time interval of two weeks. Data are averaged over three rice varieties (Supa India, IR64 and NERICA-L-20), as only a significant effect of sowing time was observed. Means within the same year, followed by the same letter are not significantly different according to LSD at $P<0.05$. 


\section{Chapter 3}

A significant Variety $\times$ Sowing Time interaction effect on rice grain yields was observed in 2012 only. In 2013, a significant Sowing Time main effect on rice grain yield was observed, while in 2014 - the year with the lowest $R$. fistulosa infection- no significant Variety or Sowing Time effects on rice yields were found. Both in 2012 and 2013, rice grain yield gradually reduced with sowing time (Table 5). In 2012, this effect was strongest with NERICA-L-20 and more moderate with the other two varieties. Average rice yields varied from 6.0 to $1.4 \mathrm{t} \mathrm{ha}^{-1}$ in 2012, from 4.3 to $2.3 \mathrm{tha}^{-1}$ in 2013 and from 3.5 to $4.0 \mathrm{t} \mathrm{ha}^{-1}$ in 2014 .

Table 5. Rice grain yield $\left(\mathrm{t} \mathrm{ha}^{-1}\right)$ per rice variety and sowing time during the three cropping seasons in the R. fistulosa infested lowland field in Kyela, Tanzania.

\begin{tabular}{llcccccc}
\hline \multirow{2}{*}{ Year } & Variety & $\mathrm{S} 1$ & $\mathrm{~S} 2$ & $\mathrm{~S} 3$ & $\mathrm{~S} 4$ & $\mathrm{~S} 5$ & Mean \\
\hline 2012 & Supa India & - & $4.05 \mathrm{c}^{1}$ & $4.60 \mathrm{c}$ & $2.71 \mathrm{~b}$ & $1.25 \mathrm{a}$ & 3.15 \\
& NERICA-L-20 & - & $8.43 \mathrm{c}$ & $5.13 \mathrm{~b}$ & $2.21 \mathrm{ab}$ & $0.86 \mathrm{a}$ & 4.16 \\
& IR64 & - & $5.59 \mathrm{~b}$ & $3.94 \mathrm{ab}$ & $3.19 \mathrm{ab}$ & $2.05 \mathrm{a}$ & 3.69 \\
& Mean & - & 6.02 & 4.56 & 2.70 & 1.39 & \\
& & & & & & & \\
2013 & Supa India & 4.89 & 2.58 & 2.96 & 2.91 & 2.17 & 3.08 \\
& NERICA-L-20 & 3.38 & 3.82 & 2.36 & 2.90 & 2.42 & 2.98 \\
& IR64 & 4.62 & 4.82 & 3.33 & 2.23 & 2.37 & 3.47 \\
& Mean & $4.30 \mathrm{~B}$ & $3.74 \mathrm{~B}$ & $2.88 \mathrm{AB}$ & $2.68 \mathrm{~A}$ & $2.32 \mathrm{~A}$ & \\
& & & & & & & \\
2014 & Supa India & 4.08 & 3.84 & 3.98 & 3.45 & 3.55 & 3.78 \\
& NERICA-L-20 & 3.33 & 3.41 & 3.88 & 3.47 & 3.36 & 3.49 \\
& IR64 & 3.02 & 3.69 & 4.14 & 4.22 & 3.91 & 3.79 \\
& Mean & 3.48 & 3.65 & 4.00 & 3.71 & 3.61 & \\
\hline
\end{tabular}

${ }^{\mathrm{I}}$ In 2012, means within the same rice variety followed by same letter are not significantly different at $P<0.05$. In 2013, this comparison was made for the means of the three rice varieties as only a significant main effect of sowing time was observed.

\subsubsection{Pot experiment}

There was a significant $(P<0.05)$ Sowing Time $\times$ Host Presence interaction effect on total $R$. fistulosa biomass dry weight (shoots and roots) (Table 6). In the absence of rice, Sowing Time did not have an effect on parasite biomass and the average parasite biomass was $1.75 \mathrm{~g}$ $\operatorname{pot}^{-1}$. Except for the first sowing time, the presence of rice always resulted in a significantly higher $R$. fistulosa biomass dry weight production than the situation without rice. In the presence of rice, parasite biomass dry weight differed significantly across sowing times. At 
$\mathrm{S} 1$, the lowest parasite biomass was obtained (3.27 $\mathrm{g} \mathrm{pot}^{-1}$ ), whereas the highest parasite biomass was obtained at S5 $\left(8.89 \mathrm{~g} \mathrm{pot}^{-1}\right)$, corresponding to a 4.3 times increase compared to $R$. fistulosa grown in the absence of rice. Parasite biomass at S3, S4 and S6 did not differ significantly from that of S5.

A significant Sowing Time $\times$ Parasite Presence interaction effect on total rice biomass dry weight was observed. In the absence of the parasite, similar to what was observed with the $S$. asiatica pot experiment, the rice biomass dry weight progressively reduced from $38.2 \mathrm{~g} \mathrm{pot}^{-1}$ at $\mathrm{S} 1$ to $14.6 \mathrm{~g} \mathrm{pot}^{-1}$ at S6 (Table 6). At each sowing time, the presence of $R$. fistulosa caused a significant reduction in rice biomass dry weight, compared to $R$. fistulosa-free rice plants, except at S1. The size of this reduction strongly increased, from $45 \%$ at $\mathrm{S} 2$ to $96 \%$ at $\mathrm{S} 6$.

Table 6. Influence of rice sowing time on total dry weight of $R$. fistulosa $\left(\mathrm{g} \mathrm{pot}^{-1}\right)$ in the presence and absence of rice and on total dry weight of rice $\left(\mathrm{g}_{\operatorname{pot}^{-1}}\right)$ in the absence and presence of $R$. fistulosa, during the greenhouse experiment in 2016. Sowing time interval of rice was 14 days (S1 to S6) and seeds of $R$. fistulosa were introduced at S4 (6 weeks after first rice sowing).

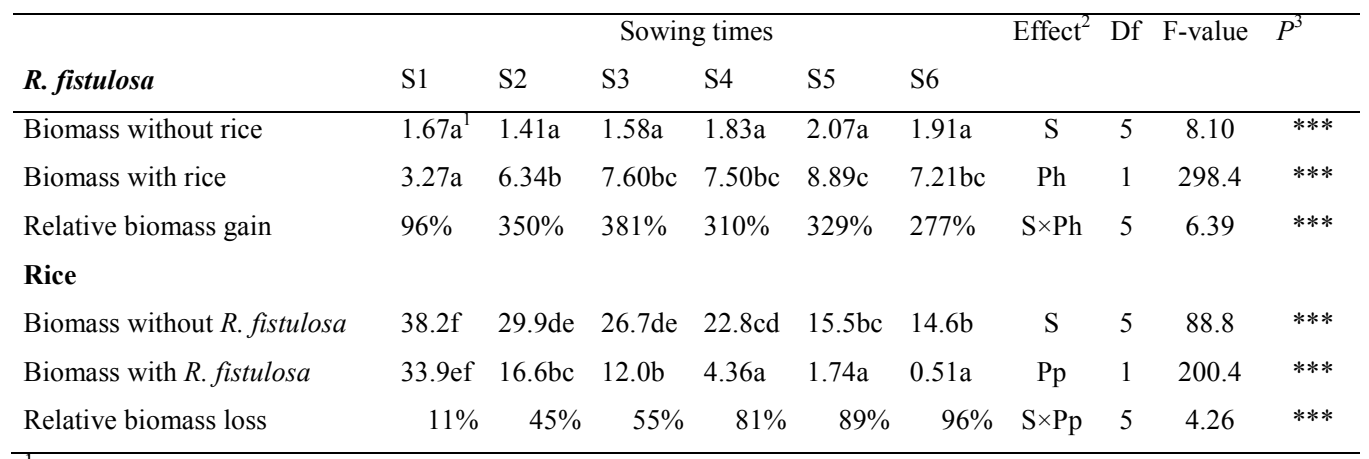

${ }^{\mathrm{T}}$ Means of parasite biomass and rice biomass followed by the same letter are not significantly different according to LSD at $P<0.05 .{ }^{2} \mathrm{~S}=$ Sowing Time, $\mathrm{Ph}=$ Presence of a host plant, $\mathrm{Pp}=$ presence of a parasite. ${ }^{3 * * *}$ significant at $P<0.001$.

\section{Discussion}

\subsection{Striga asiatica}

Late sowing tended to reduce the incidence and biomass of $S$. asiatica in the upland field, but the overall incidence of this parasitic weed differed between years. Striga asiatica infection levels were considerably more severe in 2013 than in the other two experimental years. This was evident from the short $S$. asiatica-free period (40 days), the high maximum $S$. asiatica numbers $\left(80\right.$ plants $\left.\mathrm{m}^{-2}\right)$ and the relatively high $S$. asiatica biomass $\left(5.35 \mathrm{~g} \mathrm{~m}^{-2}\right)$. A striking difference between 2013 and the other two years of experimentation was the low amount of 


\section{Chapter 3}

rainfall in the month of April (Fig. 1). With $200 \mathrm{~mm}$, this amount was considerably lower than in $2012(870 \mathrm{~mm})$ and 2014.

Also clear differences between varieties were observed. Supa India (2012) and NERICA14 (2013 and 2014) were the varieties with the highest SNmax and SDW, whereas Mwangulu consistently belonged to the varieties with the lowest parasite infection. Though at the start of the experiment not much was known on the $S$. asiatica resistance levels of the three rice varieties, a recent publication confirms that among these three varieties, Mwangulu is the variety with the highest resistance level, whereas NERICA-14 was classified as intermediate resistant and Supa India as susceptible (Rodenburg et al., 2015a).

Sowing time did not have a consistent effect on the $S$. asiatica-free period, but a clear effect on maximum $S$. asiatica numbers was observed, confirming findings of Gbèhounou et al. (2004) with sorghum and maize. For all three years, and irrespective of variety, there was a consistent reduction in SNmax with delay in sowing time.

With some exceptions, the same pattern was observed for S. asiatica biomass. At the start of the rainy season, soil moisture will increase and these moist conditions are known to favour pre-conditioning of Striga spp. seeds present in the soil (Mohamed et al., 1998). After preconditioning, the seeds are ready to germinate and will do so if they are in close proximity of the roots of a host plant. However, after a prolonged period without a host, the preconditioned seeds will turn into secondary dormancy and thereby lose their sensitivity to germination stimulants released from host plant roots (Matusova et al., 2005; Mohamed et al., 1998). This suggests that if rice sowing is delayed for a sufficiently long period of time, most of the $S$. asiatica seeds will have returned into dormancy at the time when rice roots start exploiting the soil. This might well explain why the number of emerged $S$. asiatica plants reduced with delayed sowing. The greenhouse experiment showed a similar pattern, in which $S$. asiatica numbers gradually reduced with a delay in sowing. Sowing at 10 weeks after the start of $S$. asiatica seed preconditioning (S6) even resulted in a total absence of parasite emergence. These findings confirm that the likelihood of $S$. asiatica infection reduces with a prolonged pre-conditioning period (Kebreab and Murdoch, 1999).

Despite this clear pattern for parasite number, the influence of sowing time on rice grain yield was less consistent, again confirming the study by Gbèhounou et al. (2004) on sorghum and maize. In 2013, the year with the highest $S$. asiatica infection level, the maximum yields were obtained with intermediate sowing times. For the earlier sowing times, congruent with the higher parasite infection levels, grain yield was reduced. However, with a further delay in 
sowing time, the lower S. asiatica infection level did not translate into higher grain yields, rather the opposite was observed. It is likely that the relatively low rainfall at the end of the rice growth cycle in April caused the rice to suffer from drought stress during grain filling, resulting in a lower yield than that obtained with intermediate sowing times. This explanation is confirmed by the results of 2012, in which the S. asiatica infection level was extremely low, and thus not likely to have a strong effect on rice grain yield. In this year, grain yield of the last two sowing dates, except that of Supa India at S4, was lower than the grain yields obtained with the first three sowing dates. In the absence of $S$. asiatica, the availability of water becomes the main determinant of grain yield, and it is well established that, particularly under upland conditions, late sowing increases the risk of drought stress during grain filling (Pandey et al., 2014).

In 2014, with the intermediate $S$. asiatica infection level, only the late-maturing variety Mwangulu suffered from drought stress during the last sowing. Grain yield at S5 was significantly lower than the yield obtained at the earlier sowing times. Supa India (intermediate) and NERICA-14 (early-maturing) did not suffer from drought stress at S5. For NERICA-14 the latest sowing time even gave the highest yield, suggesting that for this variety drought stress during grain filling was not encountered, probably just because of the shorter growth duration (e.g. Allah et al., 2010). The implication for farmers would be that they could reduce $S$. asiatica infection in their crop, when they attempt to delay sowing a much as possible and this strategy can be facilitated by the use of early maturing varieties.

\subsection{Rhamphicarpa fistulosa}

Rhamphicarpa fistulosa was most prominent in 2012, followed by 2013 and finally 2014. In all three years, differences in parasite biomass between varieties were absent, suggesting an equal level of resistance. This result contrasts with results of Rodenburg et al. (2016a), where IR64 was classified amongst the most resistant varieties and Supa India and NERICA-L-20 as varieties possessing an intermediate level of resistance. Sowing time had a clear impact on $R$. fistulosa biomass production but the direction of this effect was the exact opposite of that observed with $S$. asiatica. Parasite biomass increased with sowing times, independent of rice variety and year. This increase was accompanied by a decrease in the $R$. fistulosa-free period; i.e. with a delay in sowing time, the parasite was present at an earlier time after sowing of the crop, resulting in an extended growth period till rice harvest and thus allowing the parasite to interfere with the growth of the rice crop for a longer period of time. Not surprisingly, with a 


\section{Chapter 3}

delay in sowing time the rice grain yields were significantly reduced. This effect was, however, only evident in 2012 and 2013, the two years with the highest parasite infestation level. In 2014, no significant effect of sowing time on rice grain yield was observed, suggesting that in 2014 the parasite infection level was simply too low to exert a major impact on rice grain yield.

These results suggest that under lowland conditions early sowing is an effective way of escaping the detrimental effect of $R$. fistulosa infection. Previously, it was established that germination of $R$. fistulosa, being a facultative parasite, is independent of the presence of a host plant (Kabiri et al., 2016). Germination and establishment are stimulated by saturated soil conditions and occur more or less independent of the sowing time of the crop. As a consequence, effective parasitism can be shortened by sowing prior to the time when optimum soil conditions for $R$. fistulosa seed germination are attained. Rhamphicarpa fistulosa is also a slow starter; observations from the current study confirm the previous finding by Kabiri et al. (2016) that it takes considerable time (at least 7 weeks) for the seed to germinate, grow a seedling, develop roots and attach to a host plant to become parasitic.

Evidently, with a larger time gap between emergence of rice and parasite, the parasite creates less damage to the host plant (Seel and Press, 1993). Early land preparation and crop establishment thus allows farmers to escape early and severe parasite infection in rice. In the greenhouse experiment this situation was mimicked: rice was planted at six different times (S1-S6) and $R$. fistulosa seeds were added at a fixed moment in time (S4). In this experiment, it was found that rice yields under R. fistulosa infested conditions declined sharply from $89 \%$ of the control (rice without weeds) at S1 to just $4 \%$ of the control at S6. In this experiment, the parasite benefited less from the extended combined growth period, as no differences in parasite biomass were observed between S2 to S6 and only biomass of S1 was significantly lower. For the last sowing times, this absence of an advantage for the parasite might be due to the poorer growth of the rice plants, which was evident from the $R$. fistulosa-free rice plants. As mentioned earlier, this impeded growth reflects the lower light intensities encountered in September-October.

The effect of sowing time on R. fistulosa number was highly variable. In 2012, parasite number increased with sowing time from around 20 plants $\mathrm{m}^{-2}$ at $\mathrm{S} 2$, to around 50-60 plants $\mathrm{m}^{-2}$ at S5. Such an initial increase in parasite number, though at a much lower level (3-14 plants $\mathrm{m}^{-2}$ ), was also observed in 2014. In contrast, in 2013, a decreasing trend was observed with parasite number decreasing from around 30 plants $\mathrm{m}^{-2}$ to $2-5$ plants $\mathrm{m}^{-2}$ at S5. This 
trend might be related to the rainfall pattern in that year whereby the low rainfall level in April (Fig. 1), might have resulted in a lower survival rate of those R. fistulosa plants that had not yet managed to connect to a host plant. This hypothesis could be supported by observations of Kabiri et al. (2016) who showed a considerable time lap between $R$. fistulosa emergence and effective parasitism.

Still the lower parasite number did not result in a lower parasite biomass and also rice grain yield was more affected at the last two sowing dates. These observations suggest that just a few parasites are sufficient to cause a major effect, which is in line with results from previous studies on the relation between $R$. fistulosa infection and rice yields (Rodenburg et al., 2011b; Rodenburg et al., 2016a). It also confirms findings from previous greenhouse experiments, where it was observed that at higher $R$. fistulosa densities usually just a few parasites are dominant and responsible for the majority of parasite biomass (Kabiri et al., 2016).

\section{Conclusion}

Sowing time can significantly influence parasitic weed growth and rice grain yields, but the direction of this effect differs considerably between weed species with different life forms (i.e., facultative vs obligate parasites) and hence between agro-ecosystems. In $R$. fistulosa infested lowland systems, the best strategy is early sowing, as in this way parasite infection is delayed, resulting in lower parasite biomass and the highest rice grain yields. This strategy is independent of rice variety and thus allows farmers to continue growing their favoured (latematuring) local varieties. With $S$. asiatica in upland systems, the situation is more complicated. The negative effect of delayed sowing time on S. asiatica performance is evident, particularly in years with high parasite incidence. This strategy is, however, not without risks, particularly with late-maturing varieties like Mwangulu. Results suggest that an intermediate sowing time gives the best yield perspectives in these Striga-infested upland situations, whereas risks of drought-induced crop failure can be mitigated by using an earlymaturing variety, like NERICA-14. 



\section{Chapter 4}

Infestation by parasitic and ordinary weeds undermines rice yield increasing effects of soil amendments

Dennis E. Tippe ${ }^{1,5}$, Jonne Rodenburg ${ }^{2}$, Aad van Ast ${ }^{1}$, Ibnou Dieng ${ }^{3}$, Mamadou Cissoko ${ }^{4}$, Juma Kayeke ${ }^{5}$, Derek W. Makokha ${ }^{6}$, Lammert Bastiaans ${ }^{1}$

Submitted as: D.E. Tippe et al., 2019.

${ }^{1}$ Centre for Crop Systems Analysis, Wageningen UR, P.O. Box 430, 6700 AK, Wageningen, the Netherlands

${ }^{2}$ Natural Resources Institute, University of Greenwich, Central Avenue, Chatham Maritime, Kent ME4 4TB, UK

${ }^{3}$ Africa Rice Center (AfricaRice), 01 BP 4029, Abidjan 01, Côte d'Ivoire

${ }^{4}$ Department of Animal and Plant Sciences, University of Sheffield, Sheffield S10 2TN, UK

${ }^{5}$ Tanzania Agricultural Research Institute, Uyole-Center, P.O. Box 400, Mbeya, Tanzania

${ }^{6}$ Africa Rice Center (AfricaRice), P.O. Box 33581, Dar Es Salaam, Tanzania 


\title{
Chapter 4
}

\begin{abstract}
Parasitic weeds are an emerging production constraint in smallholder rainfed rice environments in subSaharan Africa (SSA). Their occurrence is frequently associated with low soil fertility. Important parasitic weed species in rice systems are the obligate Striga asiatica (L.) Kuntze, in free-draining uplands, and the facultative Rhamphicarpa fistulosa (Hochst.) Benth., in waterlogged lowlands. In this study different types of soil amendments were tested under field conditions in Kyela district, southwest of Tanzania, to investigate whether: (1) there is a significant effect of soil fertility amendments on S. asiatica / R. fistulosa infection levels in the field, and (2) rice yields benefit from soil fertility amendments when the crop suffers from ordinary or parasitic weed infestation.

Field experiments were conducted at two sites ( $S$. asiatica-infested upland and $R$. fistulosainfested lowland) from 2012 to 2015. Fertiliser treatments were either sole mineral (NPK or DiAmmonium Phosphate - DAP - plus Urea) or organic (Cattle manure or Rice husk) by nature, or combinations of mineral and organic Fertilisers. These were compared to 'No-Fertiliser' control treatments. Fertiliser effects were studied both in the absence and presence of ordinary weeds. Parasitic weeds were maintained throughout treatments. Observations consisted of parasite number, parasite biomass, ordinary weed biomass and rice grain yield. Fertiliser effects on parasitic weed infection proved to depend on the type and composition of fertilisers, the seasonal rainfall distribution and the type of parasitic weed. Fertilisers had a moderate but inconsistent suppressive effect on $S$. asiatica, but frequently promoted $R$. fistulosa. Weeding of ordinary weeds stimulated S. asiatica, but reduced the biomass of $R$. fistulosa. Positive fertiliser effects on rice grain yield, in both the upland and the lowland environment, were mainly found in the absence of ordinary weeds and under low parasitic weed infection. Rice husk alone and rice husk or manure combined with DAP were generally the most successful treatments with regards to rice grain yield for both environments. Despite modest and inconsistent effects on parasite infection levels, rice husk or manure combined with DAP offer smallholder farmers an accessible and low-cost technology to increase rice yields in parasitic weed infested fields. Farmers should be recommended to combine the use of such fertilisers with timely weeding interventions.
\end{abstract}

Keywords: Rainfed rice, Striga asiatica, Rhamphicarpa fistulosa, Soil fertility, Mineral fertilisers, Rice husks 


\section{Introduction}

Parasitic weeds are an emerging production constraint in smallholder rainfed rice environments across sub-Saharan Africa (SSA) (Rodenburg et al., 2016b). These weeds are not only competitors and potential pest vectors, but also extract resources and assimilates directly from their hosts and therefore constitute an important problem in rainfed rice production systems (Parker, 2013). Two of the most important parasitic weeds in rainfed rice systems are the well-known Striga asiatica (L.) Kuntze and the newly emerging Rhamphicarpa fistulosa (Hochst.) Benth. (Rodenburg and Johnson, 2009). Striga asiatica is a dominant parasitic weed under rainfed upland conditions. It is an obligate parasite, meaning that it cannot complete its life cycle without being connected to a host plant (Westwood et al., 2011). Rice yield reductions associated with $S$. asiatica infection were reported in the order of 64 to $80 \%$ (Elliot et al., 1993). The Striga problem is increasing in upland rice environments in SSA (Rodenburg et al., 2016b) and this increase may be associated with crop intensification combined with poor soil fertility management. Soils with low fertility, particularly those with low levels of nitrogen $(\mathrm{N})$ and phosphorus $(\mathrm{P})$, favour the growth and spread of Striga spp. (Jamil et al., 2012; Ayongwa et al., 2006; Farina et al., 1985).

In addition to the $S$. asiatica problem in upland systems, $R$. fistulosa is developing as a serious problem in rainfed lowland rice production systems (Rodenburg et al., 2015b; Ouédraogo et al., 1999). Rhamphicarpa fistulosa is a facultative parasite, meaning that it is capable of completing its life cycle with or without a host plant (Parker, 2013; Ouédraogo et al., 1999). It is naturally occurring in wetland ecosystems (Kabiri et al., 2015; Hansen, 1975). In recent years, due to increased rice demand, these wetlands are increasingly being converted to rice production (Rodenburg et al., 2014). As with Striga spp., the incidence of $R$. fistulosa seems to be associated with poor soil fertility (N'Cho et al., 2014). Rice yield losses due to $R$. fistulosa ranging from $30-100 \%$ have been reported (N'Cho et al., 2014), but these losses vary depending on the level of infection, the rice variety and the fertiliser levels applied (Rodenburg et al., 2011; Rodenburg et al., 2016a).

From the above we derive that incidence and severity of both parasitic weed species is associated with low soil fertility and that their occurrence and effect could potentially be mitigated by the application of Fertilisers. Several mechanisms have been proposed by which soil fertility may suppress parasitic weed infection: (i) nutrient availability increases vigour of crop plants making them more weed competitive (Andrew et al., 2015; Blackshaw et al., 2005) and more resilient against any type of pest and disease problem, (ii) high nutrient and 


\section{Chapter 4}

particularly nitrogen availability reduces the amount of Strigolactones released by host plant roots, which in turn reduces the germination of Striga spp. seeds (not R. fistulosa) and thus potentially the level of infection (Screpanti et al., 2016; Jamil et al., 2012), (iii) high nutrient availability is often associated with a high soil organic matter (Celik et al., 2004; Pullaro et al., 2006), which in turn stimulates soil biological activity that may expedite decay or predation of weed seeds. High soil organic matter content also increases water holding capacity of the soil which in turn positively influences crop growth and vigour (Zhao et al., 2016).

There is a general lack of suitable and affordable parasitic weed control strategies that are adapted to smallholder rice production systems in SSA (Tippe et al., 2017a). There is therefore a necessity to broaden the window of opportunities for parasitic weed control in smallholder rice production systems. Soil fertility enhancing technologies may be a valuable component in an integrated parasitic weed management strategy. Mineral fertilisers may be effective, but farmers usually find them too expensive. Lowering the costs of soil fertility enhancing technologies could be achieved by replacing mineral Fertilisers in part or as a whole, by some of the locally available inputs. Cattle manure is one option, but many farmers are reluctant to use freely available cattle manure as this may increase ordinary weed infestations (Tippe et al., 2017a). Rice husks are another alternative and, apart from transport costs, also comes at low or no additional costs. However, their effectivity as a soil amendment, let alone their influence on parasitic weed infestation level, has not been tested before.

The current study was therefore set-up to investigate the following research questions: (1) Is there a significant effect of soil fertility amendments on Striga asiatica / Rhamphicapa fistulosa infection levels in the field? (2) Do rice yields benefit from soil fertility amendments when the crop suffers from ordinary or parasitic weed infestation?

\section{Materials and Methods}

\subsection{Experimental site characterization}

A field study was conducted during four consecutive cropping seasons $(2012$ - 2015) at Kilasilo (lowland) and Mbako (upland) village in Kyela district, South-West Tanzania (09 $35^{\prime} 08^{\prime \prime} \mathrm{S}-33^{\circ} 48^{\prime} 43^{\prime \prime} \mathrm{E}$ and $9^{\circ} 37^{\prime} 30^{\prime \prime} \mathrm{S}-33^{\circ} 52^{\prime} 30^{\prime \prime} \mathrm{E}$, respectively). The trials at both sites were conducted from March to July (season 1 and 4) and January to June (seasons 2 and 3). The sites were located at around 525 meters above sea level, and have unimodal annual 


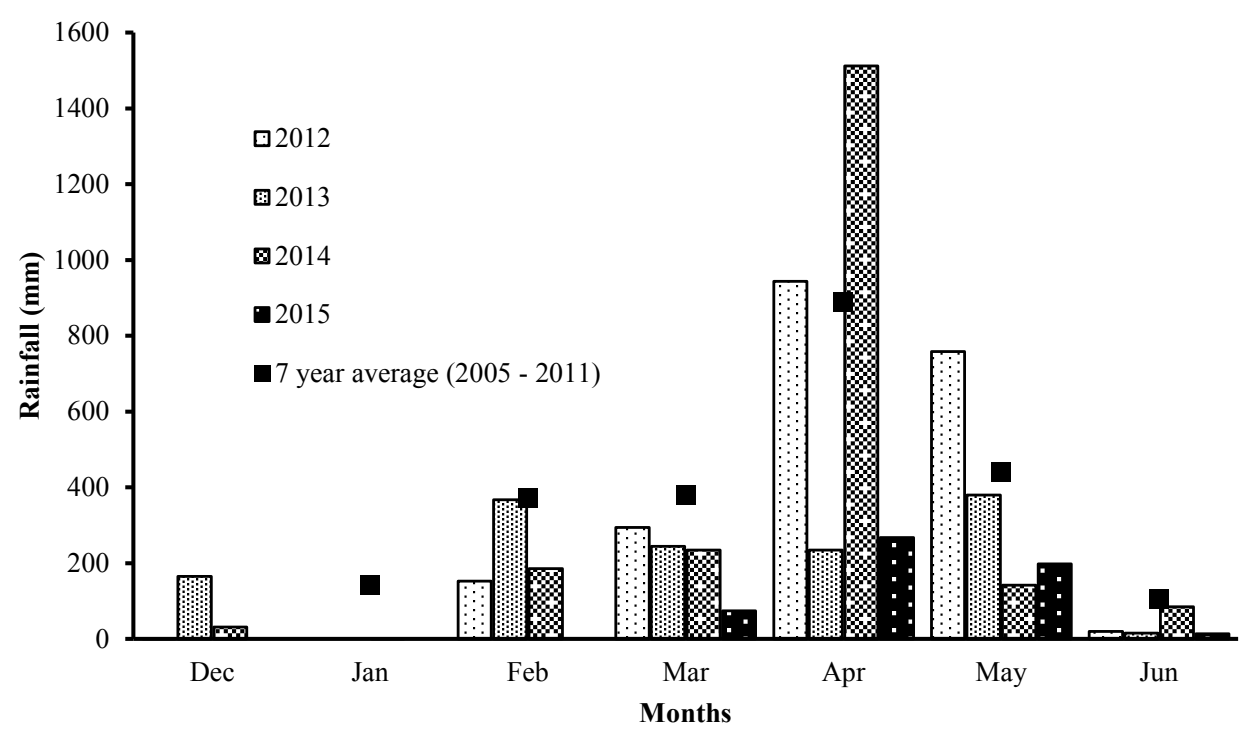

Fig. 1. Cumulative monthly rainfall $(\mathrm{mm})$ as recorded in the experimental fields in Kyela district, Tanzania from December to June. For 2015, rainfall was not recorded prior to the start of the experiment (March). Additional data for the past 7 years prior to experimentation was received from Kyela District Agriculture and Livestock Office.

precipitation patterns. Monthly average temperatures during the cropping period range from 31 to $19^{\circ} \mathrm{C}$ in December to May (Kabiri et al., 2015). During the field experiments, cumulative rainfall recorded in the field was 2,170 mm (2012), 1,440 mm (2013), 2,370 mm (2014) and $552 \mathrm{~mm}$ (2015) (Fig. 1).

Before rice was sown, the upper $20 \mathrm{~cm}$ of soils of both sites (upland and lowland) were sampled and analysed at CropNuts laboratory in Nairobi, Kenya. Soil samples from both upland and lowland sites were characterized as acidic $(\mathrm{pH}=5.5)$ and texturally classified as sandy-clay-loam (ratio sand : silt : clay of 63:12:25 in upland and 50:18:32 in lowland) (Table 1). Available phosphorous (Mehlich, 1984) in the upland and lowland fields (14.2 and 6.4 ppm, respectively) classified medium - high, while exchangeable potassium (K) was high (348.1 and $135.9 \mathrm{ppm}$, respectively). The organic matter (OM) content of the soil (Colometric; Walkley and Black, 1934) was 3.16\% (upland) and 1.95\% (lowland) and total nitrogen (Kjeldahl; Bremner and Mulvaney, 1982) was $0.16 \%$ and $0.07 \%$, respectively. Soil Cation Exchange Capacity (CEC) and Electric Conductivity (EC) for both sites was low (7.785 $\mathrm{cmol}(+) \mathrm{kg}^{-1}$ and $95.65 \mathrm{uS} / \mathrm{cm}$, respectively). 


\section{Chapter 4}

Table 1. Basic soil characteristics from the study sites at the start of the experiments (2012) in Kyela.

\begin{tabular}{llll}
\hline Soil parameter & Upland (S. asiatica) & Lowland (R. fistulosa) & \\
\hline & 2012 & 2012 \\
\hline Texture (sand: silt: clay) & $63.1: 11.6: 25.2$ & $50.2: 17.6: 32.1$ & \\
pH & 5.8 & 5.4 & \\
Total Nitrogen (\%) & 0.16 & 0.07 & $\mathrm{a}$ \\
Available Phosphorus (ppm) & 14.2 & 6.4 & $\mathrm{~b}$ \\
Potassium (ppm) & 348.1 & 135.9 & $\mathrm{~b}$ \\
Organic matter (\%) & 3.16 & 1.95 & $\mathrm{c}$ \\
\hline
\end{tabular}

${ }^{\mathrm{a}}$ Bremner and Mulvaney (1982), ${ }^{\mathrm{b}}$ Mehlich (1984), ${ }^{\mathrm{c}}$ Walkley and Black (1934).

\subsection{Plant material}

The local rice variety Supa India was used for both upland and lowland fields during all four cropping seasons. Rice seed was obtained from Kyela District Agricultural Office. In 2012, prior to rice sowing, plots were artificially infested with parasitic weed seeds to supplement and homogenise the existing soil weed seedbank in experimental plots. For both $S$. asiatica and R. fistulosa, seed was sourced from infested rice fields in Kyela during the preceding cropping season (2011). For the S. asiatica field in the upland area, artificial infestation was only done in a central area of the plots, encompassing 9 hills, at a rate of $0.463 \mathrm{~g} \mathrm{~m}^{-2}(1 \mathrm{~g}$ per plot area of $2.16 \mathrm{~m}^{2}$ ). Artificial infestation with $R$. fistulosa seed in the lowland was done at a density of approximately $1 \mathrm{~g}$ of seed $\mathrm{m}^{-2}$ for the entire plot $(3 \mathrm{~m} \times 4 \mathrm{~m})$. Prior to application, parasitic weed seeds were mixed with approximately $20 \mathrm{ml}$ of white sand per plot. The $S$. asiatica seed - sand mixture was incorporated in the upper 5-10 cm of the soil, using handheld hoes and rakes. The R. fistulosa seed - sand mixture was spread evenly on the plot surface at rice sowing, because of the light requirement for seed germination of this species (Kabiri et al., 2016). Before the artificial infestation, the implication of this approach was clearly discussed with the farmers owning the lands in both upland and lowland sites. To restore the original field condition upon conclusion of our experiments, we offered technical and financial assistance to the land owners. In the other three rice cropping seasons (2013, 2014 and 2015) no artificial infestation was done.

\subsection{Field preparation}

During the first cropping season (2012), in both sites (upland and lowland), fields were initially ploughed using a tractor (disc plough). Three weeks after initial ploughing, fields 
were harrowed using an oxen-drawn plough (mould board plough). Three days after harrowing, fields were prepared to a fine tilth, debris were removed manually and the land was levelled manually using hand-held hoes and rakes. Three days after levelling, plots were marked out with pegs and rice was sown two days later. In the other three cropping seasons (2013 - 2015), soil tillage was done plot by plot using hand-held hoes in order to avoid confusion of treatments between plots. Debris were removed manually, and soil was prepared to finer tilth and levelled using hand hoes and rakes thereafter.

\subsection{Experimental design and plot sizes}

Treatments were laid down in a Randomized Complete Block Design using 7 soil fertility treatments and 2 weeding regimes .i.e. weed free (WF) and un-weeded (UW) plots in 5 replicates, arriving at a total of 70 plots. Each plot $(3 \mathrm{~m} \times 4 \mathrm{~m})$ represented one treatment. Each plot consisted of 15 rows of 20 hills each $(15 \times 20)$, with a sowing distance of $0.2 \mathrm{~m} \times$ $0.2 \mathrm{~m}$ between hills and rows. The outer two rows were used as border rows, leaving an observation area of 176 hills.

\subsection{Soil fertility treatments}

Seven soil fertility treatments were tested: (1) A 'No-Fertiliser' (control), (2) DAP plus Urea in locally recommended rates, (3) NPK in locally recommended rates, (4) Cattle manure, (5) Rice husks, (6) Cattle manure and half the locally recommended rate of DAP plus Urea, (7) Rice husks and half the locally recommended rate of DAP plus Urea.

Recommendations by the local District Agricultural Office (supported by the National Agricultural Research System) prescribe DAP 18:46:0 $\left(\mathrm{N} \mathrm{P}_{2} \mathrm{O}_{5} \mathrm{~K}_{2} \mathrm{O}\right)$ to be applied at a rate of $125 \mathrm{~kg} \mathrm{ha}^{-1}\left(150 \mathrm{~g}\right.$ per plot) at planting and Urea $(46 \% \mathrm{~N})$ at a rate of $125 \mathrm{~kg} \mathrm{ha}^{-1}(150 \mathrm{~g}$ per plot) at 70 Days After Sowing (DAS). Local recommendations prescribe NPK 20-10-10 (N-P$\mathrm{K})$ to be applied at a rate of $200 \mathrm{~kg} \mathrm{ha}^{-1}$ in 2 splits, whereby the first split was applied at 21 DAS (140.3 g per plot) while the second split was applied at 70 DAS (99.7 g per plot). Cattle manure as well as fine rice husks derived from the second chamber of the mill, whether alone or in combination with DAP and Urea, were applied at a rate of 10 tons $\mathrm{ha}^{-1}$ (12 $\mathrm{kg}$ per plot). Both organic fertilisers were thoroughly mixed with the top $20 \mathrm{~cm}$ soil at 3 days before sowing. In plots following the combined organic and mineral fertiliser treatments, both types were applied by the same methods and at the same times as described for mineral-only (DAP and Urea) and organic-only treatments. 


\section{Chapter 4}

\subsection{Crop establishment and management}

Rice sowing was done one day after supplemental parasitic weed seed infestation in the first season (between $2^{\text {nd }}$ and $5^{\text {th }}$ March, 2012), or after seedbed preparation in the second, third (between $24^{\text {th }}$ and $30^{\text {th }}$ January, 2013 and 2014) and fourth season (between $4^{\text {th }}$ and $5^{\text {th }}$ March, 2015). Soil in each planting hole was mixed with $1 \mathrm{~g}$ of an insecticide Furadan ${ }^{\circledR}$. About 5-6 seeds per hill were directly sown at a depth of 2-3 cm below the soil surface and thinned or gap-filled at approximately 21 DAS to 3 plants per hill. The trials were regularly hand weeded to remove all weeds other than parasitic weeds, except in the weedy plots where no weeding was carried out. Rice fields were sprayed twice within 2 weeks after rice tiller initiation and then 4 weeks later with an insecticide based on Chlorpyrifos with the trade name Dursban ${ }^{\circledR}$, to control potential insect vectors of viral diseases, especially Rice Yellow Mottle Virus which is endemic in Kyela.

\subsection{Measurements and observations}

The number of parasitic weed plants growing in the net plot area (i.e. 176 hills in the $S$. asiatica field in all four years; 176 hills in the R. fistulosa field in 2012 and 144 hills thereafter) was counted approximately once a month until rice harvesting time. These counts were used to assess the maximum number of parasitic weed plants in each plot, a proven measure for infection level (Rodenburg et al., 2005). The above-ground parts of parasitic weeds were harvested at rice harvesting time and oven-dried at $70^{\circ} \mathrm{C}$ for 48 hours for biomass assessment, another proven measure for infection level (Rodenburg et al., 2005; Rodenburg et al., 2016a). In the weedy plots, the ordinary weed biomass was collected from the central area of 9 hills $\left(0.36 \mathrm{~m}^{2}\right)$ in each specific plot at rice harvesting. Harvested weed biomass was oven-dried at $70^{\circ} \mathrm{C}$ for 48 hours and weighted.

Rice harvest, for all four cropping seasons and both fields, was between $26^{\text {th }}$ May and $16^{\text {th }}$ June. Rice panicles from all plants growing within the net plot area were cut at the senescence ring and placed in cotton bags. Rice panicles were air-dried for about two weeks, threshed and winnowed to separate filled rice grains from chaff and empty grains. Filled grain weight was determined and grain moisture content was measured simultaneously using a digital grain moisture meter of SATAKE (Model SS-7) to convert all grain weights to a standard (14\%) moisture content. 


\subsection{Statistical analysis}

Before analyses, data on parasitic weed numbers ( $S N \max / R N \max$; plants $\mathrm{m}^{-2}$ ), parasitic weed biomass dry weight $\left(S D W\right.$ or $\left.R D W ; \mathrm{g} \mathrm{m}^{-2}\right)$, ordinary weed biomass dry weight $\left(W D W ; \mathrm{g} \mathrm{m}^{-2}\right)$ and rice grain yields $\left(G D W ; \mathrm{t} \mathrm{ha}^{-1}\right)$ were checked for homoscedasticity (Sokal and Rohlf, 1995). Thereafter, data were analysed using a generalized linear mixed model (McCullagh and Nelder, 1989) under the assumption of a Poisson distribution for SNmax and RNmax and a linear mixed model for $S D W, R D W, W D W, G D W$. First, a log-likelihood ratio test was performed for the homogeneity of variance and, when the variance was not constant, the heterogeneity of the variances was considered.

Significance of Year $\times$ Fertility $\times$ Weeding interaction effects was tested for all parameters. Where such three-way interaction effects were observed, a model for each year (2012, 2013, 2014 and 2015) was fitted separately, where Fertility and/or Weeding and/or Fertility $\times$ Weeding were considered as fixed factors and Replicate as random factor. For each parameter, least-square means (LS-Means) of Fertility, Weeding or Fertility $\times$ Weeding were computed when appropriate. For parameters for which there was a significant effect, ANOVA's were followed by a comparison of means using Tukey's honest significant difference test.

Statistical analyses were performed in R software, Version 3.5.1 (R Core Team, 2018) using the lme4 package (Bates et al., 2015) for the ANOVA models, the lsmeans package (Lenth, 2016) for the LS-Means estimation and the multcomp package (Hothorn et al., 2008) for the Tukey multiple comparisons of means.

\section{Results}

\subsection{Striga asiatica}

In upland field experiments with S. asiatica, significant Year $\times$ Fertiliser and Year $\times$ Weeding interaction effects were observed on maximum $S$. asiatica numbers (SNmax; plants $\left.\mathrm{m}^{-2}\right), S$. asiatica biomass $\left(S D W ; \mathrm{g} \mathrm{m}^{-2}\right)$ and rice grain yield $\left(G D W ; \mathrm{t} \mathrm{ha}^{-1}\right)$ (Table 2$)$. Additionally, on rice grain yield, a significant Fertiliser $\times$ Weeding interaction effect was observed. Only for aboveground dry weight of non-parasitic weeds $\left(W D W ; \mathrm{g} \mathrm{m}^{-2}\right)$ significant interaction effects were absent. Instead, a significant Fertiliser main effect across all seasons (2012-2015) was found for this characteristic. 


\section{Chapter 4}

\subsubsection{S. asiatica number and biomass}

Parasite infection levels were significantly higher in 2012 and 2013 (82.5 and 39.1 plants $\mathrm{m}^{-2}$, respectively) than in 2014 and 2015 (1.4 and 0.2 plants $\mathrm{m}^{-2}$, respectively). As a result, $S$. asiatica biomass $(S D W)$ was only determined in the first two years. The relative ranking of fertiliser treatments, based on their effects on S. asiatica numbers (SNmax) and biomass $(S D W)$ varied across years (Tables 3 and 4). Analysed per year, highly significant $(P<0.0001)$ Fertiliser and Weeding main effects on maximum S. asiatica numbers (SNmax) were observed in the first three years (2012-2014). No significant main effects of either fertiliser or Weeding were observed on $S$. asiatica numbers in 2015. Significant fertiliser main effects on aboveground $S$. asiatica biomass dry weight $(S D W)$ were found in both years of observation (2012: $P<0.05$; 2013: $P<0.01$ ). Weeding of non-parasitic weeds had a significant effect on $S D W$ in 2013 only $(P<0.001)$.

Over the years (2012-2014), the fertiliser treatments resulted in relatively lower $S$. asiatica infection levels compared to the control treatment (Table 3). Initially, in 2012, the treatments combining organic with inorganic fertilisers resulted in parasite numbers that were significantly higher than all (in case of M + DAP) or most (in case of RH + DAP) other treatments. In the following years, these treatments consistently resulted in the lowest parasite numbers (Table 3). For the control treatment, the opposite trend was observed; whereas in the first year (2012) the mean S. asiatica number following the control treatment was amongst the lowest, it was amongst the highest in both 2013 and 2014. In 2012 and 2013, the fertiliser effects on $S D W$ were similar to the effects on SNmax (Table 4). Compared to un-weeded (UW) conditions, consistently a higher number of $S$. asiatica plants was observed under weed-free (WF) conditions (Table 3). Probably weeding created better opportunities for $S$. asiatica, and in 2013, this resulted in a significantly higher SDW under weed-free conditions.

\subsubsection{Non-parasitic weed biomass}

Non-parasitic weed biomass $(W D W)$ increased over the years (Table 5). It was significantly $(P<0.05)$ higher in the last two cropping seasons $\left(567 \mathrm{~g} \mathrm{~m}^{-2}\right.$ in 2014 and 695 in 2015), than in $2012\left(174 \mathrm{~g} \mathrm{~m}^{-2}\right)$, while the $W D W$ in 2013 was intermediate $\left(477 \mathrm{~g} \mathrm{~m}^{-2}\right)$. Compared to the 'No-Fertiliser' control treatment $\left(401 \mathrm{~g} \mathrm{~m}^{-2}\right)$, a significantly $(P<0.05)$ higher $W D W$ was obtained in plots that received NPK, manure with DAP (both $551 \mathrm{~g} \mathrm{~m}^{-2}$ ) or rice husks $(537 \mathrm{~g}$ $\mathrm{m}^{-2}$ ) (Table 5). None of the other treatments differed significantly from either the nonfertilized control treatment or the three treatments that resulted in the highest $W D W$. 
Fertiliser effects on rice yields, parasitic and ordinary weeds

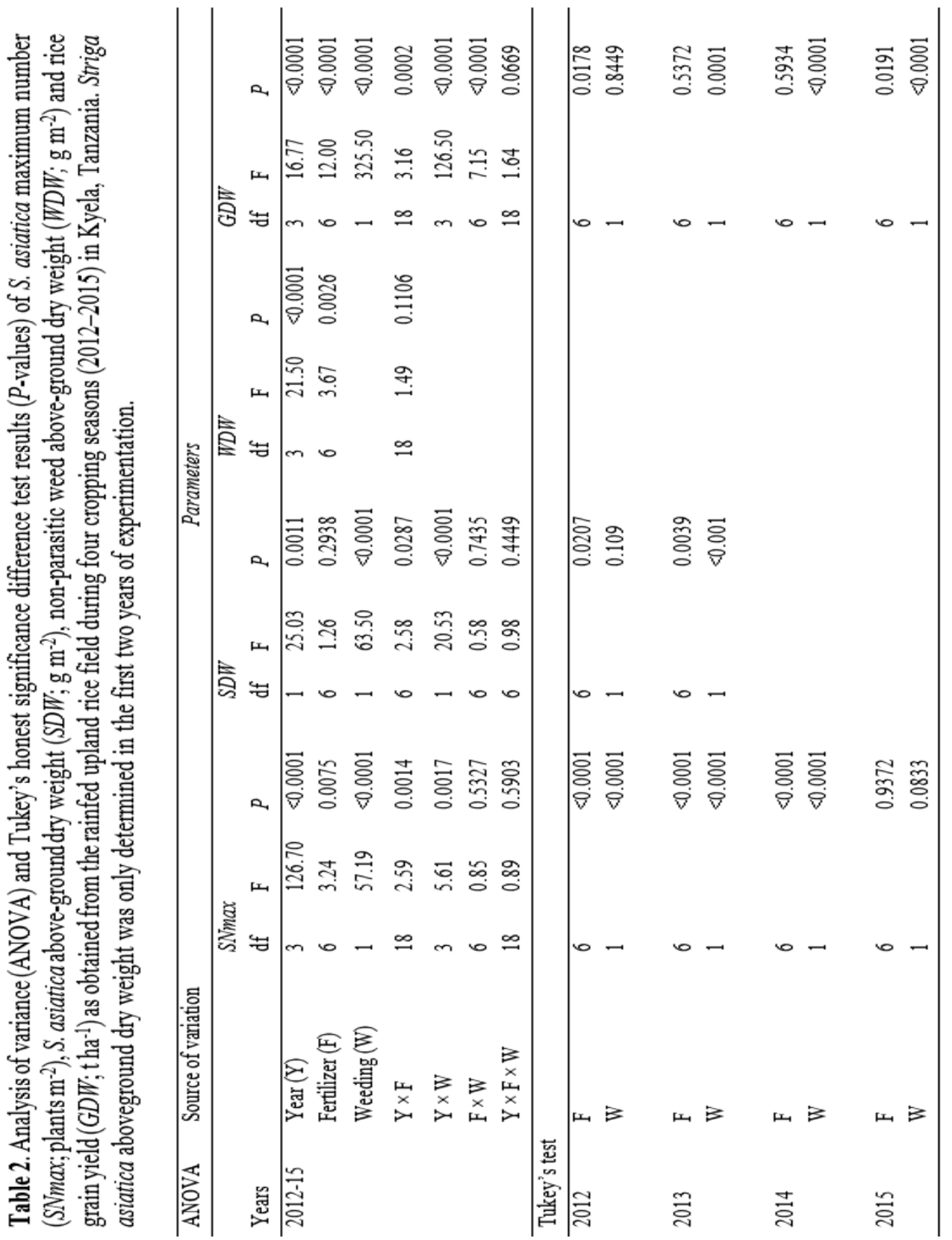

Significant fertiliser effects on rice grain yields $(G D W)$ were observed in 2012 and 2015 (Table 2). In 2012, fertiliser treatments DAP, NPK and rice husks with DAP resulted in significantly $(P<0.05)$ higher grain yields compared to the 'no-fertiliser' control and the manure-only treatment (Table 5). 


\section{Chapter 4}

Table 3. Maximum aboveground $S$. asiatica numbers (SNmax, plants $\mathrm{m}^{-2}$ ), as affected by Fertiliser and Weeding (un-weeded plots: UW; weed-free plots: WF) treatments during four cropping seasons (2012-2015) in the rainfed upland rice field in Kyela, Tanzania.

\begin{tabular}{lrlrlllll}
\hline Fertiliser & 2012 & & 2013 & 2014 & 2015 & Mean \\
\hline No-Fertiliser & 66.3 & $\mathrm{~d}$ & 47.2 & $\mathrm{ab}$ & 3.06 & $\mathrm{a}$ & 0.27 & 29.2 \\
DAP & 73.0 & $\mathrm{~cd}$ & 43.5 & $\mathrm{~b}$ & 1.56 & $\mathrm{a}-\mathrm{c}$ & 0.20 & 29.6 \\
NPK & 46.3 & $\mathrm{e}$ & 51.9 & $\mathrm{ab}$ & 0.88 & $\mathrm{bc}$ & 0.14 & 24.8 \\
M & 82.7 & $\mathrm{bc}$ & 31.0 & $\mathrm{c}$ & 1.93 & $\mathrm{ab}$ & 0.16 & 29.0 \\
RH & 85.3 & $\mathrm{~b}$ & 54.9 & $\mathrm{a}$ & 1.19 & $\mathrm{bc}$ & 0.09 & 35.4 \\
M + 1/2 DAP & 130.3 & $\mathrm{a}$ & 23.3 & $\mathrm{~d}$ & 0.62 & $\mathrm{bc}$ & 0.30 & 38.6 \\
RH + 1/2 DAP & 93.6 & $\mathrm{~b}$ & 22.0 & $\mathrm{~d}$ & 0.28 & $\mathrm{c}$ & 0.14 & 29.0 \\
Mean & 82.5 & & 39.1 & & 1.36 & & 0.19 & \\
\hline & & & & & & & & \\
Weeding & 2012 & & 2013 & & 2014 & & 2015 & Mean \\
\hline UW & 65.0 & $\mathrm{~b}$ & 14.9 & $\mathrm{~b}$ & 0.55 & $\mathrm{~b}$ & 0.09 & 20.1 \\
WF & 100.0 & $\mathrm{a}$ & 63.3 & $\mathrm{a}$ & 2.17 & $\mathrm{a}$ & 0.28 & 41.4 \\
Mean & 82.5 & & 39.1 & & 1.36 & & 0.19 & \\
\hline
\end{tabular}

Within the Fertiliser and Weeding treatments, the means followed by the same letter are not significantly different according to Tukey's honest significant difference test at $P<0.05$.

Table 4. Total aboveground $S$. asiatica dry weight $\left(S D W, \mathrm{~g} \mathrm{~m}^{-2}\right)$, as affected by Fertiliser and Weeding (un-weeded plots: UW; weed-free plots: WF) treatments during the first two cropping seasons (2012-2013) in the rainfed upland rice field in Kyela, Tanzania. During 2014 and 2015 seasons, the parasite biomass was not recorded as there were not enough $S$. asiatica plants at the end of the season.

\begin{tabular}{lrlrlr}
\hline Fertiliser & 2012 & 2013 & \multicolumn{2}{c}{ Mean } \\
\hline No-Fertiliser & 9.89 & ab & 26.5 & a-c & 18.2 \\
DAP & 6.82 & ab & 23.8 & a-c & 15.3 \\
NPK & 5.66 & b & 28.5 & ab & 17.1 \\
M & 12.6 & a & 22.7 & bc & 17.6 \\
RH & 11.2 & ab & 30.8 & a & 21.0 \\
M +1/2 DAP & 12.9 & a & 20.7 & c & 16.8 \\
RH + 1/2 DAP & 10.8 & ab & 21.1 & c & \\
Mean & 9.97 & 24.9 & & \\
\hline & & & & & \\
Weeding & 2012 & 2013 & & Mean \\
\hline UW & 7.98 & 16.9 & b & 12.5 \\
WF & 12.0 & 32.8 & a & 22.4 \\
Mean & 9.98 & 24.9 & & \\
\hline
\end{tabular}

Within the Fertiliser and Weeding treatments, means within the same year, followed by the same letter are not significantly different according to Tukey's honest significant difference test at $P<0.05$. 
Table 5. Total non-parasitic weed biomass dry weight $\left(W D W, \mathrm{~g} \mathrm{~m}^{-2}\right)$, as affected by Fertiliser treatments, and Years during four cropping seasons (2012-2015) in the rainfed upland rice field in Kyela, Tanzania.

\begin{tabular}{lll}
\hline Fertiliser & Mean & \\
\hline No-Fertiliser & 401.0 & $\mathrm{~b}$ \\
DAP & 423.3 & $\mathrm{ab}$ \\
NPK & 550.7 & $\mathrm{a}$ \\
$\mathrm{M}$ & 429.3 & $\mathrm{ab}$ \\
$\mathrm{RH}$ & 536.9 & $\mathrm{a}$ \\
$\mathrm{M}+1 / 2$ DAP & 550.8 & $\mathrm{a}$ \\
$\mathrm{RH}+1 / 2$ DAP & 456.0 & $\mathrm{ab}$ \\
Mean & 478.3 & \\
\hline & & \\
Year & Mean & \\
\hline 2012 & 174.3 & $\mathrm{c}$ \\
2013 & 477.1 & $\mathrm{~b}$ \\
2014 & 566.7 & $\mathrm{ab}$ \\
2015 & 694.9 & $\mathrm{a}$ \\
Mean & 478.3 & \\
\hline
\end{tabular}

Within Fertiliser treatment and Year, the means followed by the same letter are not significantly different according to Tukey's honest significant difference test at $P<0.05$.

Rice husk with DAP also resulted in a significantly higher yield than the manure with DAP treatments. In 2015, rice husks with or without DAP and manure with DAP resulted in a significant higher $G D W$ compared to the no-fertiliser control treatment. Rice husks with DAP also resulted in significant higher yields than the sole DAP or NPK treatments. The annual analysis for weeding showed that, with the exception of 2012, grain yields under weed-free conditions were always significantly higher than under un-weeded conditions (Table 6).

\subsubsection{Rice grain yield (GDW)}

A highly significant $(P<0.0001)$ Fertiliser $\times$ Weeding effect on rice grain yield across years was observed. Averaged over all years, no significant differences between fertiliser treatments were observed in the un-weeded plots (Table 6). Under weed-free conditions, significant differences in rice grain yields between fertiliser treatments were observed. Compared to the 'No-Fertiliser' control, significant higher yields were obtained after application of rice husks with DAP, manure with DAP or rice husks-only. Other treatments were intermediate and did not result in significant yield differences compared to either the 'No-Fertiliser' control treatment or the highest yielding treatments. Under weed-free conditions significantly higher 


\section{Chapter 4}

yields were obtained than under un-weeded conditions following the organic fertiliser treatments (Manure and Rice husks) and the combined treatments (Manure with DAP and Rice husks with DAP). Following treatments without an organic component (i.e. NoFertiliser, DAP and NPK), no significant differences between yields from weed-free and unweeded plots were observed.

Table 6. Rice grain yield ( $\left.G D W, \mathrm{t} \mathrm{ha}^{-1}\right)$, as affected by Fertiliser or Weeding main effect (unweeded plots: UW; weed-free plots: WF), and by Fertiliser $\times$ Weeding interaction effects during four cropping seasons (2012-2015) in the rainfed upland rice field in Kyela, Tanzania.

\begin{tabular}{|c|c|c|c|c|c|c|c|c|c|}
\hline Fertiliser $\times$ Weeding & UW & & WF & & & & & & \\
\hline No-Fertiliser & 0.40 & $\mathrm{~d}$ & 0.95 & b-d & & & & & \\
\hline DAP & 0.99 & $b-d$ & 1.48 & $a-c$ & & & & & \\
\hline NPK & 0.70 & $b-d$ & 1.57 & $a b$ & & & & & \\
\hline M & 0.56 & $\mathrm{~cd}$ & 1.61 & $a b$ & & & & & \\
\hline RH & 0.57 & $\mathrm{~cd}$ & 2.03 & $\mathrm{a}$ & & & & & \\
\hline$M+1 / 2 \mathrm{DAP}$ & 0.66 & b-d & 1.97 & $\mathrm{a}$ & & & & & \\
\hline $\mathrm{RH}+1 / 2 \mathrm{DAP}$ & 0.79 & $b-d$ & 2.22 & $\mathrm{a}$ & & & & & \\
\hline Mean & 0.67 & & 1.69 & & & & & & \\
\hline Fertiliser & 2012 & & 2013 & & 2014 & & 2015 & & Mean \\
\hline No-Fertiliser & 1.13 & $\mathrm{c}$ & 0.38 & & 0.95 & & 0.24 & $\mathrm{c}$ & 0.68 \\
\hline DAP & 1.71 & $a b$ & 0.73 & & 1.89 & & 0.61 & $\mathrm{bc}$ & 1.24 \\
\hline NPK & 1.62 & $a b$ & 0.53 & & 1.84 & & 0.56 & $\mathrm{bc}$ & 1.14 \\
\hline M & 1.14 & $\mathrm{c}$ & 0.62 & & 1.79 & & 0.79 & $a-c$ & 1.09 \\
\hline RH & 1.59 & $a-c$ & 0.47 & & 2.00 & & 1.14 & $\mathrm{ab}$ & 1.30 \\
\hline $\mathrm{M}+1 / 2 \mathrm{DAP}$ & 1.30 & $\mathrm{bc}$ & 0.71 & & 2.11 & & 1.14 & $\mathrm{ab}$ & 1.32 \\
\hline $\mathrm{RH}+1 / 2 \mathrm{DAP}$ & 1.83 & $\mathrm{a}$ & 0.60 & & 2.21 & & 1.38 & $\mathrm{a}$ & 1.51 \\
\hline Mean & 1.47 & & 0.58 & & 1.83 & & 0.84 & & \\
\hline Weeding & 2012 & & 2013 & & 2014 & & 2015 & & Mean \\
\hline UW & 1.49 & & 0.39 & $\mathrm{~b}$ & 0.51 & $\mathrm{~b}$ & 0.28 & $\mathrm{~b}$ & 0.67 \\
\hline WF & 1.46 & & 0.76 & $\mathrm{a}$ & 3.15 & $\mathrm{a}$ & 1.39 & $\mathrm{a}$ & 1.69 \\
\hline Mean & 1.48 & & 0.58 & & 1.83 & & 0.84 & & \\
\hline
\end{tabular}

Means within the same treatment category followed by the same letter are not significantly different according to Tukey's honest significant difference test at $P<0.05$.

\subsection{Rhamphicarpa fistulosa}

Significant $(P<0.01)$ Year $\times$ Fertiliser $\times$ Weeding interaction effects were observed on $R$. fistulosa maximum plant number (RNmax; plants $\left.\mathrm{m}^{-2}\right)$ and rice grain yield $\left(G D W ; \mathrm{t} \mathrm{ha}^{-1}\right)$ (Table 7). There were significant Fertiliser $\times$ Weeding interaction effects on RNmax in 2012, 2013 and $2014(P<0.001)$ and on $G D W$ in $2014(P<0.01)$ and $2015(P<0.001)$. In the absence 
of such interaction effects, significant main fertiliser effects were found on RNmax in 2015 and $G D W$ in 2012 and 2013. In this last year, also a significant main weeding effect was found on $G D W$. For $R$. fistulosa, dry weight $\left(R D W ; \mathrm{g} \mathrm{m}^{-2} ; P<0.0001\right)$ and the non-parasitic weed dry weight $\left(W D W ; \mathrm{g} \mathrm{m}^{-2} ; P=0.001\right)$ significant Year $\times$ Fertiliser interaction effects were observed. Further analysis showed significant fertiliser effects on $R$. fistulosa dry weight in all years $(P<0.0001)$. Fertiliser effects on non-parasitic weed dry weight $\left(W D W ; \mathrm{g} \mathrm{m}^{-2}\right)$ were only significant $(P=0.02)$ in 2014 .

\subsubsection{R. fistulosa maximum number and biomass}

Both in terms of number and biomass dry weight, the $R$. fistulosa infestation level was highest in 2012. In that year, the highest $R$. fistulosa plant number (RNmax) were observed in unweeded plots following the combination of organic and inorganic fertiliser inputs and the lowest numbers were observed in plots that received sole NPK (independent of weeding treatment) or in weed-free plots that received 'No-Fertiliser' (Table 8). Other treatments were intermediate.

In 2013, the highest $R$. fistulosa infestation level was observed under weed-free conditions after application of cattle manure, while the lowest parasite numbers were observed following sole NPK or DAP application under un-weeded conditions. Other treatments or treatment combinations, including the 'No-Fertiliser' control, resulted in intermediate parasite numbers.

During the 2014 season, the highest parasite numbers were observed under weed-free conditions, following application of organic fertilisers or combinations of organic and mineral fertilisers. Application of manure resulted also in high parasite numbers under un-weeded conditions. The lowest parasite numbers were observed under un-weeded conditions following NPK application. Other treatment combinations resulted in intermediate $R$. fistulosa infestation levels.

In 2015, only fertiliser effects on parasite numbers were observed. Application of manure with or without DAP and application of rice husks resulted in the highest $R$. fistulosa numbers. Plots receiving 'No-Fertiliser', sole NPK or rice husks with DAP had the lowest parasite infection levels, while the plots receiving DAP were intermediate (Table 8). 


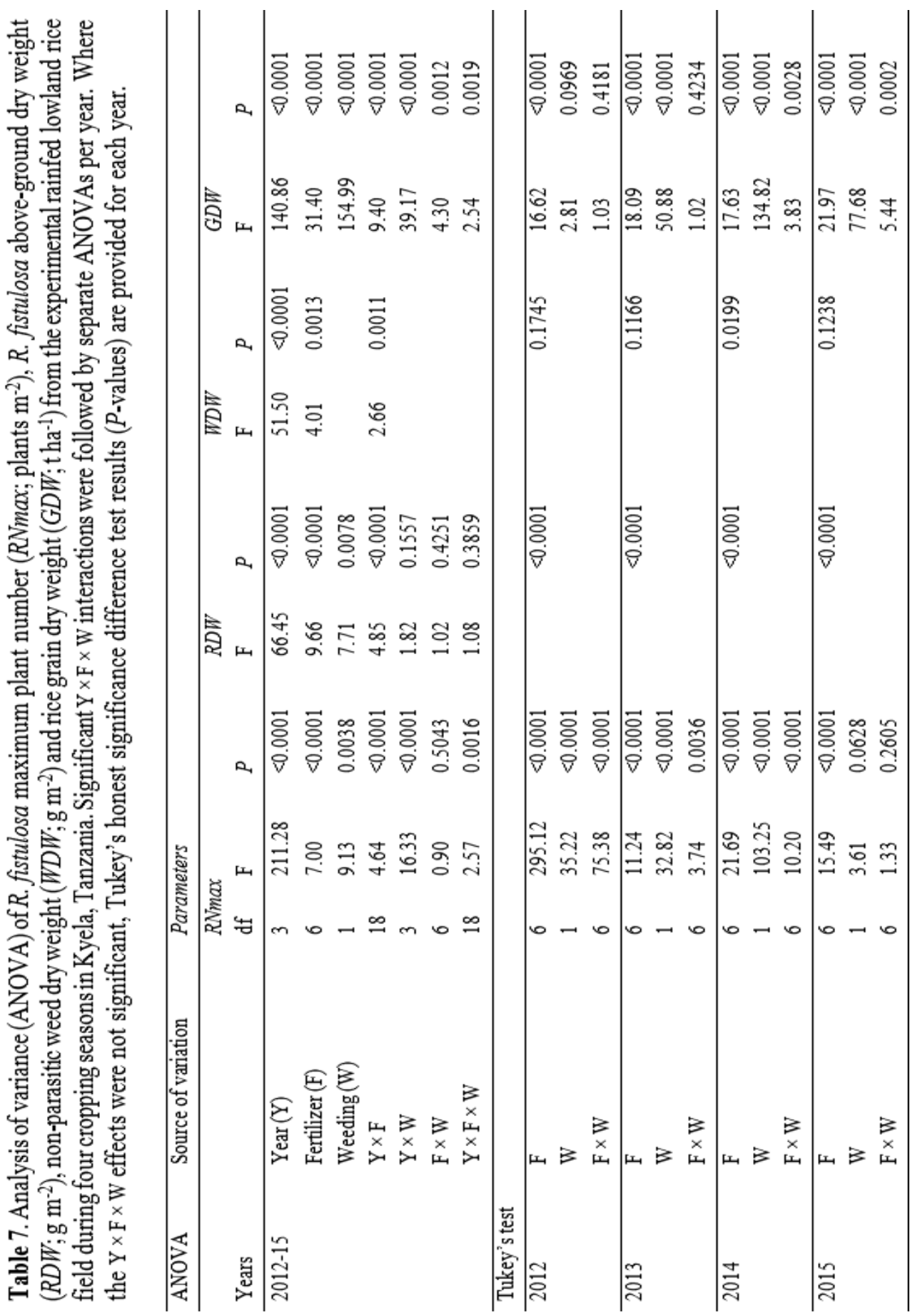


Fertiliser effects on rice yields, parasitic and ordinary weeds

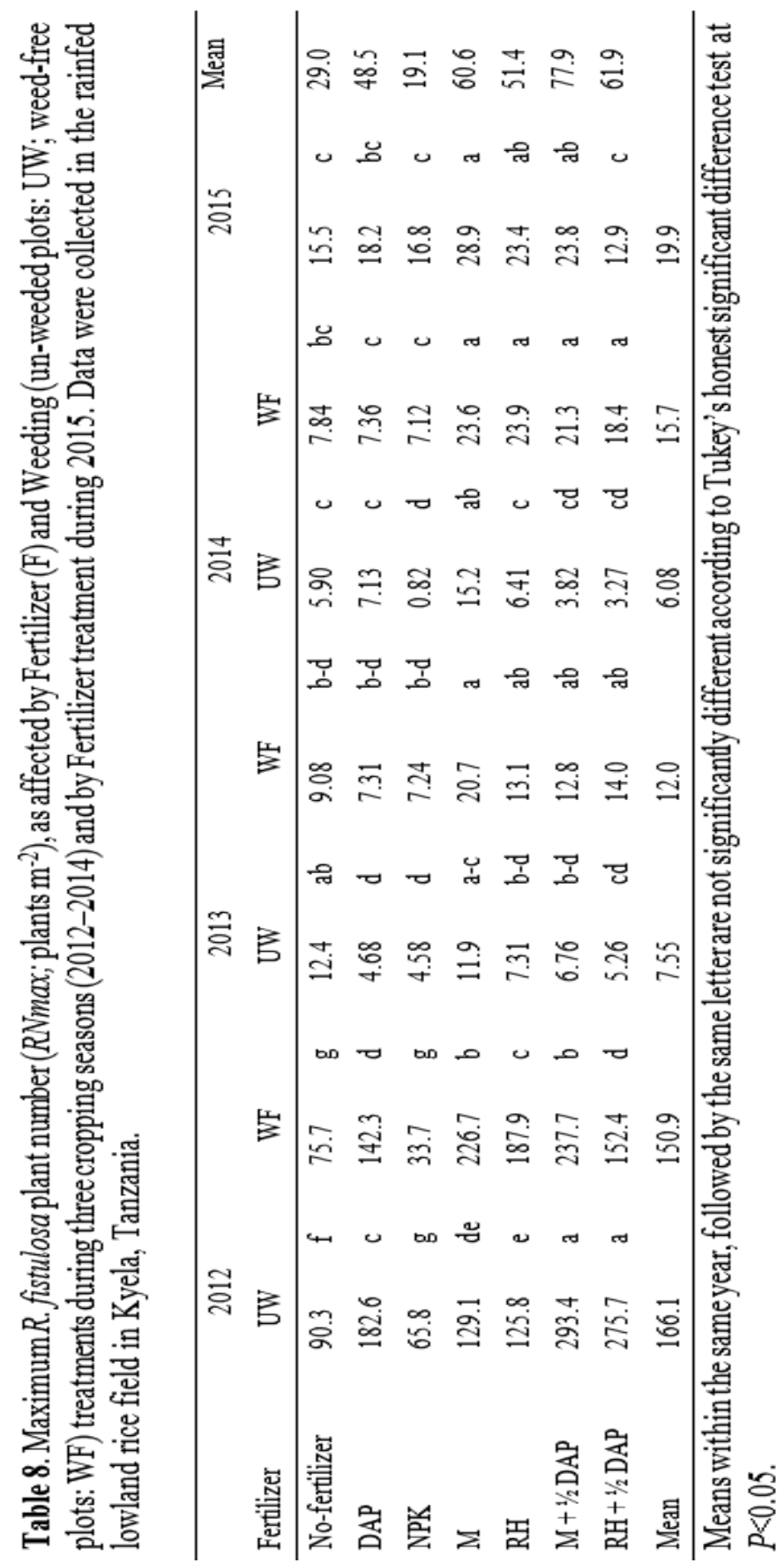




\section{Chapter 4}

Table 9. Total above-ground $R$. fistulosa dry weight $\left(R D W ; \mathrm{g} \mathrm{m}^{-2}\right)$, as affected by Fertiliser and Weeding (un-weeded plots: UW; weed-free plots: WF) treatments during four cropping seasons (2012-2015) in the rainfed lowland rice field in Kyela, Tanzania.

\begin{tabular}{|c|c|c|c|c|c|c|c|c|c|}
\hline Fertiliser & 2012 & & 2013 & & 2014 & & 2015 & & Mean \\
\hline No-Fertiliser & 111.5 & $\mathrm{bc}$ & 42.1 & $a b$ & 15.6 & $a b$ & 40.9 & $\mathrm{~b}$ & 52.5 \\
\hline DAP & 212.3 & $a-c$ & 10.3 & $\mathrm{~b}$ & 33.0 & $a b$ & 62.2 & $a b$ & 79.4 \\
\hline NPK & 94.6 & $\mathrm{c}$ & 28.4 & $a b$ & 10.1 & $\mathrm{~b}$ & 87.8 & $a b$ & 55.2 \\
\hline M & 254.3 & $\mathrm{a}$ & 69.5 & $\mathrm{a}$ & 75.3 & $\mathrm{a}$ & 111.5 & $a b$ & 127.6 \\
\hline $\mathrm{RH}$ & 224.7 & $\mathrm{ab}$ & 29.2 & $a b$ & 59.2 & $a b$ & 129.2 & $\mathrm{a}$ & 110.6 \\
\hline$M+1 / 2 \mathrm{DAP}$ & 296.7 & $\mathrm{a}$ & 21.3 & $a b$ & 34.0 & $\mathrm{ab}$ & 115.0 & $a b$ & 116.7 \\
\hline $\mathrm{RH}+1 / 2 \mathrm{DAP}$ & 257.3 & $\mathrm{a}$ & 23.0 & $a b$ & 22.0 & $a b$ & 59.0 & $a b$ & 90.3 \\
\hline Mean & 207.3 & & 32.0 & & 35.6 & & 86.5 & & \\
\hline Weeding & Mean & & & & & & & & \\
\hline UW & 100.4 & $\mathrm{a}$ & & & & & & & \\
\hline WF & 80.3 & $\mathrm{~b}$ & & & & & & & \\
\hline
\end{tabular}

Means within the same year, followed by the same letter are not significantly different according to Tukey's honest significant difference test at $P<0.05$.

Fertiliser treatment effects on R. fistulosa biomass dry weights $(R D W)$ were variable across years (Table 9). Sole application of NPK resulted in the lowest parasite biomass in 2012 and 2014. Application of DAP alone resulted in the lowest parasite biomass in 2013 while in 2015 the lowest biomass was observed in the 'No-Fertiliser' control plots (Table 9). Plots fertilised with organic fertiliser always resulted in the highest $R$. fistulosa biomass. Over the four years of experimentation, weeding of non-parasitic weeds resulted in a $20 \%$ lower parasite biomass.

\subsubsection{Non-parasitic weed biomass}

Only in 2014 a significant fertiliser effect on non-parasitic weed biomass (WDW) was observed. In this year, application of rice husks with or without additional DAP, manure with additional DAP, and NPK resulted in significantly higher weed dry weights than the "NoFertiliser' control treatment (Table 10). The other fertiliser treatments did not result in weed dry weights that were significantly different from that of the control treatment.

\subsubsection{Rice grain yield}

In 2012, a significant fertiliser effect on rice grain yields was found. Rice husks-only, rice husks with DAP and NPK-only treatments resulted in rice grain yields that were significantly higher than that following the 'No-Fertiliser' control, while the other treatments did not outperform the control treatment (Table 11). Weeding of non-parasitic weeds, did not result in 
a significantly higher yield in 2012. In 2013, the plots treated with DAP or DAP in combination with either manure, or rice husks resulted in the highest rice grain yields. Also the rice husk-only and cattle manure-only treatments resulted in yields that were significantly higher than that of the 'No-Fertiliser' control treatment. Grain dry weights $(G D W)$ under weed-free conditions were significantly higher than under un-weeded conditions.

In 2014 and 2015, significant Weeding $\times$ Fertiliser interaction effects were observed on rice grain dry weights (Table 11). The positive fertiliser effect on grain yields was most pronounced under weed-free conditions. In 2014, under un-weeded conditions, sole NPK was the only fertiliser treatment that resulted in significant higher grain yields than the "NoFertiliser' control treatment, while under weed-free conditions all fertiliser treatments, except manure application, resulted in significant higher yields than the control. In 2015, similar trends were observed. Under un-weeded conditions, it was only the application of sole DAP that resulted in significant higher yields than the 'No-Fertiliser' control treatment. Under weed-free conditions, application of DAP with or without manure or rice husks, and application of rice husks alone resulted in significantly higher yields compared to the "NoFertiliser' control.

Table 10. Total above-ground non-parasitic weed dry weight $\left(W D W ; \mathrm{g} \mathrm{m}^{-2}\right)$, as affected by Fertiliser treatment during four cropping seasons (2012-2015) in the rainfed lowland rice field in Kyela, Tanzania.

\begin{tabular}{lllllll}
\hline Fertiliser & 2012 & 2013 & 2014 & & 2015 & Mean \\
\hline No-Fertiliser & 82.0 & 3.89 & 147.8 & $\mathrm{c}$ & 40.6 & 68.6 \\
DAP & 66.8 & 6.62 & 372.7 & $\mathrm{a}-\mathrm{c}$ & 115.3 & 140.4 \\
NPK & 81.7 & 4.73 & 482.8 & $\mathrm{ab}$ & 160.2 & 182.4 \\
$\mathrm{M}$ & 82.1 & 5.78 & 306.4 & $\mathrm{bc}$ & 57.7 & 113.0 \\
$\mathrm{RH}$ & 68.3 & 6.56 & 526.1 & $\mathrm{ab}$ & 90.6 & 172.9 \\
$\mathrm{M}+1 / 2$ DAP & 76.5 & 6.96 & 441.3 & $\mathrm{ab}$ & 88.5 & 153.3 \\
RH + 1/2 DAP & 71.4 & 6.47 & 597.4 & $\mathrm{a}$ & 128.3 & 200.9 \\
Mean & 75.6 & 5.86 & 410.6 & & 97.3 & \\
\hline
\end{tabular}

Means within the same year, followed by the same letter are not significantly different according to Tukey's honest significant difference test at $P<0.05$ 
Chapter 4

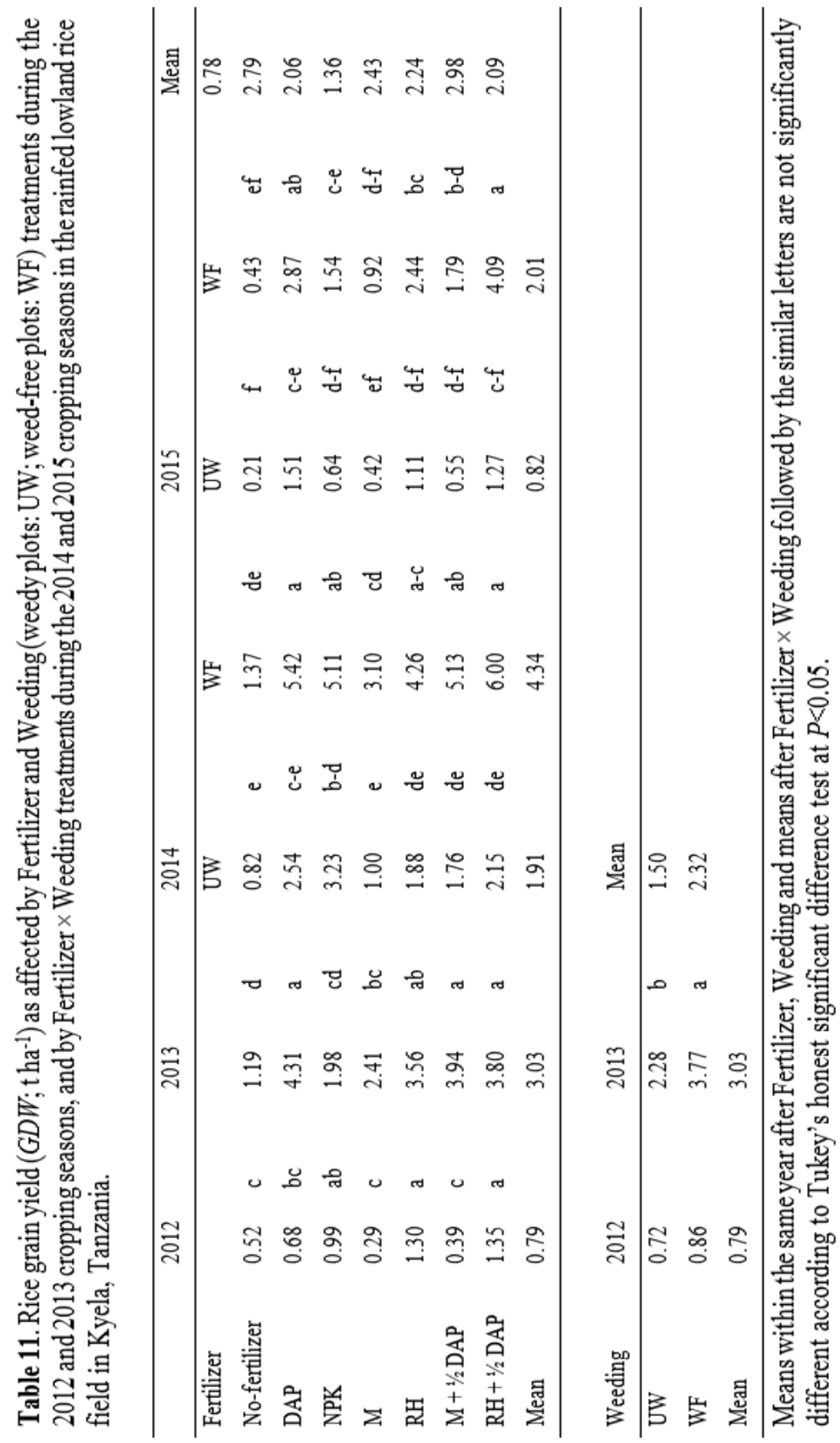




\section{Discussion}

Parasitic weeds are frequently associated with low soil fertility. Probably one of the earliest reports on this relation comes from Porteres (1948) who characterised parasitic weeds as indicators of poor (or declining) soil fertility of arable land: "The first appearance of Striga marks the moment when a less exiguous crop must be grown, or the land fallowed. Rhamphicarpa fistulosa is of similar significance". This suggests that fertilisation might be an effective management strategy against parasitic weeds. This was tested under field conditions in an experiment that lasted for four years, in a rainfed upland field infested with S. asiatica and a rainfed lowland field infested with $R$. fistulosa. The study specifically aimed at testing soil amendments that were affordable and accessible by smallholder farmers, and focussed on two research questions: (1) is there a significant effect of soil fertility amendments on $S$. asiatica / R. fistulosa infection levels in the field, and (2) do rice yields benefit from soil fertility amendments when the crop suffers from ordinary or parasitic weed infestation?

\subsection{Is there a significant effect of soil fertility amendments on $S$. asiatica / $R$. fistulosa infection levels in the field?}

For both S. asiatica and R. fistulosa the infection levels between years differed markedly. The same was true for parasitic biomass, though for $R$. fistulosa to a lesser extent than for $S$. asiatica. Compared to this annual variation, the differences brought about by the application of soil amendments were only marginal.

Variation in Striga spp. numbers between years is a common phenomenon, and is most likely the result of differences in rainfall distribution between years as previously suggested by Johnson et al. (1997) and Rodenburg et al. (2017). In the current study this seems a plausible reason as well, with low S. asiatica numbers in 2014, showing an unusual wet month of April, and in 2015 with a remarkably low rainfall throughout the season. Rodenburg et al. (2017) observed that such climatic variation did not affect the expression of varietal resistance in rice as the variety rankings based on Striga spp. numbers showed to be rather stable across years. Contrastingly, the current study showed that fertiliser effects on Striga asiatica do depend on rainfall distribution, as the ranking of the fertiliser treatments changed between years. Nevertheless, some patterns were observable. In the second and third year, soil amendments primarily reduced $S$. asiatica numbers, in particular the treatments where organic and mineral fertilisers were combined. This was remarkable, since in the first year these treatments resulted in higher infection levels than the no-fertiliser control. In the fourth year $S$. 


\section{Chapter 4}

asiatica levels were so low that no conclusion could be drawn. The differences in infection level were not translated into differences in parasite biomass. Apart from rainfall effect, observed seasonal variations in the effects of soil amendments could be the result of variations in quality of these fertilisers. Previously, Ayongwa et al. (2011) showed that in particular sub-optimal $\mathrm{N}$ rates in soil amendments could actually increase parasite numbers.

As with $S$. asiatica, seasonal differences in $R$. fistulosa have been reported before and suggested to be related to annual rainfall distribution patterns (Kabiri et al., 2015). In the current study, the lowest $R$. fistulosa infection levels were observed in 2013, the year with the highest early-season and lowest mid- and late-season rainfall. The application of soil amendments frequently resulted in increased $R$. fistulosa infection levels, mostly in terms of parasite numbers. Also in this case it were mainly the fully or partly organic amendments that created differences. In years with the highest infection levels (2012 and 2015), some of these amendments also resulted in higher parasite biomass. In some years, the inorganic fertilisers (NPK and DAP) caused a reduction in infection level. The observed higher infection levels following soil amendments, seems to contradict with a field study by N'cho et al. (2014) who observed that $R$. fistulosa incidence was negatively related to soil fertility. There are, however, other reports of fertiliser-induced shoot biomass increases of hemi-parasitic plant species (e.g. Borowicz and Armstrong, 2012). Seel et al. (1993) observed that the facultative hemi-parasite Rhinanthus minor benefited from mineral fertilisers when they were not parasitizing on a host. Possibly, a cohort of plants of the $R$. fistulosa populations in the current study was growing independently and benefited directly from additional nutrients supplied by the soil amendment treatments, just like ordinary weeds were observed to do here.

The outcomes of this study demonstrate the importance of field experimentation, as pot experiments often suggest that fertiliser application is a highly effective management strategy against parasitic weeds. A great number of studies under controlled conditions showed a clear negative relation between important soil fertility parameters, such as N and P, and Striga spp. (Jamil et al., 2013; Jamil et al., 2011a; Cechin and Press, 1993). Under comparable controlled conditions of a pot experiment, also the numbers and biomass of $R$. fistulosa showed to be negatively related with fertiliser application rates (Rodenburg et al., 2011b). Similarly with Rhinanthus minor, a facultative hemi-parasite like $R$. fistulosa, under the semi-controlled conditions of a pot experiment phosphorus fertilisation reduced the parasite biomass (Davies and Graves, 2000). The implication of such findings was the notion that fertiliser application could be a suitable strategy to reduce parasitic weed infestations in the field. 
For Striga spp., previous field studies showed that fertilisers indeed reduced infection rates, but results were less consistent than under controlled conditions (Jamil et al., 2012). Counter-intuitive effects from $\mathrm{N}$-fertiliser on Striga infection levels in the field have also been reported before, e.g. increased infection going from 120 to $150 \mathrm{~kg} \mathrm{~N}$ ha (Showemimo et al., 2002). The current study confirms that under actual field conditions the effects of fertiliser applications on $S$. asiatica are less strong and consistent than under controlled conditions. It has been suggested, by Ahonsi et al. (2002), that the lack of a clear-cut relation between Nfertiliser and Striga, in particular under field conditions, could be related to differences in activity of soil flora and fauna. They reported that when the soil microbiome was inactivated, nitrogen fertilization increased $S$. hermonthica infection levels, but when the microbiome was active the opposite effects were observed.

For R. fistulosa the applicability of findings under controlled experimental conditions was not field-tested earlier. Surprisingly, here it was found that the effects on $R$. fistulosa were quite different from what was expected based on previous results under more controlled conditions.

Evidently, the application of soil amendments, even for an extended period of time, does not provide the silver bullet for dealing with parasitic weeds and sometimes even stimulate their presence. Fertiliser effects seem to depend not just on the type and composition of fertilisers, as earlier concluded by Hearne (2009), but also on the seasonal rainfall distribution and the type of parasitic weed. The experiments show moderate differences between the parasitic weed species: $S$. asiatica is mostly suppressed while $R$. fistulosa is primarily promoted. Such a difference in response to a cultural control measure, albeit more strongly, was also observed for the effect of sowing time in another experiment. Late sowing of rice reduced $S$. asiatica infection while early sowing reduced $R$. fistulosa infection (Tippe et al., 2017b). Kabiri et al., $(2015,2016)$ previously clearly identified the differences between these two species in terms of ecology (i.e. upland vs lowland affinity) and biology (i.e. obligate vs facultative parasitism) and based on that derived the assumption that parasitic weed management strategies in rice need to be made species-specific. Interestingly, both Tippe et al. (2017b) and the current study, prove this assumption to be correct.

Another remarkable difference between the two parasitic weed species that was observed in the current study was their response to weeding of non-parasitic weeds. Weeding stimulated S. asiatica, both in terms of number and biomass. The dry weight of R. fistulosa, on the other hand, was stimulated by the presence of weeds. The negative effect of ordinary 


\section{Chapter 4}

weed presence on Striga spp. is most likely the result from competition for light. Many hemiparasitic weed species are negatively affected by shade (Borowicz and Armstrong, 2012). In fact, the availability of other weeds can have similar effects on Striga spp. as cover crops have. Apart from light reductions, such additional vegetation can increase the humidity and thereby stimulate microbial activity that in turn negatively affect Striga spp. seed viability and germination (e.g. Randrianjafizanaka et al., 2018). Reduced soil temperatures due to vegetative cover can also reduce Striga spp. seed germination rates (Carson, 1989). Finally, Striga spp. plants will also perform less under reduced temperature and increased humidity conditions, as this reduces the parasite transpiration rates required to facilitate extraction of nutrients and water from the host (Ackroyd and Graves, 1997). The positive effects of weeds on $R$. fistulosa, on the other hand, could be the result from the presence of potential host species in the weed community from which the parasite can benefit, as shown previously (Houngbédji et al., 2016). Compared to $S$. asiatica, the host range of $R$. fistulosa is presumably broad, as it includes both monocotyledons such as cereal crops, grasses and sedges and dicotyledons such as groundnut, soybean and members of the Leguminosae and Labiatae families (Bouriquet, 1933; Houngebdji and Gibot-Leclerc, 2015). Removal of weeds that had $R$. fistulosa attached to their roots could also have had a direct negative effect on these parasites.

\subsection{Do rice yields benefit from soil fertility amendments when the crop suffers from ordinary or parasitic weed infestation?}

Weeding of ordinary weeds regularly resulted in higher rice grain yields. Exceptions were observed in years with high infection levels of parasitic weeds, such as in 2012. Apparently, under such high infection rates the yield losses from parasitic weeds alone already reach a maximum level. Reports of the rice yield reducing effects of both weeds and parasitic weeds are well covered by the literature (e.g. Rodenburg et al., 2016a; Rodenburg and Johnson, 2009), but to our knowledge the current study is the first to show their combined yield reducing effects on rice.

Positive effects of fertilization on rice grain yields under weedy conditions were rare. The absence of positive effects, or even negative effects from (nitrogen) fertilisers under weedy conditions, has been frequently observed before in cereal production systems (e.g. Appleby et al., 1976; Carlson and Hill, 1985; Anderson, 1991). Negative fertiliser effects on yields seem to be mostly occurring when weed infestation levels are moderate to high. In the current 
study, positive fertiliser effects were mostly found under lowland conditions in 2013. In this year, infection levels of both ordinary weeds and $R$. fistulosa were low, creating ideal conditions for the growth promoting effects of soil amendments to come to expression. Under weed-free conditions, positive effects of soil amendments on rice grain yields were more frequently observed. Rice husk alone and rice husk or manure combined with DAP were successful under both upland and lowland conditions. While the application of DAP and NPK also frequently resulted in a higher rice grain yield than that obtained following the 'NoFertiliser' control treatment, farmers in the intervention area indicate that mineral fertilisers are too expensive and not reliably available on rural markets (Tippe et al., 2017a). Rice husks may therefore offer smallholder farmers with a suitable alternative to mineral fertilisers, as Mekuria et al. (2013), previously demonstrated this to be a low-cost technology to increase soil fertility and crop yields.

The results of this study thus make us to conclude that medium to high infestation levels, from parasitic and ordinary weed species alike, seriously undermine the potential yield increasing effect of soil amendments. Presence of ordinary weeds is a clear contributing factor to this undermining effect. Fertilisation did either have no or a positive effect on ordinary weed biomass. This means that the rice crop was not able to make use of the additional Fertiliser to turn into a more competitive crop. Evidently, the weeds also made use of the extra nutrients and did this in a better, or at least equally good, manner as the crop. It is a well-established principle that weeds become generally more competitive with the crop following fertiliser applications (e.g. DiTomaso, 1995). The timing of fertiliser applications is, however, very important in this respect (Dobermann et al., 2002). The organic soil amendments were applied all at once, in the beginning of the season, whereas the mineral fertilisers were applied in two splits. Probably the timing of fertiliser application, in particular that of the more readily available mineral fertilisers, could be better adjusted to ensure that weeds are not benefiting from it at the expense of the crop.

Ordinary weed biomass under upland conditions was always higher than in lowland conditions. In the upland field, weed biomass in the absence of weeding gradually increased over time. Obviously, by not weeding, the weed seedbank can build up and increase the weed population density in successive years, as shown previously by Davis et al. (2005). However, such a trend was absent under lowland conditions. Possibly, weed populations show a slower build up under such temporary flooded conditions because of a higher degree of decay of weed seeds and rhizomes. Weeds are generally more difficult to control under upland 


\section{Chapter 4}

conditions than under lowland conditions. Lowland rice environments usually have a narrower range of weed species (Johnson and Kent, 2002) and a lower range of crop yield losses due to uncontrolled weeds than upland environments (Rodenburg and Johnson, 2009).

\section{Conclusion}

This study has shown the utility of fertiliser application in parasitic weed infested rice fields. The direction of the fertiliser effect seems to depend on the parasitic nature of the species. We have identified moderately reduced infection rates of the obligate parasitic weed Striga asiatica, whereas fertiliser applications generally increased the biomass production of the facultative parasitic weed species Rhamphicarpa fistulosa as well as that of ordinary weeds. Positive fertiliser effects on rice grain yield were mainly found in the absence of ordinary weeds and under conditions of relatively low parasitic weed infection. The effects of fertilisers were subject to variability between years, because parasitic weeds are subject to strong year effects. Fertilisers with organic components, in particular rice husks, were found to have a more pronounced effect compared to fertilisers that are purely of mineral nature. These are highly relevant and useful findings for farmers of affected rainfed cereal production systems in sub-Saharan Africa. 
Chapter 5

General Discussion 


\section{Chapter 5}

\section{Background}

In recent years, rice has become an increasing food commodity in sub-Saharan Africa (SSA). Rice seems to better match the consumer preferences of the growing urban population, as its preparation is less cumbersome and time-consuming compared to some of the other staple foods (Seck et al., 2012). This has driven farmers to increase rice production, often by expanding arable land or by intensifying the use of already existing farmland. The area under rice in Africa has indeed increased in the last four decades (van Oort et al., 2015), and this increase has in some cases come at the expense of traditional cereal crops (Norman and Kebe, 2006). Another result of this rice area expansion is that the crop is increasingly produced on more marginal lands characterized by soils deficient of nutrients and organic matter, and in environments where invasive weed species, in particular parasitic weeds, thrive (N'Cho et al., 2014; Rodenburg et al., 2010; Gbehounou, 2003).

\section{Parasitic weeds in rice production systems of sub-Saharan Africa}

In SSA, the most important parasitic weed species in upland rice production environments are the Witchweeds: Striga asiatica (L.) Kuntze, S. hermonthica (Del.) Benth and S. aspera (Willd.) Benth. (Rodenburg and Johnson, 2009). Striga infestation is accelerated by continuous cultivation of cereal crops without proper soil fertility replenishment (Spallek et al., 2013; Ayongwa et al., 2006). Rice cultivation provides favourable conditions for these weeds to reproduce and spread, and consequently they develop into serious problems in these production systems (Parker, 2012; Rodenburg et al., 2010; Scholes and Press, 2008). In lowlands, Rice vampire weed Rhamphicarpa fistulosa (Hochst.) Benth, is the most important parasitic weed species (Rodenburg et al., 2015b; Ouédraogo et al., 1999). Rhamphicarpa fistulosa was not regarded a major problem in rainfed lowland ecosystems until rice farmers started cultivating marginal wetlands, which in some places are natural habitats of this species (Kabiri et al., 2015; Houngbedji et al., 2014). The weed species is prominent in rice production systems with poor water management and poor soil fertility (N'Cho et al., 2014).

Rice yield losses due to weed infestation in rainfed production environments in SSA are estimated to be between 16\% (upland) and 23\% (lowland), resulting in estimated monetary losses of US\$ 906 M for African economies (Rodenburg and Johnson, 2009). In SSA, about $66 \%$ of the total rice producing area can be characterised as rainfed agro-ecosystems (Diagne et al., 2013) and rice yields in these environments are only $29 \%$ (in uplands) to $80 \%$ (in lowlands) of the yields obtained under irrigated conditions (Tanaka et al., 2017). The low productivity of the rainfed 
environments is the result of a myriad of constraints, among which weeds and parasitic weeds. Parasitic weed invasions not only result in severe crop losses, but frequently drive farmers to abandon their fields (Houngbedji et al., 2014; N'Cho et al., 2014). Striga spp. occur in 31 African countries with upland rice, while $R$. fistulosa occurs in 28 countries with rainfed lowland rice, and together these weeds are estimated to negatively affect 1.3 million ha, leading to production losses of nearly 0.5 million tonnes of milled rice (worth US \$200 million) per year (Rodenburg et al., 2016).

Evidence from literature in support of an increase of parasitic weeds in rice in the course of time is limited. Rhamphicarpa fistulosa has been reported to increase in Benin (Rodenburg et al., 2011a) and Uganda (Rodenburg et al., 2015b), while the rice area infested by S. hermonthica is reportedly increasing in Ghana (Aflakpui et al., 2008) and Côte d'Ivoire (Kouakou et al., 2015). Based on data presented by these studies, the rice area infested by parasitic weeds is projected to increase by 1.2 to $2.2 \%$ per year in sub-Saharan Africa (Rodenburg et al., 20016b). Apart from the aforementioned expansion of (marginal) arable land, Parker (2012) suggested that an increase of this type of weeds is likely to be stimulated by on-going, unsustainable crop production intensification with losses in soil fertility and an increased rainfall variability due to climate change.

\section{Why are parasitic weeds in smallholder rice systems such a wicked problem?}

Biotic agricultural production constraints, like insect pests, diseases and weeds, are generally controlled through curative control measures combined with the use of resistant varieties (Oerke, 2006). Since rice producers in SSA are resource-poor with little access to external inputs, they primarily rely on hand weeding to minimize parasitic weed infection in rice (Chapter 2, this thesis). This measure is both very labour intensive and often ineffective, as Striga spp. already causes considerable damage well before its emergence aboveground (Dugje et al., 2006; Emechebe et al., 2004). Mechanical weeding, like the use of a hoe, has similar limitations. On top of that, hoe weeding requires row planting, which brings an additional cost due to the high additional labour requirement for crop establishment (Chapter 2, this thesis).

In some cases, farmers apply herbicides to kill non-parasitic weeds, and combining this with hand weeding could be an effective method for farmers in lowlands to control R. fistulosa in SSA (Rodenburg et al., 2011b). In contrast to Striga spp., R. fistulosa does not have a belowground phase and this potentially allows to control the weed plant before damage is done. However, an important constraint to chemical control is that application of herbicides requires knowledge on 


\section{Chapter 5}

suitable products, application rates and timing to be effective and to avoid phytotoxic effects on the crop (Rodenburg et al., 2015c). In Kyela (Tanzania), we observed farmers that use herbicides (usually in small amounts) to control ordinary weeds, including R. fistulosa. Unfortunately, in this area farmers mostly use the wrong herbicide products like ametryn-atrazine, a herbicide that is often used to kill sugarcane ratoons but can also kill other grass species including rice. Farmers in this study mentioned that they are not relying on the recommended herbicides because of the high costs associated with these products (Chapter 2, this thesis). This price-induced farmer preference towards cheap but suboptimal, and often unsuitable, herbicide products is observed across the continent (Rodenburg et al., 2019; Haggblade et al., 2017). One example of effective herbicide application against Striga spp., the use of imazapyr resistant herbicide-coated maize seed (De Groote et al., 2008; Kanampiu et al., 2002), has not been developed for rice yet. It is also highly questionable that such herbicide technologies will be a viable business model for the herbicide industry due to marginal profits in smallholder rice systems in Africa (Demont et al., 2009). Finally, this technology is not well adapted to production systems of smallholder rice farmers working in rainfed agro-ecosystems, because they use their own harvested seeds (e.g. Chapter 2, this thesis), and formal seed systems for rice are either absent or dysfunctional in remote rural areas.

Farmers also demonstrated awareness of the existence and potential of resistant varieties (Chapter 2, this thesis). At the same time, apart from the poor accessibility to certified seeds, the strong consumer preferences for local varieties have made farmers reluctant to adopt improved varieties. In sorghum, Mrema et al. (2017) noted that the adoption rate of Striga-resistant varieties was low due to a lack of locally preferred traits. Grain size, shape, taste and aroma are among the preferred varietal attributes of rice that secure a good price at the local market in Tanzania (Singh et al., 2013). Rice varieties resistant against the parasitic weeds $S$. asiatica and $R$. fistulosa have been identified (Rodenburg et al., 2015a, 2016b, 2017), but as long as these varieties are not easily accessible to farmers and are not made more attractive for uptake, by introgressing consumer-preferred grain traits like the ones mentioned above, they may not make much difference.

Earlier, Rodenburg and Johnson (2009) concluded that, for smallholder farmers in subSaharan Africa the labour scarcities and poor accessibility to information, inputs and financial credit are factors that predominantly constrain production. The above illustrates that these factors also very much hinder the combat against parasitic weeds in rainfed rice production systems, rendering this a truly wicked problem. The limited number of feasible and effective options for 
parasitic weed management poses a threat to the food security and income generation of smallholder farmers (N'Cho et al., 2014).

\section{The role of cultural control measures}

The above situation strongly suggests that, next to curative control and the use of resistant varieties, farmers' toolkits should be enriched with more options if the aim is to construct a sustainable integrated parasitic weed management strategy. Cultural weed control measures, defined as any modification to the general management of the crop that contributes to the regulation of weed populations or reduces the negative impact of weeds on crop production, are an obvious addition. For weed management, the interest in cultural control measures is increasing, not only in poor countries, but also in rich countries, albeit for mostly different reasons (e.g. Melander et al., 2005). In rich countries, the strong dependence on chemical curative weed control is an important motive in the search for alternative measures. This heavy reliance implies an extensive use of compounds with a potential negative side effect on food safety, public health and the environment. Furthermore, cropping systems with a narrow focus on herbicidal control are becoming increasingly vulnerable, as herbicide resistance and more strict regulations with regard to herbicides are frequently creating situations where part of the weed community can no longer be controlled by chemical means (Heap, 2013).

There are some obvious differences between curative and cultural control measures. Rather than removal of weed seedlings (i.e. the purpose of curative control), cultural control measures tend to consider a wider array of life-cycle stages of weeds. As such curative control is more directed at a reduced recruitment of weed seedlings, at a reduced impact of the weeds on crop production or at a gradual decline of the weed seedbank (Bastiaans et al., 2007). Despite their potential, adoption of cultural control measures is only steadily progressing and a number of hindrances have been identified (Bastiaans et al., 2008; Liebman et al., 2016). Cultural control measures frequently lack general applicability, as they are only appropriate with certain crops, against particular weeds or in specific environments. An increased seeding rate, frequently used as a weed control measure in small cereal grains, is for instance, not suitable for crops like maize, where the highest marketable yield is obtained at a relatively small plant density range. Seeding beyond this optimum will evoke a too strong level of intraspecific competition and have direct negative consequences for maize cob yield. Another example is the lack of interest in the use of stale seed beds in water-scarce regions. This strategy requires delayed planting, as the crop is only sown after the induced weed flush following seedbed preparation is removed (Rao et al., 
2007). Under rain-fed conditions, delayed sowing might easily result in severe reductions in crop yield following from water shortage during the final part of the growing season. This is what makes the measure risky for this specific environment. In addition, the efficacy of cultural control measures is usually well below that of curative control measures, or the result is highly variable and depending on environmental conditions. For some of the measures, efficacy and reliability have simply not been established under field conditions.

Another important matter is that application of cultural control measures not only affects weeds. Adjustment of specific crop management practices, or adjustment of cropping systems design, to achieve improved weed control might be at the cost of other objectives. Such tradeoffs might easily render a measure less suitable. The earlier mentioned Crop Protection Programme on promotion of green manure for enhancing rice productivity on Striga infested fields (Mbwaga, 2005) provides a clear example of this. Using Crotalaria ochroleuca in rotation with rice on Striga infested soils in Kyela showed very promising results, as the rotation system resulted in severe reduction in Striga infestation. Ten years later, many farmers in the area still ranked crop rotation, just like intercropping with leguminous species, among the best possible control strategies (Chapter 2, this thesis). At the same time, the system is not widely practised anymore. Farmers mentioned that reduction of the area under rice, a direct consequence of applying crop rotation, would immediately result in a reduced income. It illustrates that farmers have no financial buffer that allows them to envisage the parasitic weed problem in a longer time perspective. Evidently, they are in need of measures that can be implemented at low cost and result in an immediate return on investment.

\section{Farmer perception and field efficacy of two selected cultural control measures}

To be able to reflect and align the proposed cultural control measures for parasitic weed management in rainfed rice production systems to the possibilities and needs of the farmers the current research used a two-pronged approach: acquiring farmers' views on alternative weed control measures through a wide range of activities and establishing the effectiveness of two cultural control measures through field testing. This approach was followed for S. asiatica in upland and for $R$. fistulosa in lowland conditions.

The first part centred around the perception of farmers, as a key step in problem solving is to assess whether and how the problem is perceived by those that are affected. Farmers surveyed in this study were aware of the existence of parasitic weeds, though usually only of the species that was prominent in their region (Chapter 2, this thesis). The parasitic character of the weed 
was recognized, as both withdrawal of nutrients and a weakening of the rice plant were frequently mentioned by farmers as the way the weed affected its host. To some extent, this insight might be a result of earlier projects on $S$. asiatica, conducted in collaboration with the National Resources Institute from the UK, that were held in the same region. Here attention was given to the incorporation of knowledge on Striga in teaching curriculum for primary school pupils (Mbwaga, 2003). Farmers considered S. asiatica and R. fistulosa to be more important problems for rice production than ordinary weeds and about half of them perceived that the parasitic weed problem had increased over time. For controlling these weeds, the large majority of farmers used the same control method as for non-parasitic weeds, i.e. hand weeding. Farmers indicated that in order for an alternative parasitic weed control strategy to be acceptable and adoptable, the technology should be (1) locally accessible, (2) easy to implement, (3) effective and (4) of low costs (Chapter 2). During the surveys and workshops it became evident that farmers are generally aware of potential solutions that go beyond the current practice of hand weeding. Factors that the surveys revealed as keeping farmers from implementing them included: a lack of resources (e.g. money or land) to acquire or implement solutions and the (perceived) trade-offs associated with many control options. In addition to being interviewed, farmers were also invited to visit the sites where two cultural control measures were field-tested and they were asked about their opinion on the suitability of these measures for managing $S$. asiatica in upland and R. fistulosa in lowland conditions. Finally, groups of farmers were asked to install their preferred combination of measures in their own crop and compare these measures with their usual practice of growing rice.

The second part of this study was about the actual field-testing of two cultural control measures. Here the main aim was to establish their efficacy under field conditions. The measures were selected based on informal discussions with farmers in the area where the experiments were laid out. Note that these informal discussions were conducted prior to the interviews discussed in the previous paragraph and reported in Chapter 2. The first of the selected measures, sowing time, was proposed based on these farmers' experience with $S$. asiatica. They were of the impression that delayed sowing results in lower Striga-infestation levels. This observation seems in line with the knowledge on the ecology of this parasitic weed. Seeds of obligate parasitic weed species will only germinate when exposed to root exudates of their host plants. This mechanism causes germination to be synchronized with the presence of a host plant (Westwood et al., 2010). After pre-conditioning, initiated by the wetting (usually the onset of the wet season), seeds become responsive to these root exudates. If, however, after pre-conditioning, seeds are not exposed to root exudates, the seeds will go back into a state of dormancy (Rich and Ejeta, 2007). 


\section{Chapter 5}

This makes delayed sowing of rice a potential strategy to escape or reduce infection by obligate parasites. But in spite of these promising indications, effectiveness of this strategy to manage parasitic weeds under uncontrolled farm field conditions had not been tested. Furthermore, prior to this study it was unknown whether this strategy could also work for R. fistulosa, a facultative parasitic weed species that does not require host-derived germination cues,. Farmers also mentioned their concerns related to delayed planting. Particularly under upland conditions, where $S$. asiatica prevails, and in seasons with a low amount or irregular pattern of precipitation, delayed sowing might easily result in drought stress during grain filling. In the absence of possibilities to irrigate the experimental upland site, it was decided to include two additional rice varieties, with shorter growth duration, in the experiment. This tripled the size of the experiment, but in this way the influence of late season drought stress on crop production could be ascertained and potentially addressed, in an indirect manner.

The second cultural control measure that was selected for field-testing was the use of soil amendments. Parasitic weeds are frequently classified as indicators of poor soil fertility. The incidence of parasitic weeds and their negative effects on crop production are often assumed to be considerably lower, or even completely absent, under more fertile conditions. Under controlled conditions, in pot experiments, mineral fertilisers have indeed shown effective in reducing parasitic weed (both $R$. fistulosa and Striga spp.) infection levels (Jamil et al., 2011a; Rodenburg et al., 2011a). Fertilisers generally increase crop growth rate and crop plants may simply become more tolerant, resistant or competitive against weeds (Andrew et al., 2015; Blackshaw et al., 2005). Additionally, a higher uptake of nitrogen and phosphorus fertilisers by the host, reduces the amounts of strigolactones released by host plant roots (Screpanti et al., 2016). Striga spp. use strigolactones as a trigger for germination and therefore a lower production of this hormone may ultimately reduce Striga infection. Greenhouse experiments indeed confirmed that fertilization resulted in lowered infection levels (Jamil, et al., 2012), whereas field experiments with $S$. asiatica in rice showed that the application of urea resulted in lower parasite infection levels (Mbwaga, 2001). Farmers however were not supportive of using mineral fertilisers, as they considered them too expensive. For that reason, cheaper organic options were also tested in the current experiments. The use of organic material sources like rice husks and cattle manure as fertilisers increases the organic matter content of the soil, which in turn enhances soil biological activities and thereby increases the decay and predation rates of weed seeds (Celik et al., 2004) which in turn may reduce the parasitic weed seed bank. Since such an effect might only become apparent after a number of years, the experiment was maintained for a period of 
four years. Treatments with mineral fertilisers and combinations of mineral and organic fertilisers were included for comparison. Whether and how the application of soil amendments would affect a facultative parasitic weed, like $R$. fistulosa, was the most important research question here.

\subsection{Sowing time as control option for managing $S$. asiatica and $R$. fistulosa}

For both the obligate (S. asiatica) and facultative ( $R$. fistulosa) parasitic weeds the researchermanaged on-farm experiments showed a clear effect of sowing time on parasite infection level and parasite biomass (Chapter 3, this thesis). These effects were most evident in years with high infection levels: 2013 for S. asiatica and 2012 for R. fistulosa. But direction of the sowing time effect was opposite for the obligate than for the facultative parasite. For the obligate $S$. asiatica, delayed sowing resulted in gradual reductions in parasite number and parasite biomass, whereas for the facultative $R$. fistulosa the opposite was observed: a gradual increase in parasite number and parasite biomass with delayed sowing. Reductions in S. asiatica infection level following from delayed planting did not necessarily translate into higher rice yields, due to increased chances of drought stress during kernel filling. This particularly held for the traditional rice varieties Supa India and Mwangulu, whereas this risk was mitigated by the use of an improved early-maturing variety (NERICA-14). For R. fistulosa, the differences in parasite biomass between sowing times and years were clearly reflected in rice grain yield, irrespective of rice variety. In years with the highest infection levels, 2012 and 2013, rice grain yield gradually reduced with a delay in sowing time. In 2014, with a relatively mild infection level, no significant effect of sowing time on rice grain yield was observed. The pot experiments conducted under controlled conditions confirmed these responses.

At the start of the first year of experimentation, during the workshops, farmers characterized late planting as an effective option for escaping $S$. asiatica. They also pointed at the risk of drought stress during the crop ripening, when this strategy was applied with their traditional late maturing varieties. During field evaluations, this view was confirmed, as the short-duration rice variety NERICA-14 was selected as the preferred variety (Chapter 2, this thesis). The importance of a suitable variety for the success of delayed planting as a control strategy for S. asiatica was further emphasized after the farmer-managed field-trial, when the majority of farmers selected late sowing combined with NERICA-10 as the best way to combat $S$. asiatica. NERICA-10 was described as an early maturing variety with good grain appearance and $S$. asiatica resistance. Further advantages of delayed planting that were brought up during field evaluations were minimal bird damage and the possibility of early weed control. 


\section{Chapter 5}

During the workshops, early planting and/or use of early maturing rice varieties were frequently mentioned as potential strategy for combating $R$. fistulosa. The further implications of an early and relatively short growing season were discussed. At the positive side, reduced hunger due to earlier food supply, a better price on the market and increased time for land preparation for the next crop were mentioned. Untimely, availability of agro-inputs, higher intensity of ordinary weeds, higher costs of bird control and higher social pressure to lend rice to neighbours were brought up as disadvantages. During field evaluations, the effectiveness of early sowing as control measure for $R$. fistulosa was confirmed and reflected in the preference for early sowing dates. Such a confirmation was not obtained for the role of early maturing varieties, as the traditional rice variety Supa India maintained itself as a popular variety. The evaluation after the farmer-managed field trial confirmed this view, as early sowing combined with Supa India was selected as the best way to combat $R$. fistulosa. Making sure sowing is completed before fields get flooded was mentioned as an additional advantage of early planting, whereas concerns were expressed regarding an increased risk of infection by Rice Yellow Mottle Virus.

\subsection{Soil amendments and their influence on parasitic weed infestation level}

The relevance of the research question whether soil amendments would comprise an additional control option against $R$. fistulosa, was confirmed by the results of this experiment. Whereas moderately reduced infection rates of $S$. asiatica were observed, fertiliser applications had an opposite effect on $R$. fistulosa plants that generally showed increased biomass production. Alongside this undesired effect, positive soil amendment effects were observed on rice grain yield, in particular following applications of rice husks. Positive effects on yield were most prominent under low infestation levels of parasitic weeds and in the absence of ordinary weeds, and it was therefore concluded that this practice should always be combined with effective and timely (parasitic) weed management options (Chapter 4, this thesis).

At the start of the experimentation, during the workshops, mineral and organic fertilisers were listed among the potential options for reducing parasitic weed infestation levels. Neither for S. asiatica nor for $R$. fistulosa, this option received a top ranking. Farmers considered the use of mineral fertilisers an expensive option, whereas manure was believed to increase the ordinary weed infestation level. At the same time, these measures were considered to have positive effects beyond the control of parasitic weeds, like a positive effect on soil fertility and thus crop yield. During the field evaluations, no clear differences in parasite infection levels were observed and treatments were thus assessed based on the general appearance of the rice crop. Treatments 
containing rice husks were clearly preferred, and farmers mentioned the affordability of this soil amendment as an important consideration. Evaluations after the farmer-managed field trial indicated that the combination of rice husks with a reduced rate of DAP and urea was most frequently selected as the preferred option. Also in this case this selection was driven by financial reasons: the realization that application of the relatively cheap rice husks allowed farmers to substantially reduce the rates of the relatively expensive mineral fertilisers.

\section{Final considerations}

\subsection{Potential of cultural control measures}

Two measures were investigated: sowing time and soil amendments. Results of soil amendments towards reducing parasitic weed infection levels and their related damage were disappointing. Only with $S$. asiatica a small reduction was observed, whereas with $R$. fistulosa an increase was observed. Expectations were based on the common notion that parasitic weeds are indicators of poor soil fertility and the implicit belief that improving soil fertility would thus lower parasite infection levels. Four years of field experimentation showed that it is not necessarily as simple as that. On the up side, fertilisers, in particular the cheaper organic substitutes (rice husks) of mineral fertilisers, contributed to improved rice yields, where (parasitic) weed infestation levels were low to moderate. This implies that when combined with other, more effective, (parasitic) weed control practices, rice husks would be a good and affordable means for farmers to boost their crop output. At the same time, it should be noted that, with 10 ton $^{-1}{ }^{-1}$, the actual amounts of rice husks in the current experiments were unrealistically high. In the experiments this amount was used to evoke an effect, but with rice yields in the order of 2-3.5 ton ha ${ }^{-1}$, its evident that annual application rates of 10 ton $\mathrm{ha}^{-1}$ are far from realistic.

Results of sowing time hold promise. It is a measure that is in line with all the requirements of a successful measure: easy to implement, affordable and with low direct costs. The value of the experiments carried out in this study is that they revealed more information on the fourth aspect: effectiveness. Both for S. asiatica and R. fistulosa significant effects were observed. Nonetheless, it is evident that this measure applied in isolation is not sufficient to manage parasitic weeds. This is what is generally observed: only when several cultural control measures are combined it is possible to realize effective control, a phenomenon referred to as the strategy of the many little hammers (Liebman and Gallandt, 1997). This is also what abiotic stress factors, such as nutrient deficiency, differentiate from biotic production constraints, such as weeds. Plant nutrition response curves show that under nutrient-deficient conditions, the addition of the first 


\section{Chapter 5}

dose of fertiliser creates the greatest benefit. With a further increase the yield is likely to further increase, but at a slower pace: the law of diminishing returns. With biotic stressors such as weeds this is different. Lowering the infestation level a little bit is generally not having an effect at all. It just alleviates the intraspecific competition among weed plants, but doesn't have a major impact on the yield of the crop. Only a major reduction in weed infestation level, tends to have a significant effect on crop yield.

In search for additional curative control measures, the farmer managed field trials suggest that focusing on resistant and/or tolerant rice varieties seems the best bet. Under upland conditions and after a year with high $S$. asiatica infestation levels, farmers indicated to have preference for a modern resistant variety, like NERICA-10, despite the absence of favoured grain qualities like taste and aroma. Whether this preference still holds after a number of years with low Striga infestation remains a question, as farmers during surveys, workshops and field visits always mentioned the importance of the specific taste and aroma of their traditional varieties. is however questionable. What really is needed is the introgression of consumer-preferred grain traits in the resistant rice varieties.

\subsection{Specificity of cultural control measures}

Next to the increasing importance of parasitic weeds in rice production systems, another driver for the current research project was the facultative nature of the relatively new parasitic weed $R$. fistulosa. Its facultative character clearly distinguishes this species from the obligate Striga species; essentially facultative and obligate parasitism can be considered clearly distinct ecological strategies. These differences between the ecology (i.e. upland vs lowland affinity) and the biology (i.e. obligate vs facultative parasitism) of $R$. fistulosa and S. asiatica were the main focus of another PhD-study within the PARASITE-project (Kabiri, 2017). Based on her study, Kabiri (2017) suggested that parasitic weed management strategies in rice need to be attuned to the ecological strategy of the parasite in question. The current study confirmed this; dealing with a facultative parasite seems quite different from dealing with an obligate one. Clear differences were manifested in the contrasting response of the two parasitic weed species to the proposed cultural control measures. Soil amendments provided a slight control of $S$. asiatica, whereas $R$. fistulosa benefitted from fertilisers application. An even larger difference was observed with sowing time: delayed planting reduced $S$. asiatica infection whereas early planting did this for $R$. fistulosa. Biologically this last difference can be explained. Dormancy of seeds of S. asiatica is released after wetting. At the same time, the seeds become responsive to host root exudates. In 
the absence of these exudates, the seeds will go back into dormancy. Delayed planting will cause this to happen and it explains why, with this parasite, this measure will result in lower infection levels. The seeds of R. fistulosa on the other hand, need light and moist to germinate. At the start of the wet season, those seeds that are close enough to the soil surface will germinate. Before they are able to connect to a host plant, their root systems need to develop, to get in the close proximity of a host root. Since seeds and thus seedlings are extremely small, it takes a long time before this will occur. Early planting therefore offers a means to escape or delay infection. Unlike curative control, which simply tries to kill and remove weed plants, these more subtle interferences with the biology of the species causes the measure to be species-specific.

\subsection{Involvement of farmers in the research project}

Next to the experiments to resolve the efficacy of cultural control measures at field level, also the involvement of farmers was an important element of this study. Farmers' involvement consisted of four stages: 1) Surveys were held to establish the current knowledge of farmers on parasitic weeds and their actual management strategies; 2) Workshops were held as a follow up to get a better understanding of the pros and cons of various potential control measures and to better appreciate based on which criteria control measures are valued; 3) Technology evaluations were organized during the experimental cropping seasons, where farmers were invited to visually inspect the experiments and to indicate their preferred treatments; 4) Participatory evaluation was held in the final season, when small groups of farmers were encouraged to install a management strategy on a field on their own farm. Prior to installation their motivation for the selected strategy was discussed and afterwards their views and considerations regarding the measures were collected.

Farmers' involvement was crucially important and helped to put this research in a proper context. The interactions with farmers exposed the importance of parasitic weeds from their point of view, revealed their awareness of the problem and their current practices to manage parasitic weeds. Discussions also unfolded the hurdles and hindrances related to many of the potential control measures as experienced by farmers. Through that, we learned about implications of the field-tested measures that are not directly relevant for parasitic weed management, but are important for other reasons. We also learned about their fears, like the expected enhanced infestation levels of ordinary weeds after manure application, that were not observed in our experiments. 


\section{Chapter 5}

Farmer participatory research is encouraged for a number of reasons (Le Gal et al., 2011). Here it was the involvement of the farmers in the final stage, that most closely resembled this type of research. Farmers installed the measures themselves, experienced the consequences of the measures in a more intense manner and were able to directly compare the results with that of their current practices. Some interesting notions were made during this part of the research. Most notably was the appreciation for the resistant variety NERICA-10 by upland farmers. Though in the previous activities the preference for local varieties was stressed time after time, a majority of farmers indicated a preference for NERICA-10 at the end of the season. Important reasons for this change were the high level of resistance expressed by this variety during a season with heavy $S$. asiatica infection levels. Next to that, its earliness, allowing for crop maturity before drought began to interfere with crop production, and its good grain appearance were praised. This shows that such real-life experiences are able to open the mind for new developments.

\subsection{Need for institutional involvement}

Since the project was designed as a research project, it is evident that only a small part of the farmer community got involved. To have a greater outreach, communication channels should be used and set up to create an easy transfer of new and available knowledge to the farmer community at large. Here there is a clear role for governmental institutions and extension services. In the earlier referred NRI-project, teachers at elementary schools were selected as the target group to spread general knowledge on parasitic weeds to the rural community. Next to information, also the poor access to inputs and financial credits were regularly mentioned as major hindrances to further progress. This aligns with the analysis of Rodenburg and Johnson (2009), who concluded that for smallholder farmers in sub-Saharan Africa poor accessibility to information, inputs and financial credits are the true crop production constraints. Seed systems, that guarantee easy access to newly developed varieties and introgression of favourable grain quality traits into modern resistant cultivars were also identified as important. Such improvements, related to infrastructure and breeding activities are out of reach of local farmer groups, let alone individual smallholder farmers. It shows that parasitic weed management is not just an item at farm and field level, but that it requires innovations at institutional and policymaker level to make a real change (Schut et al, 2015a). Only when such improvements are realized, will the measures uncovered by the current project be able to truly help advance farmers' fight against parasitic weeds to its full potential. 
References 


\section{References}

Ackroyd, R., Graves, J. 1997. The regulation of the water potential gradient in the host and parasite relationship between Sorghum bicolor and Striga hermonthica. Ann. Bot. 80, 649-656.

Aflakpui, G. K., Bolfrey-Arku, G. E.-K., Anchirinah, V., Manu-Aduening, J. \& Adu-Tutu, K. 2008. Incidence and severity of Striga spp. in the coastal savanna zone of Ghana: results and implications of a formal survey. Outlook on Agriculture 37, 219-224.

Ahonsi, M.O., Berner, D.K., Emechebe, M.A., Lagoke, S.T. 2002. Effects of soil pasteurisation and soil N status on severity of Striga hermonthica (Del.) Benth. in maize. Soil Bio. and Bioch. 34, $1675-1681$

Allah, A.A., Ammar, M., Badawi, A. 2010. Screening rice genotypes for drought resistance in Egypt. J. Plant Breed. Crop Sci. 2, 205-215.

Anderson R.L. 1991. Timing of nitrogen application affects downy brome (Bromus tectorum) growth in winter wheat. Weed Tech. 5, 582-585

Andrew, I. K. S., Storkey, J., Sparkes, D. L. 2015. A review of the potential for competitive cereal cultivars as a tool in integrated weed management. Weed Res. 55, 239-248.

Andriesse, W., Fresco, L.O. 1991. A characterization of rice-growing environments in West Africa. Agric. Ecosyst. Environ. 33, 377-395.

Appleby A.P., Olson P.D., Colbert D.R. 1976. Winter wheat yield reduction from interference by Italian ryegrass. Agron. J. 68, 463-466.

Ayongwa G.C., Stomph T.J., Kuyper T.W. 2011. Host-parasite dynamics of Sorghum bicolor and Striga hermonthica - The influence of soil organic matter amendments of different C:N ratio. Crop Prot. 30, 1613-1622.

Ayongwa, G.C., Stomph, T.J., Emechebe, A.M., Kuyper, T.W. 2006. Root nitrogen concentration of sorghum above 2\% produces least Striga hermonthica seed stimulation. Ann. Appl. Biol. 149, $255-262$.

Balasubramanian, V., Sie, M., Hijmans, R.J., Otsuka, K. 2007. Increasing rice production in subsaharan Africa: challenges and opportunities. Adv. Agron. 94, 55-133.

Banwo, O.O., Makundi, R.H., Abdallah, R.S., Mbapila, J.C., Kimmins, F.M. 2002. Vector bionomics of two species of Chaetocnema (Coleoptera chrysomelidae) in rice yellow mottle virus transmission in lowland rice in Tanzania. J. Sustain Agr. 20, 95-104.

Bastiaans, L., Paolini, R. and Baumann, D.T., 2008. Focus on ecological weed management: What is hindering adoption?. Weed Res. 48,481-491.

Bastiaans, L., Zhao, D.L., den Hollander, N.G., Baumann, D.T., Kruidhof, H.M. \& Kropff, M.J., 2007. Exploiting diversity to manage weeds in agro-ecosystems (eds. J.H.J. Spiertz, P.C. Struik \& H.H. van Laar), 267-284. Springer, Dordrecht, The Netherlands

Bates, D., Mächler, M., Bolker, B., Walker, S. 2015. Fitting linear mixed-effects models using lme4. J. Stat. Softw. 67, 1-48.

Berner, D., Cardwell, K., Faturoti, B., Ikie, F., Williams, O. 1994. Relative roles of wind, crop seeds, and cattle in dispersal of Striga spp. Plant Dis. 78, 402-406. 
Blackshaw, R.E., Molnar, L.J., Larney, F.J. 2005. Fertilizer, manure and compost effects on weed growth and competition with winter wheat in western Canada. Crop Prot. 24, 971-980.

Borowicz V.A., Armstrong J.E. 2012. Resource limitation and the role of a hemiparasite on a restored prairie. Oecologia 169, 783-792.

Bouriquet, G. 1933. Une Scrophulariacée parasite du riz à Madagascar. Revue de Pathologie Végétale et D’Entomologie Agriculture de France 20, 149-151

Bremner, J.M., Mulvaney, C.S. 1982. Nitrogen-total. In: Page, A.L., Miller, R.H., Keeney, D.R. (Eds.), Methods of Soil Analysis, Part 2, Chemical and Microbiological Properties, 2nd edn. American Society of Agronomy Madison, WI, pp. 595-624. Conway, K.E., 1996. An overview of the influence of sustainable agricultural systems on plant diseases. Crop Prot. 15, $223-228$.

Carlson H.L., Hill J.E. 1985. Wild oat (Avena fatua) competition with spring wheat: effects of nitrogen fertilization. Weed Sci. 34, 29-33.

Carson, A. G. 1989. Effect of intercropping sorghum and ground-nut on density of Striga hermonthica in the Gambia. Tropical Pest Manage 35, 130-132.

Cavestro, L. 2003. PRA-participatory Rural Appraisal Concepts Methodologies and Techniques.

Cechin, I., Press, M. C. 1993. Nitrogen relations of the sorghum-Striga hermonthica host-parasite association: germination, attachment and early growth. New Phytol. 124, 681-687.

Celik, I., Ortas, I., Kilic, S. 2004. Effects of compost, mycorrhiza, manure and fertilizer on some physical properties of a Chromoxerert soil. Soil and Tillage Res. 78, 59-67.

Cissoko, M., Boisnard, A., Rodenburg, J., Press, M.C., Scholes, J.D., 2011. New Rice for Africa (NERICA) cultivars exhibit different levels of post-attachment resistance against the parasitic weeds Striga hermonthica and Striga asiatica. New Phytol. 192, 952-963.

Davies D. M., Graves J.D. 2000. The impact of phosphorus on interactions of the hemiparasitic angiosperm Rhinanthus minor and its host Lolium perenne. Oecologia 124, 100-106.

Davis, A. S., Renner, K. A., Gross, K. L. 2005. Weed seedbank and community shifts in a long-term cropping systems experiment. Weed Sci. 53, 296-306

De Groote, H., Wangare, L., Kanampiu, F., Odendo, M., Diallo, A., Karaya, H., Friesen, D. 2008. The potential of a herbicide resistant maize technology for Striga control in Africa. Agricultural Systems 97, 83-94.

Debrah, S.K. 1994. Socio-economic constraints to the adoption of weed control techniques: the case of Striga control in the West African Semi-Arid Tropics. Int. J. Pest Manage 40, 153-158.

Demont M, Rodenburg J, Diagne M, Diallo, S, 2009. Ex-ante impact assessment of herbicide resistant rice in the Sahel. Crop Prot. 28, 728-73

Diagne, A., Amovin-Assagba, E., Futakuchi, K., Wopereis, M. C. 2013. Estimation of cultivated area, number of farming households and yield for major rice-growing environments in Africa.

Diagne, A., Amovin-Assagba, E., Futakuchi, K., Wopereis, M.C.S. 2013. Farmers perceptions of the 
biophysical constraints to rice production in sub-Saharan Africa, and potential impact of research. In: Wopereis, M.C.S., Johnson, D.E., Ahmadi, N., Tollens, E., Jalloh, A. (Eds.), Realizing Africa's Rice Promise. CABI, Wallingford, Oxfordshire, UK, pp. 46-68.

Diako, C., Sakyi-Dawson, E., Bediako-Amoa, B., Saalia, F.K., Manful, J.T. 2010. Consumer perceptions, knowledge and preferences for aromatic rice types in Ghana. Nat. Sci. 8, 12-19.

DiTomaso, J. 1995. Approaches for improving crop competitiveness through the manipulation of fertilization strategies. Weed Sci. 43, 491-497.

Dobermann, A., Witt, C., Dawe, D., Abdulrachman, S., Gines, H., Nagarajan, R., Satawathananont, S., Son, T., Tan, P., Wang, G. 2002. Site-specific nutrient management for intensive rice cropping systems in Asia. Field Crops Res. 74, 37-66.

Dugje, I., Kamara, A., Omoigui, L. 2006. Infestation of crop fields by Striga species in the savanna zones of northeast Nigeria. Agriculture, ecosystems \& environment 116, 251-254.

Ejeta, G. 2012. The Striga scourge in Africa: a growing pandemic. In: Integrating New Technologies for Striga Control. World Scientific. 3-16.

Ejeta, G., Gressel, J. 2007. Integrating new technologies for Striga control: towards ending the witchhunt: World Scientific, Singapore. 327-337.

Elliot, P., Clarisse, R., Beby, R., Josue, H. 1993. Weeds in rice in Madagascar. International Rice Research Notes 18, 53-54.

Emechebe, A.M., Ellis-Jones, J., Schulz, S., Chikoye, D., Douthwaite, B., Kureh, I., Tarawali, G., Hussaini, M.A., Kormawa, P., Sanni, A. 2004. Farmers' perception of the Striga problem and its control in northern Nigeria. Exp. Agr 40, 215-232.

Farina, M. P. W., Thomas, P. E. L., Channon, P. 1985. Nitrogen, phosphorus and potassium effects on the incidence of Striga asiatica (L.) Kuntze in maize. Weed Res. 25, 443-447.

Gbèhounou, G. 2003. Rhamphicarpa fistulosa (Hochst.) Benth.(Scrophulariaceae): new pest on lowland rice in Benin. Results of a survey and immediate control possibilities. Annales des Sciences Agronomiques. 4, 89-103.

Gbèhounou, G., Adango, E., Hinvi, J.C., Nonfon, R. 2004. Sowing date or transplanting as components for integrated Striga hermonthica control in grain-cereal crops? Crop Prot. 23, $379-386$.

Haggblade, S., Minten, B., Pray, C., Reardon, T., Zilberman, D. 2017. The Herbicide Revolution in Developing Countries: Patterns, Causes, and Implications. The European Journal of Development Research 29, 533-559.

Hansen, O. J. 1975. The genus Rhamphicarpa Benth. emend. Engl.(Scrophulariaceae): a taxonomic revision. Bot. Tidsskr. 70, 103-125.

Heap, I. 2013. Herbicide Resistant Weeds. Integrated Pest Manage. 3, 281-301.

Hearne, S.J. 2009. Control the Striga conundrum. Pest Manage. Sci. 65, 603-614. 
Hothorn, T., Bretz, F., Westfall, P. 2008. Simultaneous inference in general parametric models. Biom. J. 50, 346-363.

Houngbédji T., Dessaint F., Nicolardot B., Shykoff J.A., Gibot-Leclerc S. 2016. Weed communities of rainfed lowland rice vary with infestation by Rhamphicarpa fistulosa. Acta Oecologica 77, 8590.

Houngbédji T., Gibot-Leclerc S. 2015. First report of Rhamphicarpa fistulosa on peanut (Arachis hypogaea), soybean (Glycine max), and tossa jute (Corchorus olitorius) in Togo. Plant Dis.99, 1654.

Houngbedji, T., Pocanam, Y., Shykoff, J., Nicolardot, B., Gibot-Leclerc, S. 2014. A new major parasitic plant in rice in Togo: Rhamphicarpa fistulosa. Cah. Agric. 23, 357-365.

Huang, J., Lu, X. X., Sellers, J. M. 2007. A global comparative analysis of urban form: Applying spatial metrics and remote sensing. Landsc Urban Plan. 82, 184-197.

Jamil, M., Charnikhova, T., Cardoso, C., Jamil, T., Ueno, K., Verstappen, F., Asami, T., Bouwmeester, H. J. 2011a. Quantification of the relationship between strigolactones and Striga hermonthica infection in rice under varying levels of nitrogen and phosphorus. Weed Res. 51, 373-385.

Jamil, M., Rodenburg, J., Charnikhova, T., Bouwmeester, H.J. 2011b. Pre-attachment Striga hermonthica resistance of New Rice for Africa (NERICA) cultivars based on low strigolactone production. New Phytol. 192, 964-975.

Jamil, M., Kanampiu, F.K., Karaya, H., Charnikhova, T., Bouwmeester, H.J. 2012. Striga hermonthica parasitism in maize in response to $\mathrm{N}$ and $\mathrm{P}$ fertilisers. Field Crop Res. 134, 1-10.

Jamil, M., Van Mourik, T. A., Charnikhova, T., Bouwmeester, H. J. 2013. Effect of diammonium phosphate application on strigolactone production and Striga hermonthica infection in three sorghum cultivars. Weed Res. 53, 121-130.

Johnson, D.E., Riches, C.R., Diallo, R., Jones, M.J. 1997. Striga on rice in West Africa; crop host range and the potential of host resistance. Crop Prot. 16, 153-157.

Johnson D.E. and Kent R.J. 2002. The impact of cropping on weed species composition in rice after fallow across a hydrological gradient in west Africa. Weed Res. 42, 89-99.

Kabiri, S., Rodenburg, J., Kayeke, J., Van Ast, A., Makokha, D.W., Msangi, S.H., Irakiza, R., Bastiaans, L. 2015. Can the parasitic weeds Striga asiatica and Rhamphicarpa fistulosa cooccur in rain-fed rice? Weed Res. 55, 145-154.

Kabiri, S., van Ast, A., Rodenburg, J., Bastiaans, L. 2016. Host influence on germination and reproduction of the facultative hemi-parasitic weed Rhamphicarpa fistulosa. Ann. Appl. Biol. 169, $144-154$.

Kamara, A.Y., Ellis-Jones, J., Amaza, P., Omoigui, L.O., Helsen, J., Dugje, I.Y., Kamai, N., Menkir, A., White, R.W. 2008. A participatory approach to increasing productivity of maize through Striga hermonthica control in northeast Nigeria. Exp. Agr 44, 349-364.

Kamara, A.Y., Ekeleme, F., Jibrin, J.M., Tarawali, G., Tofa, I. 2014. Assessment of level, extent and factors influencing Striga infestation of cereals and cowpea in a Sudan Savanna ecology of 


\section{References}

northern Nigeria. Agr. Ecosyst. Environ. 188, 111-121.

Kanampiu, F. K., Ransom, J. K., Friesen, D., Gressel, J. 2002. Imazapyr and pyrithiobac movement in soil and from maize seed coats to control Striga in legume intercropping. Crop Prot. 21, 611619.

Kayeke, J., Sibuga, P., Msaky, J., Mbwaga, A. 2007. Green manure and inorganic fertiliser as management strategies for witch weed and upland rice. ACSJ 15, 161-171.

Kayeke, J., Rodenburg, J., Mwalyego, F., Mghogho, R. 2010. Incidence and Severity of the Facultative Parasitic Weed Rhamphicarpa fistulosa in Lowland Rain-fed Rice in Southern Tanzania, 2nd Africa Rice Congress. Innovation and Partnerships to Realize Africa's Rice Potential.

Kebreab, E., Murdoch, A. 1999. A quantitative model for loss of primary dormancy and induction of secondary dormancy in imbibed seeds of Orobanche spp.. J. Exp. Bot. 50, 211-219.

Kirchhof, G., So, H.B., Adisarwanto, T., Utomo, W.H., Priyono, S., Prastowo, B., Basir, M., Lando, T.M., Subandi, Dacanay, E.V., Tan-Elicano, D., Sanidad, W.B. 2000. Growth and yield response of grain legumes to different soil management practices after rain-fed lowland rice. Soil Till Res. 56, 51-66.

Kouakou, C.K., Akanvou, L., Bi, I.A.Z., Akanvou, R., N'da, H.A., 2015. Striga species distribution and infestation in cereal food crops of northern $\mathrm{C}^{\wedge}$ ote d'Ivoire. Cah. Agric. 24, 37-46.

Le Gal, P.-Y., Dugué, P., Faure, G., Novak, S. 2011. How does research address the design of innovative agricultural production systems at the farm level? A review. Agric. Syst. 104,714-728

Lenth, R.V., 2016. Least-squares means: the R package 1smeans. J. Stat. Softw. 69, 1-33.

Liebman M and Gallandt, E.R., 1997. Many little hammers: ecological management of crop-weed interactions. In: Ecology in Agriculture (ed LE Jackson), 291-343. Academic Press, San Diego, USA

Liebman, M., Baraibar, B., Buckley, Y., Childs, D., Christensen, S., Cousens, R., Eizenberg, H., Heijting, S., Loddo, D., Merotto J. A. 2016. Ecologically sustainable weed management: How do we get from proof-of-concept to adoption? Ecol. Appl. 26, 1352-1369.

Matusova, R., Rani, K., Verstappen, F.W.A., Franssen, M.C.R., Beale, M.H., Bouwmeester, H.J. 2005. The Strigolactone germination stimulants of the plant-parasitic Striga and Orobanche spp. are derived from the carotenoid pathway. Plant Physiol. 139, 920-934.

Mbwaga, A.M., 2001. Striga research activities in Central, Eastern, Lake and Southern Highlands Zones of Tanzania: on-station and On-farm trials for 2000-01 season. Ilonga Agricultural Research Institute, Tanzania

Mbwaga, A.M., 2003. Incorporation of Awareness and Control of Striga in the school curriculum. Project Working Paper No. 5. Ilonga Agricultural Research Institute, Kilosa, Tanzania. 46 pp.

Mbwaga, A.M., 2005. On-farm verification and promotion of green manure for enhancing upland rice productivity on Striga infested fields in Tanzania. Final Technical Report. Ilonga Agricultural Research Institute, Kilosa, Tanzania. 45 pp. 
McCullagh, P., Nelder, J.A. 1989. Generalized Linear Models, Vol. 37 of Monographs on Statistics and Applied Probability, 2nd edn. Chapman and Hall, London.

Mehlich, A. 1984. Mehlich 3 soil test extractant: a modification of Mehlich 2 extractant. Commun. Soil Sci. Plan. 15, 1409-1416.

Mekuria W., Getnet K., Noble A., Hoanh C.T., McCartney M., Langan S. 2013. Economic valuation of organic and clay-based soil amendments in small-scale agriculture in Lao PDR. Field Crop Res. 149, 379-389.

Melander, B., Rasmussen, I.A. \& Barberi, P., 2005. Integrating physical and cultural methods of weed control - Examples from European research. Weed Sci. 53, 369-381.

Mohamed, A.H., Ejeta, G., Butler, L.G., Housley, T.L. 1998. Moisture content and dormancy in Striga asiatica seeds. Weed Res. 38, 257-265.

Mohamed, K.I., Papes, M., Williams, R., Benz, B.W., Peterson, A.T. 2006. Global invasive potential of 10 parasitic witchweeds and related Orobanchaceae. Ambio. 35, 281-288.

Mrema, E., Shimelis, H., Laing, M., Bucheyeki, T. 2017. Farmers' perceptions of sorghum production constraints and Striga control practices in semi-arid areas of Tanzania. Int. J. Pest Manage. 63, 146-156.

Muzari, W., Gatsi, W., Muvhunzi, S. 2012. The impacts of technology adoption on smallholder agricultural productivity in Sub-Saharan Africa: A review. J Sustain. Dev. 5, 69.

N'Cho, S.A., Mourits, M., Rodenburg, J., Demont, M., Lansink, A.O. 2014. Determinants of parasitic weed infestation in rainfed lowland rice in Benin. Agr Syst. 130, 105-115.

Norman, J. \& Kebe, B. 2006. African smallholder farmers: Rice production and sustainable livelihoods. International Rice Commission Newsletter 55, 33-44.

Norton, G.A., Adamson, D., Aitken, L.G., Bilston, L.J., Foster, J., Frank, B., Harper, J.K. 1999. Facilitating IPM: the role of participatory workshops. Int. J. Pest Manage. 45, 85-90.

Ogwuike, P., Rodenburg, J., Diagne, A., Agboh-Noameshie, A. R. \& Amovin-Assagba, E. 2014. Weed management in upland rice in sub-Saharan Africa: impact on labor and crop productivity. Food Secur. 6, 327-337.

Oswald, A. 2005. Striga control technologies and their dissemination. Crop Prot. 24, 333-342.

Ouédraogo, O., Neumann, U., Raynal-Roques, A., Sallé, G., Tuquet, C., Dembélé, B. 1999. New insights concerning the ecology and the biology of Rhamphicarpa fistulosa (Scrophulariaceae). Weed Res. 39, 159-169.

Pandey, A., Kumar, A., Pandey, D., Thongbam, P. 2014. Rice quality under water stress. IJAPR 1, 2326.

Pantuwan, G., Fukai, S., Cooper, M., Rajatasereekul, S., O'Toole, J.C. 2002. Yield response of rice (Oryza sativa L.) genotypes to drought under rain-fed lowland: 3. Plant factors contributing to drought resistance. Field Crop Res. 73, 181-200.

Parker, C. 2012. Parasitic weeds: a world challenge. Weed Sci. 60, 269-276. 


\section{References}

Parker, C. 2013. The Parasitic Weeds of the Orobanchaceae. Parasitic Orobanchaceae: Parasitic Mechanisms and Control Springer-Verlag Berlin Heidelberg, pp. 313-344.

Parker, C. 2014. The continuing threat from parasitic weeds. Outlooks on Pest Manage. 25, 237-242.

Parkinson, V., Efron, Y., Bello, L., Dashiell, K. 1987. Trap crops as a cultural measure in Striga control in Africa. FAO Plant Protection Bulletin, 35, 51-54.

Porteres, R. 1948. Plants indicating the fertility level of the edapho-climatic cultural complex in tropical Africa. Agronomie Tropicale 3, 246-257.

Pullaro, T. C., Marino, P. C., Jackson, D. M., Harrison, H. F., Keinath, A. P. 2006. Effects of killed cover crop mulch on weeds, weed seeds, and herbivores. Agr Ecosyst. Environ. 115, 97-104.

R Core Team,. 2016. R: A Language and Environment for Statistical Computing. R foundation for statistical computing, Vienna, Austria (URL). https://www.R-project.org/.

R Core Team,. 2018. R: A Language and Environment for Statistical Computing. R foundation for statistical computing, Vienna, Austria (URL). https://www.R-project.org/.

Raju, P., Osman, M., Soman, P., Peacock, J. 1990. Effects of N, P and K on Striga asiatica (L.) Kuntze seed germination and infestation of sorghum. Weed Res. 30, 139-144.

Randrianjafizanaka M.T., Autfray P., Andrianaivo A.P., Ramonta I.R., Rodenburg J. 2018. Combined effects of cover crops, mulch, zero-tillage and resistant varieties on Striga asiatica (L.) Kuntze in rice-maize rotation systems. Agr Ecosyst. Environ. 256, 23-33.

Rao, A.N., Johnson, D.E., Sivaprasad, B., Ladha, J.K., Mortimer, A.M., 2007. Weed management in direct-seeded rice. Adv. in Agron. 93, 153-255

Rich, P.J. and Ejata G., 2007. Biology of Host-Parasite Interactions in Striga species. In: Integrating New Technologies for Striga control. Towards ending the Witch-hunt (eds. G. Ejeta \& J. Gressel), 19-32. World Scientific Publishing Co. Pte. Ltd., Signapore

Riches, C., Mbwaga, A., Mbapila, J., Ahmed, G. 2005. Improved weed management delivers increased productivity and farm incomes from rice in Bangladesh and Tanzania. Asp. Appl. Biol. 75, 127-138.

Rigg, J. 2006. Land, farming, livelihoods, and poverty: rethinking the links in the rural South. World Dev. 34, 180-202.

Rodenburg, J., Bastiaans, L., Weltzien, E. \& Hess, D. E. 2005. How can field selection for Striga resistance and tolerance in sorghum be improved? Field Crop Res. 93, 34-50.

Rodenburg, J., Johnson, D.E. 2009. Weed management in rice-based cropping systems in Africa. Adv. Agron. 103, 149-218.

Rodenburg, J., Riches, C.R., Kayeke, J.M. 2010. Addressing current and future problems of parasitic weeds in rice. Crop Prot. 29, 210-221.

Rodenburg, J., Meinke, H., Johnson, D.E. 2011a. Challenges for weed management in African rice systems in a changing climate. J. Agr. Sci. 149, 427-435. 
Rodenburg, J., Zossou-Kouderin, N., Gbèhounou, G., Ahanchede, A., Toure, A., Kyalo, G., Kiepe, P. 2011b. Rhamphicarpa fistulosa, a parasitic weed threatening rain-fed lowland rice production in sub-Saharan Africa - a case study from Benin. Crop Prot. 30, 1306-1314.

Rodenburg, J., Demont, M., Zwart, S. J., Cissoko, M., Bastiaans, L. 2014. The importance of parasitic weeds in Rice in Africa. Proceedings of the 4th International Rice Congress, 2014, Bangkok, Thailand.

Rodenburg, J., Cissoko, M., Kayeke, J., Dieng, I., Khan, Z.R., Midega, C.A.O., Onyuka, E.A., Scholes, J.D. 2015a. Do NERICA rice cultivars express resistance to Striga hermonthica (Del.) Benth. and Striga asiatica (L.) Kuntze under field conditions? Field Crop Res. 170, 8394.

Rodenburg, J., Morawetz, J.J., Bastiaans, L. 2015b. Rhamphicarpa fistulosa, a widespread facultative hemi-parasitic weed, threatening rice production in Africa. Weed Res. 55, 118-131.

Rodenburg, J., Saito, K., Irakiza, R., Makokha, D. W., Onyuka, E. A. \& Senthilkumar, K. 2015c. Labor-Saving Weed Technologies for Lowland Rice Farmers in sub-Saharan Africa. Weed Tech. 29, 751-757.

Rodenburg, J., Schut, M., Demont, M., Klerkx, L., Gbèhounou, G., Oude Lansink, A., Mourits, M., Rotteveel, T., Kayeke, J., van Ast, A., Akanvou, L., Cissoko, M., Kamanda, J., Bastiaans, L. 2015d. Systems approaches to innovation in pest management: reflections and lessons learned from an integrated research program on parasitic weeds in rice. Int. J. Pest Manage 61, 329339.

Rodenburg, J., Cissoko, M., Dieng, I., Kayeke, J., Bastiaans, L. 2016a. Rice yields under Rhamphicarpa fistulosa-infested field conditions, and variety selection criteria for resistance and tolerance. Field Crop Res. 194, 21-30.

Rodenburg, J., Demont, M., Zwart, S.J., Bastiaans, L. 2016b. Parasitic weed incidence and related economic losses in rice in Africa. Agr Ecosyst. Environ. 235, 306-317.

Rodenburg, J., Cissoko, M., Kayongo, N., Dieng, I., Bisikwa, J., Irakiza, R., Masoka, I., Midega, C.A.O., Scholes, J.D.C. 2017. Genetic variation and host-parasite specificity of Striga resistance and tolerance in rice: the need for predictive breeding. New Phytol. 214, 12671280 .

Rodenburg J, Johnson JM, Dieng I, Senthilkumar K, Vandamme E, Akakpo C, Allarangaye MD, Baggie I, Bakare SO, Bam RK, Bassoro I, Abera BB, Cisse M, Dogbe W, Gbakatchetche H, Jaiteh F, Kajiru GJ, Kalisa A, Kamissoko N, Keita S, Kokou A, Mapiemfu-Lamare D, Lunze FM, Mghase J, Maïga IM, Nanfumba D, Niang A, Rabeson R, Segda Z, Sillo FS, Tanaka A, Saito K. 2019. Status quo of chemical weed control in rice in sub-Saharan Africa. Food Secur. 11, 69-92

Schut, M., Rodenburg, J., Klerkx, L., Hinnou, L.C., Kayeke, J., Bastiaans, L. 2015a. Participatory appraisal of institutional and political constraints and opportunities for innovation to address parasitic weeds in rice. Crop Prot. 74, 158-170.

Schut, M., Rodenburg, J., Klerkx, L., Kayeke, J., van Ast, A., Bastiaans, L. 2015b. RAAIS: rapid Appraisal of Agricultural Innovation Systems (Part II). Integrated analysis of parasitic weed problems in rice in Tanzania. Agr Syst. 132, 12-24. 


\section{References}

Screpanti, C., Yoneyama, K., Bouwmeester, H. J. 2016. Strigolactones and parasitic weed management 50 years after the discovery of the first natural strigolactone strigol: status and outlook. Pest Manage. Sci. 72, 2013-2015.

Seck, P. A., Tollens, E., Wopereis, M. C., Diagne, A., Bamba, I. 2010. Rising trends and variability of rice prices: Threats and opportunities for sub-Saharan Africa. Food Policy. 35, 403-411.

Seck, P.A., Diagne, A., Mohanty, S., Wopereis, M.C.S. 2012. Crops that feed the world 7: Rice. Food Secur 4, 7-24.

Seel, W.E., Press, M.C. 1993. Influence of the host on three sub-Arctic annual facultative root hemiparasites. New Phytol. 125, 131-138.

Showemimo, F.A., C.A. Kimbeng, and Alabi, S.O. 2002. Genotypic response of sorghum cultivars to nitrogen fertilization in the control of Striga hermonthica. Crop Prot. 21, 867-870.

Singh, R.K., Murori, R., Ndayiragije, A., Bigirimana, J., Kimani, J., Kanyeka, Z., Surapong, S., Singh, Y., Ndikumana, I., Lamo, J., Mkuya, M., Tusekelege, H., Rickman, J. 2013. Rice breeding activities in eastern and southern Africa. Sabrao J. Breed. Genet. 45, 73-83.

Sokal, R.R., Rohlf, F.J. 1995. Biometry: The Principles and Practice of Statistics in Biological Research, 3rd Edition. W.H Freeman and Co., New York.

Spallek, T., Mutuku, M. \& Shirasu, K. 2013. The genus Striga: A witch profile. Mol Plant Pathol. 14, 861-869.

Tanaka, A., Johnson, J. M., Senthilkumar, K., Akakpo, C., Segda, Z., Yameogo, L. P., Bassoro, I., Lamare, D. M., Allarangaye, M. D., Gbakatchetche, H., Bayuh, B. A., Jaiteh, F., Bam, R. K., Dogbe, W., Sékou, K., Rabeson, R., Rakotoarisoa, N. M., Kamissoko, N., Mossi, I. M., Bakare, O. S., Mabone, F. L., Gasore, E. R., Baggie, I., Kajiru, G. J., Mghase, J., Ablede, K. A., Nanfumba, D. \& Saito, K. 2017. On-farm rice yield and its association with biophysical factors in sub-Saharan Africa. European J. of Agron. 85, 1-11.

Tippe, D. E., Rodenburg J, Schut M, van Ast A, Kayeke J, Bastiaans L. 2017a. Farmers' knowledge, use and preferences of parasitic weed management strategies in rain-fed rice production systems. Crop Prot. 99, 93-107.

Tippe, D. E., Rodenburg J, van Ast A, Anten NPR, Dieng I, Kayeke JM, Cissoko M, Bastiaans L. $2017 \mathrm{~b}$. Delayed or early sowing: timing as parasitic weed control strategy in rice is species and ecosystem dependent. Field Crop Res. 214, 14-24.

Van Ast, A., Bastiaans, L. 2006. The role of infection time in the differential response of sorghum cultivars to Striga hermonthica infection. Weed Res. 46, 264-274.

Van Ittersum, M. K., Van Bussel, L. G., Wolf, J., Grassini, P., Van Wart, J., Guilpart, N., Claessens, L., de Groot, H., Wiebe, K. \& Mason-D'Croz, D. 2016. Can sub-Saharan Africa feed itself? Proceedings of the National Academy of Sciences.113, 14964-14969.

van Oort, P., Saito, K., Tanaka, A., Amovin-Assagba, E., Van Bussel, L., van Wart, J., de Groot, H., van Ittersum, M., Cassman, K. \& Wopereis, M. 2015. Assessment of rice self-sufficiency in 2025 in eight African countries. Global Food Secur. 5, 39-49.

Walkley, A., Black, I.A. 1934. An examination of the Degtjareff method for determining soil organic 
matter, and a proposed modification of the chromic acid titration method. Soil Sci. 37, 29-38.

Westwood, J. H., dePamphilis, C. W., Das, M., Fernández-Aparicio, M., Honaas, L. A., Timko, M. P., Wafula, E. K., Wickett, N. J. \& Yoder, J. I. 2011. The Parasitic Plant Genome Project: New Tools for Understanding the Biology of Orobanche and Striga. Weed Sci. 60, 295-306.

William, H. M., Nicholas, K. 2015. World Population, Food Growth, and Food Security Challenges, in Andrew Schmitz, P. Lynn Kennedy, Troy G. Schmitz (ed.) Food Security in an Uncertain World (Frontiers of Economics and Globalization), Emerald Group Publishing Limited. 15, $161-177$.

Wise, T. A. 2013. Can we feed the world in 2050?. A scoping paper to assess the evidence (Working Paper No. 13-04). Tufts University, Global Development and Environment Institute.

Zhao, Y.-N., He, X.-H., Huang, X.-C., Zhang, Y.-Q. \& Shi, X.-J. 2016. Increasing Soil Organic Matter Enhances Inherent Soil Productivity while Offsetting Fertilization Effect under a Rice Cropping System. Sustainab. 8, 879. 

Summary 


\section{Summary}

In sub-Saharan Africa (SSA), rice demand is increasing due to population growth and changes in consumer preferences. However, domestic rice production in many countries in the region lags behind the consumption rates. This is in part due to suboptimal production, caused by a myriad of production constraints that are insufficiently addressed. In SSA, rice is largely grown under rainfed conditions due to poorly developed irrigation systems in many places. Under rainfed conditions rice production is often hampered by a variety of factors, but most importantly drought and weeds. In particular parasitic weed species, a sub-category of weeds that connect to a host plant, are becoming a more prominent threat to rice production. An important reason is that farmers, in order to address increased rice demand, have expanded rice production into areas where parasitic weeds naturally or historically occur.

Striga asiatica (L.) Kuntze and Rhamphicarpa fistulosa (Hochst.) Benth. are among the most important parasitic weed species in rainfed rice production systems in SSA. Striga asiatica is an obligate hemi-parasitic weed adapted to rainfed upland rice growing environments, while $R$. fistulosa is a facultative hemi-parasitic weed developing into a problem in lowland rice growing environments. This latter species is capable of completing its life cycle without a host plant. Parasitic weed invasions in rice production systems in SSA not only result in severe crop losses, but frequently drive farmers to abandon their fields. Parasitic weeds continue to constitute a severe problem, mainly because potentially effective solutions are not affordable or not accessible for resource-poor smallholder farmers Consequently, food security and income generation of these farmers in SSA is highly endangered by parasitic weed invasion.

Research on root hemi-parasitic weeds has mainly been focused on maize and sorghum, the main staple food crops in SSA. For these two crops, several strategies have been proposed to control Striga spp. ranging from soil fertility amendments, the use of resistant crop varieties or adjustments in sowing methods. Despite all these efforts, parasitic weed management strategies that were developed for maize and sorghum have been poorly adopted by farmers. Often, technology development and transfer was poorly linked to the needs and capacities of farmers. In many previous research endeavours, the existing knowledge, experience and preferences of local farmers have not been adequately considered. Currently, most farmers continue to use hand weeding, their standard control measure for ordinary weeds, to control parasitic weeds. However, hand weeding is not effective for control of Striga spp., simply because the parasitic weed causes damage to rice even before the parasite emerges aboveground. Hand weeding also consumes valuable time and resources. Other 
control options are, however, often not locally accessible or affordable. In many places, herbicides are not used because they are expensive and their use and application equipment requires technical know-how that farmers often lack.

Farmers' involvement in designing and testing new control strategies against parasitic weeds could increase the likelihood that effective and adoptable solutions will be found. For this reason, the study described in this thesis focused on (1) assessing the current state in terms of farmer's awareness of parasitic weeds in different rainfed rice environments, their current control practices, their knowledge of alternative control strategies and their reasons for adoption or non-adoption of these technologies, (2) investigating the effectiveness of altered sowing times and new rice varieties on parasitic weed growth and rice yield in rainfed rice systems, (3) investigating the effectiveness of different soil amendment sources on parasitic weed growth and rice yield, and (4) evaluating the effectiveness of these measures in farmers' fields and gauging farmers' appreciation of the selected control measures.

In the first investigation (Chapter 2), workshops and surveys were organized in three affected rice growing areas in Tanzania: Morogoro-rural, Songea and Kyela districts and supplemented with on-farm experiments in Kyela district. In this study, farmers' awareness, use, preference and adoption criteria of parasitic weed management practices in rainfed rice production systems were assessed. The study revealed that, in all districts, farmers were aware of the locally occurring parasitic weed species Rhamphicarpa fistulosa (in lowland) and Striga asiatica (in upland). They considered these weeds more problematic than non-parasitic weeds. Farmers mostly practised hand weeding, though they were aware of a wide range of control options. Local access, affordability, ease of implementation and control efficacy were considered important criteria for adoption. Before the installation of the on-farm experiments in both upland and lowland, informal discussions with farmers were held, based on which altered sowing time, short-duration rice varieties and soil amendments were marked as feasible control options and selected as experimental factors. During the on-farm trials, farmers from the nearby villages were invited to select parasite control technologies of their preference within each of the three selected factors. For the control of $S$. asiatica, late planting was preferred, requiring a short-duration variety to minimize risk of drought stress during grain filling. The control of $R$. fistulosa was best realized by early crop establishment, escaping major parasite damage due to the relatively slow early development of this weed species. The local variety Supa India, appreciated for its grain qualities and marketability, remained farmers preferred variety due to its good grain quality and aroma. Regarding 


\section{Summary}

farmers' preference of soil amendments under both upland and lowland conditions, there was a clear preference for the treatments that contained combination of mineral fertilisers and rice husks. Their preferences were highly motivated by accessibility and affordability of this soil amendment option.

In a second investigation (Chapter 3), the altered sowing times were tested in a factorial researcher-managed experiment. For these reasons, in Kyela district in south-west Tanzania, field experiments were conducted in both upland (S. asiatica) and lowland (R. fistulosa) rainfed rice eco-systems during three cropping seasons (2012-2014). Five sowing times were evaluated, in which the first sowing time coincided with the start of the rainy season and two weeks intervals were used for the rest. Sowing time was combined with three rice varieties, varying in crop-cycle length. In the upland, where S. asiatica is the prevailing parasitic weed, parasite number and biomass reduced with a delay in sowing time. Effect on rice grain yield was less clear cut. In years with mild $S$. asiatica infection, rice grain yield was significantly lower at the last two sowing times, particularly with the traditional varieties. In lowland, where $R$. fistulosa is the principal parasitic weed, parasite number did not reflect a clear pattern, but there was a significant increase in parasite biomass with a delay in sowing time. In general, with a delay in sowing time, the duration of the parasite free period shortened. Early rice planting thus resulted in partial escape of parasite infection, and resulted in higher rice grain yields.

In the third investigation (Chapter 4), it was hypothesized that infection levels of parasitic weeds and their associated rice yield losses depend on soil fertility level, and that these could be mitigated by soil amendments. Mineral fertilisers have previous been proven effective, mostly under controlled conditions, but farmers usually find them too expensive. Lowering the costs of soil fertility enhancing technologies can be achieved by replacing mineral fertilisers, in part or as a whole, by some of the locally available inputs. However, their effectivity as a soil amendment, let alone their influence on parasitic weed infestation level, has not been tested before. For this reason, a field study was conducted in both upland $(S$. asiatica) and lowland ( $R$. fistulosa) in Kyela district from 2012-2015 to investigate whether: (1) there is a significant effect of soil fertility amendments on $S$. asiatica / R. fistulosa infection levels in the field, and (2) rice yields benefit from soil fertility amendments when the crop suffers from ordinary or parasitic weed infestation. In this study, seven soil fertility treatments were tested: (1) No fertiliser (control), (2) DAP plus Urea in locally recommended rates, (3) NPK in locally recommended rates, (4) Cattle manure, (5) Rice husks, (6) Cattle 
manure and half the locally recommended rate of DAP plus Urea, (7) Rice husks and half the locally recommended rate of DAP plus Urea. All treatments were tested under two weeding regimes: (1) Weedy, whereby neither parasitic nor ordinary weeds were weeded, and (2) Weed-free, whereby all ordinary weeds were regularly removed but parasitic weeds were allowed. The study revealed that under upland field conditions fertilisation generally reduces $S$. asiatica infection levels on the medium term (after two seasons), but these positive effects are not strongly pronounced. It does have a clearer and more direct effect on rice yield, in particular in the absence of ordinary weeds and in years with general low S. asiatica infection levels. Under weed-free conditions, fertiliser treatments with manure and DAP or rice husks with DAP resulted in the highest rice grain yields. Both $S$. asiatica infection levels and rice yields are highly variable over years. In years with generally high $S$. asiatica infection levels, weeding of ordinary weeds favours parasite establishment. In the absence of weeding, ordinary weed biomass increases over the years. For the lowland fields, with R. fistulosa, fertiliser application, particularly manure with DAP or rice husks, mostly stimulate the parasite biomass production. Fertilisers, specifically rice husks with DAP have a direct effect on rice grain yield; this effect is again most pronounced under weed-free conditions and at low $R$. fistulosa infection levels. Weeding of ordinary weeds reduces $R$. fistulosa infection but only increases rice grain yields in years when $R$. fistulosa infection levels are generally low.

In conclusion, parasitic weed management practices are often parasite-species specific. Manipulating rice sowing time is a feasible control strategy to minimize parasitic weed infection, but the proper application and associated risk of this practice are strongly species and ecosystem dependent. In upland ( $S$. asiatica), sowing rice two to four weeks after the onset of the rain was the optimal time, as parasite infection decreased and rice grain yields increased. Improved short-duration varieties can help to avoid risks of drought stress associated to late sowings. In lowland (R. fistulosa), the best strategy is early sowing, it delays and reduces parasite infection, resulting in the highest rice grain yields. Resistant, tolerant or early maturing varieties are useful components of locally adapted integrated control strategies. For varieties to be adopted, they should meet farmers and consumers preferences such as good grain quality and aroma.

Also, the contribution of soil amendment to parasitic weed suppression seems to depend on the parasitic nature of the weed species. Infection levels of the parasitic weed S. asiatica are largely reduced by fertiliser applications, while of the parasitic weed $R$. fistulosa specifically the biomass is generally stimulated. The extent of the effect depends on the nature 
of the fertiliser. The use of rice husks with DAP has a more pronounced effect than purely mineral fertilisers. Rice grains yields show more consistent effects from fertilisers in both $S$. asiatica and R. fistulosa infected crops. These effects are more pronounced in the absence of ordinary weeds and at low parasitic weed infection levels.

Potential strategies for dealing with parasitic weeds usually have trade-offs with other production objectives or with ecological or socio-economic parameters. That is the reason why farmers are still mainly relying on hand hoe to minimize parasite infection in rice. A combination of measures, such as the use of early maturing and resistant varieties, the use of optimum sowing time in combination with locally affordable soil amendment sources will ease farmers' fights against parasitic weeds. The accessibility of fertilisers and good quality seed of improved varieties that resist parasitic weed infection with preferred traits like aroma and good grain quality at affordable prices is a precondition for the feasibility of such an approach. Limited financial support and production resources of the farming communities, lack of agricultural input supply and credits are the constraints that need immediate attention to enable rice farmers to diminish parasitic weeds infection in rainfed rice production systems in sub-Saharan Africa. Evidently, parasitic weed management is not just an effort at farm and field level, it also requires attention at institutional and policy-maker level. Only when these aspects are simultaneously addressed, it will be possible to sustainably solve the parasitic weed problem in rainfed rice. 
Acknowledgments 
The research presented in this thesis has been conducted within the framework of the NWOWOTRO - Science for Global Development in its program Preparing African Rice Farmers Against Parasitic Weeds in a Changing Environment "PARASITE". The PARASITE program enabled me to start my PhD journey in September, 2013 at the Crop and Weed Ecology group of Professor Dr Niels Anten at Wageningen University. For this particular chance as well as for all support I received during the past five years, I sincerely need to acknowledge a great number of people.

I started my research on parasitic weeds under the inspirational supervision of four persons who had since long won their spurs in this field: Dr Lammert Bastiaans and Dr Aad van Ast of the Crop and Weed Ecology group of Wageningen University and Research, Dr Jonne Rodenburg of the Africa Rice Centre in Dar es Salaam, Tanzania and later at the Natural Resources Institute, University of Greenwich, in the UK and Dr Juma Kayeke Mohamed of Tanzania Agricultural Research Institute (TARI), Uyole Center in the Ministry of Agriculture in the United Republic of Tanzania. I gained my first knowledge and experience in the field of parasitic weeds as an agricultural research officer from Uyole Tanzania Agricultural Research Institute (TARI), Uyole Center in Tanzania when I was first located at the rice production improvement program.

A few people I would like to thank specifically. Firstly, my daily supervisor, Dr Lammert Bastiaans. Lammert, I like to thank you for your inspiring attitude and enthusiasm for the project, for your daily guidance since day one when I arrived in the Netherlands. We spent a lot of time together during my PhD proposal development. The inspiring attitude, the clear ideas when discussing the data, and your thorough comments and inputs on my manuscripts, and many more the energetic thoughts that occasioned from these discussions, powerfully donated to the comprehension of this thesis. Lammert, I am very thankful for all the period you devoted to my thesis, and for your unremitting self-confidence in a respectable concluding outcome. Also, I remember with a countless desire when you and Aad van Ast visited my field experiments in Kyela and on the way back to Dar es Salaam when we visited Mikumi National Park in Tanzania. In Mikumi we actually combined science and wildlife. Lammert, I look forward to our continued collaboration in research for coming years.

I am deeply indebted to my second daily supervisor Dr Aad van Ast. Aad, you have been so inspirational to me, and your courage, guidance and support whenever pitfalls were encountered, will not easily be overlooked. I really appreciated your experience and the coaching I received during the greenhouse experiments. Apart from the experiments, you 
have been a fatherly trainer towards social life practically when comes time to combine science and social events. We had been together for various discussions and even out of the office we had dinner several times at your house. With this regards, I would like to thank Ans, your wife, for those wonderful and delicious dinners. Aad, it was a really noble phase in my life time having you around, you truly contributed a lot in moral support for compilation of this thesis.

I am also thankful to Dr Jonne Rodenburg my local supervisor in Tanzania, for the confidence he showed in me when I applied for the $\mathrm{PhD}$ position in the WOTRO programs. Jonne, I appreciated not only confidence you had in me but also your daily guidance and commitment during my field works in Kyela, Tanzania. You were always there to make sure we accomplished the tasks we started. In Tanzania, we had great moments, not only in Dar es Salaam but also in Kyela. All the time we shared a lot about science, social life and good time. In Kyela, we nearly never missed to have a lunch at Kasumulu town near the border between Tanzania and Malawi. I think, Kyela was the best place I have ever been during my research work. I am also indebted to Dr Juma Kayeke my second local supervisor in Tanzania. Mzee Kayeke, you have been so inspirational to me, I received a lot of guidance and experience in research. Working with farmers through research collaboration taught me a lot. I realized that there is even more to learn from farmers when it comes to aspects of research output application.

In the course of my thesis work at Wageningen University, I thank Prof. Dr Niels Anten, my promotor, for the time and efforts he dedicated reading various drafts of my thesis. Niels, you had been so helpful particularly when my daily supervisors were overwhelmed with teaching and other office duties. Your comments and inputs helped me to finalize this thesis. I look forward to our collaboration in research for the coming years. In addition to this, I will not ever forget to mention the people from the secretariat of Centre for Crop Systems Analysis (CSA) of the Wageningen University and Research, who have been organizing my travels, course participations and for the regular discussions. Sjanie, Alex-Jan and Nicole, you made my time and $\mathrm{PhD}$ life better and more relaxed.

In relation to the field work in Kyela-Tanzania, I thank Dr Mamadou Cissoko, Mr Derek Makokha and Daniel Elifadhili Dowson for their time and their efforts they dedicated to my work. I really appreciate the time we spent during data collection and the discussions that put my work in the broader perspective of food production and food security in Tanzania, if not in Sub-Saharan Africa. 
The research was enabled by many people around me. First, I would like to thank sincerely Mr Deogratias B. Kisandu of the Tanzania Agricultural Research Institute (TARI), Uyole Center for the courage and assistance he gave to me during his time in the office. He took my office responsibilities while I started my studies away from home. I also thank all our field research assistants in Kyela, Tanzania particularly Ghambis' family, led by Elias Ghambi, Joseph Ghambi and Aron Elias. They were really a support team for me from the moment I arrived in the village until we finished our field work. I also appreciated the collaboration with some other families in Kilasilo village in Kyela, particularly the families of Mr Kanyunya and Mr Saidia Mwakafyuju. I am very grateful to the farmer groups from both Striga and Rhamphicarpa fields in Mbako and Kilasilo villages for their time during various meeting and their countless efforts for running the farmers managed field trials.

I also recognize my fellow $\mathrm{PhD}$ students in the PARASITE program. I am thankful to my colleague $\mathrm{PhD}$ students Stella Kabiri and Simon N'Cho for the stimulating conversations on our shared research projects and for the moments where our discussions took place. Stella, I also like to thank you for your companionship and for being such an excellent host during my first arrival in the Netherlands, particularly your help with the cycling from the University to hostels in Haarweg-Wageningen. I recall how difficult it was for me at the beginning to keep the right cycling site. That was a really tremendous experience in my life. I am considering the bright future collaboration. In addition, I really appreciated the help of postdoc fellow in the PARASITE program Dr Marc Shut. Marc has been so kind and interactive to me during different stages of my thesis writing. His inputs in second chapter of my thesis is highly appreciated. Apart from Marc, I am also highly appreciative to Dr Josey Kamanda, another postdoc who joined the program in the last phase. Josey, I really appreciate your time and the discussions we had in Kyela about farmers experience on parasitic weed management and constraints they encounter.

In the course of the greenhouse experiment at Unifarm of Wageningen University, there are students who contributed to my parasitic weed experiment in rice. I am thankful to the following students for their dedication and stimulating collaboration: Evangelica Chatzaki, Ruben Dümmer and Cyprian Mwale. When performing the experiment I could continually ask for a help of the staff of the Crop System Analysis (CSA) group. In particular, I would like to mention Peter van der Putten. I would also like to thank the Unifarm staff for helping me to find my way in the greenhouse.

Special thanks go to my dear paranymphs, Luuk van Dijk and Wilson Charles Wilson. 
Luuk and Charles, thank you for being my paranymphs and for your valuable discussions during the course of my $\mathrm{PhD}$ study. You made my $\mathrm{PhD}$ journey unforgettable.

Sincerely, I thank Prof. John. J. Msaky of Sokoine University of Agriculture, my aunt Marietta Leo Maswada, brother Daniel N. Kwaslema, my younger sisters Angelina and Sabina and my young brother Marco E. Tippe and other family members of late Erro M. Tippe for their unremitting interest and stimulating attitude towards my studies. It is a deep sadness to me that my parents have not lived to witness my $\mathrm{PhD}$ studies and the graduation. They would have been very proud of this achievement. I also want to thank my sons Derick and Dickson for their humble trust and supporting minds, consideration and endurance. Sometimes during the course of my $\mathrm{PhD}$ it was a bit difficult to share all ups and downs of the research with them. Gratefully, they understood that I was doing something valuable for their future too. I appreciate your tranquilly, and love you guys very much more than you think.

Grace N. Maleko, the last words of this foreword are for you. I thank you in particular for your constant interest in my work, and for the autonomy you provided me to spent so abundant of our backup time in the field and abroad when preparing this thesis. These deeds were frequently at the expenditure of our shared welfares separate to scientific research. Most and above all, I appreciate very much that you took all our family duties on your shoulders and, if that was not enough, you were always there to encourage me during the various pitfalls in the course of my study. Today, the work is complete, time has arisen for countless things that were adjourned due to $\mathrm{PhD}$ life and expenses. Thanks for everything I owe you, and for that I gratefully dedicate this thesis to you. 



\section{Published articles}

Tippe, D. E., Rodenburg, J., Schut, M., van Ast, A., Kayeke, J., Bastiaans, L. 2017a. Farmers' knowledge, use and preferences of parasitic weed management strategies in rain-fed rice production systems. Crop Protection. 99, 93-107.

Tippe, D. E., Rodenburg, J., van Ast, A., Anten, N. P. R., Dieng, I., Kayeke, J., Cissoko, M., Bastiaans, L. 2017b. Delayed or early sowing: Timing as parasitic weed control strategy in rice is species and ecosystem dependent. Field Crops Research. 214, 14-24.

Ngailo J. A., Mwakasendo J. A., Kisandu D. B., Tippe, D. E. 2016. Rice farming in the Southern Highlands of Tanzania: Management practices, socio-economic roles and production constraints. European Journal of Research in Social Sciences. 4, 1-13

\section{Presentations at Congresses}

Tippe, D. E., van Ast, A., Rodenburg, J., Kayeke, J., Anten, N. P. R., Bastiaans, L. 2017. Sowing time as a measure to regulate host pant-parasite interactions in rainfed rice production systems. EWRS-workshop on 'Physical and cultural weed control tools as moderators of crop weed interactions'. Nyon, Switzerland, April 2-5, 2017. (oral)

Tippe, D. E., van Ast, A., Rodenburg, J., Kayeke, J., Anten, N. P. R., Bastiaans, L. 2017. Sowing time as a measure to regulate host pant-parasite interactions in rainfed rice production systems. Netherlands Annual Ecology Meeting. Lunteren, the Netherlands, February 14-15, 2017. (poster) 
Curriculum Vitae 


\section{Dennis Erro Tippe}

Email: tippedeny@yahoo.ca; dennytippe@gmail.com

Researchgate: https://www.researchgate.net/profile/Dennis_Tippe2

LinkedIn: https://www.linkedin.com/in/dennis-e-tippe-155b0b2b

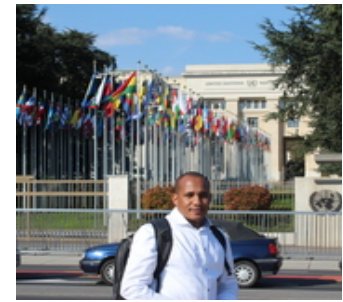

Dennis Erro Tippe was born on $18^{\text {th }}$ October 1981 in Mbulu district, northern Tanzania. In 1995 he completed primary education from Dirim primary school in Mbulu district. In 1999, he completed ordinary level secondary education in Ifakara-Morogoro, Tanzania. In 2002, he completed higher secondary education from Mkwawa high school in Iringa, Tanzania. In 2005 he joined Sokoine University of Agriculture (SUA), Tanzania and graduated with a BSc. degree in Agronomy in 2008.

In 2008, he was employed at Mtibwa Sugar Estate (MSE), Morogoro, Tanzania, where he worked as an agronomist to improve sugar cane productivity and where he gained his first experiences in the field of agronomy. In 2009, he started working at Tanganyika Planting Company Limited (TPC Ltd), Moshi, Tanzania as an Area Assistant Manager. At TPC Ltd he worked to improve sugarcane productivity, mainly in post-harvest and sugarcane husbandry, a position which he held until January 2010.

In the same year 2010, he joined the Ministry of Agriculture in Tanzania as an Agricultural Research Officer. He was positioned by the Ministry in the Southern Highlands Zone in Mbeya, at Tanzania Agricultural Research Institute (TARI), Uyole Center. He was assigned in rice production improvement program for Southern Highlands of the country, covering six rice growing regions. This position he holds till to date.

In October 2010, he was awarded a scholarship from the International Rice Research Institute (IRRI), the Philippines, under the Japan Rice Breeding Project (PC034J100000240) to pursue his Master degree at Sokoine University of Agriculture (SUA) in Morogoro, Tanzania. During his Master study he worked on the rice milling recovery of rice variety SARO 5 in Bagamoyo and Dakawa Tanzania, testing different nitrogen levels, harvesting times and drying periods. During his research and thesis work, he collaborated with IRRI, Dar es Salaam station, Tanzania and he completed his MSc-study in November, 2012.

In September 2013, he was awarded a sandwich PhD scholarship from the Netherlands Organization for Scientific Research through Science for Global Development (NWOWOTRO, grant W01.65.327.00). He worked within the research program Preparing African 
Rice Farmers Against Parasitic Weeds in a Changing Environment (PARASITE) from September 2013 to May 2016. After the PARASITE project faced out in May 2016, he was employed as a PhD candidate from June 2016 to May 2017 at the Center for Crop Systems Analysis (CSA) - Wageningen University, Wageningen, the Netherlands.

Dennis is married to Grace N. Maleko, and has two sons Derick and Dickson. Currently, he is working as an Agricultural Research Officer of the Ministry of Agriculture at Tanzania Agricultural Research Institute (TARI), Uyole Center in Mbeya, Tanzania. 

PE\&RC Training and Education Statement 
PE\&RC Training and Education Statement

With the training and education activities listed below the $\mathrm{PhD}$ candidate has complied with the requirements set by the C.T. de Wit Graduate School for Production Ecology and Resource Conservation (PE\&RC) which comprises of a minimum total of 32 ECTS (= 22 weeks of activities)

\section{Review of literature (6 ECTS)}

- Strategies for prevention and damage control of root parasitic weeds (2014)

\section{Writing of project proposal (1 ECTS)}

- Evaluation and dissemination of integrated technological packages for prevention and damage control of parasitic weeds in rice farming systems (2013)

\section{Post-graduate courses (2.6 ECTS)}

- Climate Smart Agriculture (CSA); PE\&RC (2016)

- Introduction to R-statistics; PE\&RC (2016)

\section{Deficiency, refresh, brush-up courses (1.5 ECTS))}

- Basic statistics; PE\&RC (2016)

\section{Competence strengthening / skills courses (8.9 ECTS)}

- Scientific publishing; WGS (2015)

- Essential scientific writing and publishing; WGS (2015)

- EndNote; WUR-Library (2015)

- Techniques for SWP; WGS 2016)

- Brain training; WGS (2016)

- Grant proposal writing; WGS (2016)

- Project and time management; WGS (2016)

- Interpersonal communication for PhD; PE\&RC (2016)

- Communication with media and general P; PE\&RC (2016)

- PhD Symposium; WGS (2016) 
PE\&RC Annual meetings, seminars and the PE\&RC weekend (2.4 ECTS)

- PE\&RC Weekend (2013, 2015)

- PE\&RC Day (2014, 2015, 2016)

Discussion groups / local seminars / other scientific meetings (5.8 ECTS)

- Sustainable Intensification in Agricultural Science (SIAS) (2015-2017)

- Soil Plant Interaction (SPI) (2016-2017)

- Land dynamics (2016-2017)

- $\quad$ PhD Carousel (2016)

International symposia, workshops and conferences (2.1 ECTS)

- Netherlands Annual Ecology Meeting (NAEM); Lunteren, Netherlands (2017)

- European Weed Research Society (EWRS); Nyon, Switzerland (2017)

- Symposium: water stressed futures; Water Systems and Global Change Group (2017)

\section{Lecturing / Supervision of practical / tutorials (3.3 ECTS)}

- Effective medium for Striga hermonthica germination and attachment in Sorghum (2016)

- Master students' poster evaluation (2017) 

Funding 


\section{Funding}

The research described in this thesis was financially supported by the Netherlands Organization for Scientific Research, through Science for Global Development (NWOWOTRO; W01.65.327.00). It forms part of the PARASITE programme "Preparing African Farmers against Parasitic Weeds in a Changing Environment". Additional funds were received from the CGIAR Research Program on Climate Change, Agriculture and Food Security (CCAFS) and The Global Rice Science Partnership (GRiSP). 